Leonardo Jorge Sales

\title{
Proposta de modelo de classificação do risco de contratos públicos
}

Brasília

2016 

Leonardo Jorge Sales

\title{
Proposta de modelo de classificação do risco de contratos públicos
}

\author{
Trabalho apresentado como requisito parcial \\ para obtenção do título de Mestre em Econo- \\ mia do Setor Público. \\ Universidade Nacional de Brasília \\ Faculdade de Economia, Administração e Contabilidade - FACE/UnB \\ Programa de Pós-Graduação em Economia
}

Orientador: Prof. Dr. Rafael Terra de Menezes

Brasília

2016 
Leonardo Jorge Sales

\section{Proposta de modelo de classificação do risco de contratos públicos} Trabalho apresentado como requisito parcial
para obtenção do título de Mestre em Econo-
mia do Setor Público.

Trabalho aprovado. Brasília, 14 de setembro de 2016:

Prof. Dr. Rafael Terra de Menezes

Orientador

Prof. Dr. Vander Mendes Lucas

Convidado 1

Prof. Dr. Rommel Novaes Carvalho

Convidado 2

Brasília

2016 
Este trabalho é dedicado a Vinícius. Que eu possa ajudar o seu Brasil a ser um pouquinho melhor que o meu. 



\section{Agradecimentos}

Primeiramente, a Iza, pelo apoio, dedicação, amor e revisão textual.

Aos amigos da Diretoria de Pesquisas e Informações Estratégicas da CGU, pelo incentivo. Especialmente quero agradecer a Rommel e a Ricardo, pela ajuda na modelagem com o R, a Guilherme, por me ensinar a fazer consultas em SQL de maneira mais profissional, a Evaldo e a Vítor, pela ajuda nas primeiras travadas com a matemática, a David e a Ernane, pelas cargas dos dados, a Calil, pelas sugestões de indicadores, a Patrícia, por me convencer de que eu sairia do mestrado uma pessoa melhor (melhor eu não sei mas com mais tempo livre, certamente!), a Cláudio, pelos questionamentos que enriqueceram a metodologia, e novamente a Rommel pela revisão final minuciosa.

Aos colegas e novos amigos do MESP, principalmente pela consideração com a "Bancada de Humanas".

A Rafael Terra, por acreditar no projeto rabiscado no verso de um papel de trabalho qualquer.

A minha família, por inflarem meu ego sempre que necessário. 

"Essentially, all models are wrong, but some are useful." (George Box)

"Tudo deve ser feito da maneira mais simples possível. Mas não mais simples do que isso."

(Albert Einstein)

"You have to stay faithful to what you're working on."

(Stephen King)

"Don't ask me about my thesis."

(Autor desconhecido)

"O sábado é uma ilusão."

(Nelson Rodrigues) 



\section{Resumo}

Contratos públicos são o meio pelo qual os recursos do governo são aplicados e as políticas públicas são desenvolvidas. No Brasil, respondem por mais de $19 \%$ do PIB. Considerando o desafio das instituições de controle governamental brasileiras de garantir eficiência e regularidade desses processos, propõe-se neste trabalho a utilização de modelos econométricos para seleção de casos para auditoria. Foram desenvolvidas três abordagens, sendo a primeira a estruturação de um modelo de quantificação do risco do fornecedor (empresa contratada), baseado em características como sua capacidade operacional e histórico de contratações anteriores, e a segunda, um modelo mais amplo de quantificação do risco dos contratos, com base nas características do fornecedor contratado, do próprio contrato e da licitação que o antecedeu. Esses dois modelos utilizaram a técnica de Regressão Logística para a estimação dos parâmetros. A terceira abordagem propôs um modelo de decisão multicritério para seleção final de contratos a serem auditados, considerando os scores de risco criados pelos dois primeiros modelos juntamente com os aspectos logísticos mais relevantes para a execução das fiscalizações. O modelo multicritério utilizou a técnica de Analytic Hierarchy Process (AHP). Os dois modelos de Regressão Logística obtiveram acurácia geral acima de 80\%. O modelo de decisão multicritério foi aplicado nos contratos com índice de risco maior que $80 \%$, com vistas a verificar seu impacto na ordenação dos riscos.

Palavras-chave: Econometria. Aprendizagem de Máquina Supervisionada. Regressão Logística. Análise de Decisão Multicritério. Analytic Hierarchy Process (AHP). Auditoria. Contratos Públicos. 



\section{Abstract}

Public contracts represent the means by which government resources are applied and public policies are developed. In Brazil, they account for more than $19 \%$ of GDP. Considering the challenge of Brazilian control institutions in ensuring efficiency and regularity in these processes, it is proposed in this study the use of econometric models for the selection of cases for audit. Three approaches are developed. In the first one, a logistic regression model is used to develop a classification scoring system for public suppliers. The second approach proposes a similar model with focus on public contracts. The third approach proposes a multi-criteria decision model to select public contracts to be audited, considering the risk scores created by the previous approaches and the most relevant operational aspects. The multi-criteria model uses the technique of Analytic Hierarchy Process (AHP). The two models of logistic regression obtained overall accuracy above $80 \%$. The two models of logistic regression obtained overall accuracy above $80 \%$. The multi-criteria decision model was applied in contracts with risk index greater than $80 \%$ in order to highlight its impact on the ranking of risks.

Key-words: Econometrics. Supervised Machine Learning. Logistic Regression. Multicriteria Decision Analysis. Analytic Hierarchy Process (AHP). Auditing. Public Procurement. 



\section{Lista de ilustrações}

Figura 1 - Processo de Auditoria Contínua . . . . . . . . . . . . . . . 33

Figura 2 - Trade-off viés x variância (FORTMANN-ROE, 2012) . . . . . . . 36

Figura 3 - Evolução da quantidade de compras e contratos . . . . . . . . . . . 53

Figura 4 - Distribuição das ocorrências de interrupção contratual por tipo . . . . 54

Figura 5 - Motivação das rescisões de 2015 e 2016 . . . . . . . . . . . . . . . . 54

Figura 6 - Distribuição dos tipos de penalidade . . . . . . . . . . . . . 55

Figura 7 - Doações eleitorais em $2014 \ldots \ldots$. . . . . . . . . . 58

Figura 8 - Alertas do monitoramento de licitações realizado pela CGU . . . . . . 58

Figura 9 - Fluxo padrão da Aprendizagem Supervisionada (RASCHKA, 2015) . . 66

Figura 10 - Acurácia para diversas configurações . . . . . . . . . . . . . . . 72

Figura 11 - Acurácia para diversas configurações . . . . . . . . . . . . . . . . . 73

Figura 12 - Acurácia para diversas configurações . . . . . . . . . . . . . . . 73

Figura 13 - Acurácia para diversas configurações . . . . . . . . . . . . . . 78

Figura 14 - Acurácia para diversas configurações . . . . . . . . . . . . . . . . 79

Figura 15 - Acurácia para diversas configurações . . . . . . . . . . . . . . . . . 79 



\section{Lista de tabelas}

Tabela 1 - Matriz de confusão padrão. . . . . . . . . . . . . . . . . . . . 40

Tabela 2 - Variáveis selecionadas - Forward Stepwise. . . . . . . . . . . 70

Tabela 3 - Parâmetros Estimados - Modelo de Risco do Fornecedor . . . . . . . . 74

Tabela 4 - Variáveis selecionadas - Forward Stepwise. . . . . . . . . . 77

Tabela 5 - Parâmetros Estimados - Modelo de Risco do Contrato . . . . . . . . . 80

Tabela 6 - Escala numérica da Matriz de Julgamentos . . . . . . . . . . . . . . 82

Tabela 7 - Resultado da Matriz de Julgamentos . . . . . . . . . . . . . . . 82

Tabela 8 - Matriz de Julgamentos Normalizada . . . . . . . . . . . . . . 82

Tabela 9 - Matriz de confusão - Risco do Fornecedor. . . . . . . . . . . . . . . 87

Tabela 10 - Matriz de confusão - Risco do Fornecedor, com threshold alterado. . . . 87

Tabela 11 - Valores do índice x Interpretação (LANDIS; KOCH, 1977) . . . . . . . 88

Tabela 12 - Matriz de confusão - Risco do Contrato. . . . . . . . . . . . . . . . . 90

Tabela 13 - Aplicação da equação de Índice de Auditoria nos contratos com risco maior que $0,8 \ldots \ldots \ldots . \ldots \ldots 2 \ldots \ldots . \ldots \ldots$ 



\section{Sumário}

INTRODUÇÃO $\ldots \ldots \ldots \ldots \ldots \ldots \ldots$

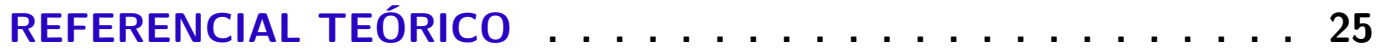

2.1 Teorias econômicas, licitações públicas e auditoria . . . . . . . . 25

$2.1 .1 \quad$ Teoria dos Leilões . . . . . . . . . . . . . . . . . . . . 25

2.1.2 Economia de Custos de Transação . . . . . . . . . . . . . . . . . . 27

2.1.3 Teoria dos Jogos e aplicações na análise de cartéis . . . . . . . . . . . . 29

2.1 .4 Teoria da Agência . . . . . . . . . . . . . . . . . . . . . . . . . . 29

$2.1 .5 \quad$ Licitações Públicas no Brasil . . . . . . . . . . . . . . . . . 30

2.1.6 Auditoria Governamental e Controle Interno . . . . . . . . . . . . . . . . 31

2.2 Modelos de Regressão e de Decisão Multicritério . . . . . . . . . . 33

2.2.1 Modelos de Regressão . . . . . . . . . . . . . . . . . . . . 33

2.2.2 Procedimentos para tratamento dos dados e validação dos modelos de regressão 37

2.2.3 Modelos de Decisão Multicritério . . . . . . . . . . . . . . . . . . . . . 41

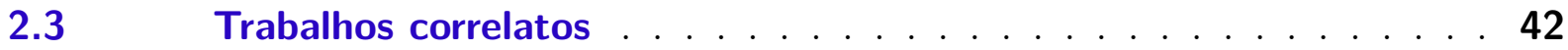

3 METODOLOGIA . . . . . . . . . . . . . 47

3.1 Entendimento do Negócio . . . . . . . . . . . . . . . . 47

3.1.1 Aspectos institucionais . . . . . . . . . . . . . . . . . . . 47

3.1.2 Dimensões do risco contratual . . . . . . . . . . . . . . . 49

$3.2 \quad$ Entendimento dos Dados . . . . . . . . . . . . . 51

3.2.1 Contratações Públicas . . . . . . . . . . . . . . . . . . . . . 51

3.2.2 Cadastro de Empresas . . . . . . . . . . . . . . . . 56

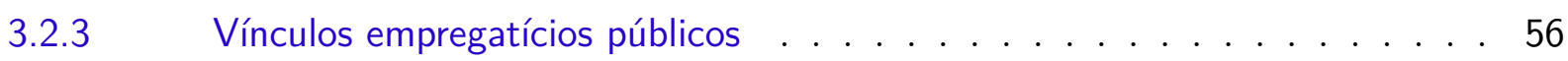

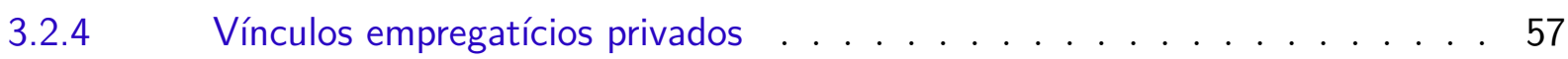

3.2.5 Pagamentos e transferências da União . . . . . . . . . . . . . . . . 57

3.2.6 Vinculações políticas . . . . . . . . . . . . . . . . 57

3.2 .7 Indícios mapeados pela CGU . . . . . . . . . . . . . . 58

$3.3 \quad$ Formulação dos indicadores de risco . . . . . . . . . . . . 59

3.3.1 Indicadores do risco do fornecedor . . . . . . . . . . . . . . . . . 59

3.3.2 Indicadores do risco do contrato . . . . . . . . . . . . . 62

$3.4 \quad$ Modelagem . . . . . . . . . . . . . . . . 65

3.4.1 Estimação do modelo de risco do fornecedor . . . . . . . . . . . . 68

3.4.1.1 Seleção de variáveis - método Forward Stepwise . . . . . . . . . . . . . . . . . . 69

3.4.1.2 Teste de parâmetros para modelagem utilizando Regressão Logística . . . . . . . . . 71

3.4.1.3 Criação do modelo final na base de treinamento . . . . . . . . . . . . . . . . . . 74 
3.4.2 Estimação do modelo de risco do contrato . . . . . . . . . . . . . . 75

3.4.2.1 Seleção de variáveis - método Forward Stepwise ～. . . . . . . . . . . . . . . . 76

3.4.2.2 Teste de parâmetros para modelagem utilizando Regressão Logística . . . . . . . . . 77

3.4.3 Proposta de modelo de decisão multicritério para seleção dos contratos a serem auditados . . . . . . . . . . . . . . . . . . . 80

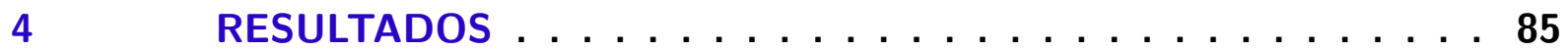

$4.1 \quad$ Modelo de risco do fornecedor . . . . . . . . . . . . . . . 85

4.1.1 Interpretação dos coeficientes obtidos . . . . . . . . . . . . . 85

4.1.2 Desempenho preditivo na base de teste . . . . . . . . . . . 86

4.2 Modelo de risco do contrato . . . . . . . . . . . . . . 89

4.2.1 Interpretação dos coeficientes obtidos . . . . . . . . . . . . . . . 89

4.2.2 Desempenho preditivo na base de teste . . . . . . . . . . . . . . 90

4.3 Modelo de decisão para auditoria . . . . . . . . . . . . . . 91

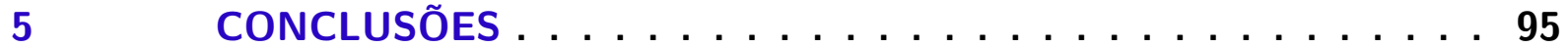

REFERÊNCIAS ...................... 99

$\begin{array}{ll}\text { ANEXOS } & 105\end{array}$

ANEXO A - DESCRIÇÃO DOS INDICADORES UTILIZADOS . . 107 


\section{Introdução}

Contratos públicos podem ser entendidos como ajustes realizados entre a Administração Pública e particulares, para a consecução de objetivos de interesse público, com regras e condições estabelecidas pela própria Administração, esta sendo entendida como qualquer órgão ou entidade pública das esferas federal, municipal ou estadual (PIETRO, 1999).

Os gastos do governo, oriundos de contratos públicos e aquisições diretas de bens e serviços, vêm respondendo por aproximadamente 19\% do Produto Interno Bruto brasileiro nos últimos anos. Dados do Instituto Brasileiro de Geografia Estatística (IBGE), publicados no Relatório de Contas Nacionais referente ao quarto trimestre de 2015 quantificam em $\mathrm{R} \$ 1,07$ trilhão o montante de despesas de consumo do governo nesse ano (IBGE, 2016). As licitações e contratos públicos são o meio institucional pelo qual esse consumo se materializa, tendo relevante papel na busca pela eficiência e eficácia dos gastos públicos.

No Brasil, o modelo de compras públicas (especialmente no âmbito da administração federal direta, autárquica e fundacional) passou, nas últimas décadas, por um processo intenso de automação, podendo destacar-se, como momento chave, a criação do Portal de Compras Governamentais ${ }^{1}$ e a implantação e difusão dos pregões eletrônicos a partir de 2005 (BRAGA et al., 2008).

Além do claro benefício de agilizar e baratear os inúmeros processos de compras que são realizados ano a ano pelos órgãos públicos, o sistema centralizado de registro das contratações trouxe outros benefícios ao modelo de aquisições públicas brasileiro, como possibilitar a participação de mais empresas nas disputas, potencializar a publicidade dos atos e criar um repositório centralizado dos dados referentes às diversas fases dos processos de contratação (FILHO, 2009).

No âmbito federal, o crescimento do PIB brasileiro entre 2000 e 2010 foi acompanhado pela elevação do patamar dos gastos públicos (IBGE, 2016), e isso se reflete no aumento do número de contratos firmados e licitações ou compras diretas realizadas. Segundo dados do Sistema de Administração de Serviços Gerais $\left(\mathrm{SIASG}^{2}\right.$ ), somente no ano de 2015, o governo federal brasileiro realizou 167.184 licitações e assinou 25.140 contratos de prestação de serviços ou entrega continuada de bens, tudo representando um montante de mais de $\mathrm{R} \$ 29$ bilhões. Se tomarmos para comparação o ano de 2005, esse valor seria $56 \%$ menor $^{3}$. Ressalte-se que o SIASG, bem como o Portal de Compras Governamentais,

1 <www.comprasgovernamentais.gov.br > . O Portal já usou o nome de ComprasNet.

2 O SIASG é o sistema transacional que registra compras e contratos do Governo Federal, e tem parte dos dados refletido ou alimentdo pelo portal de Compras Governamentais.

3 Consulta ao DW-SIASG (sistema de Data Warehouse mantido pelo Ministério do Planejamento, 
só registra as compras e contratos de parte das unidades administrativas do governo, conforme detalharemos na Subseção 2.1.5.

Do ponto de vista dos órgãos de controle do governo, responsáveis por fiscalizar a atuação das unidades administrativas, esse contexto gera o grande desafio de atuar de maneira eficiente na identificação de problemas de gestão, fraudes e corrupção, dado o enorme número de contratos e processos de compra a se auditar. Tomemos o exemplo da Controladoria-Geral da União (CGU), unidade central de controle interno do Governo Federal, que é responsável por auditar qualquer transação que represente gasto de origem da União, seja esse gasto conduzido pelas unidades centrais dos ministérios, seja pelas 2.947 unidades descentralizadas $^{4}$ ou mesmo por qualquer estado ou município que receba recursos federais via transferências voluntárias.

A CGU possui atualmente 2.294 servidores, segundo dados do Sistema de Administração de Pessoal (SIAPE ${ }^{5}$ ). Desses, aproximadamente 1.200 trabalham diretamente realizando auditorias. Se considerarmos a possibilidade de auditar todas as licitações de 2015, seriam distribuídos mais de 150 processos para cada auditor, algo claramente inviável. Perpassando esse contexto, lembremos de um senso comum dentre os especialistas em auditoria, que diz que o custo de se auditar deve ser menor do que o ganho potencial da auditoria.

Assim, a problemática que surge envolve a necessidade de se racionalizar a utilização dos recursos de auditoria. Fica clara a necessidade de se otimizar a escolha do que se vai efetivamente auditar, uma vez que o censo completo é impossível e antieconômico. Atuar preventivamente, evitando o surgimento de problemas, também se mostra essencial, já que a maior parte das falhas na execução desses processos gera danos irrecuperáveis, como a paralização de uma obra ou a necessidade de refazê-la.

Tanto a racionalização das escolhas, numa atuação a posterior, quanto a compreensão e o tratamento de vulnerabilidades, no caso da atuação preventiva, podem ser analisados dentro do conceito mais geral de avaliação de riscos, afinal o que se busca num caso e noutro é identificar fatores ou características das compras ou contratos que contribuam para aumentar a chance de haver (no presente ou no futuro) problemas, sejam falhas de gestão ou mesmo fraudes.

Têm-se problemáticas similares no setor privado. Instituições financeiras, por exemplo, necessitam avaliar o risco de potenciais tomadores de empréstimo, dentre muitos pretendentes, com características e históricos diferentes. Empresas seguradoras enfrentam problema semelhante: como atribuir o valor ao seguro de um bem, se o risco de ter que

Desenvolvimento e Gestão, utilizando os dados transacionais do SIASG) realizada em 29/4/2016.

4 Número de unidades administrativas do governo que possuem registro de compra no SIASG, conforme consulta ao DW-SIASG realizada em 29/4/2016.

5 Consulta ao DW-SIAPE (sistema de Data Warehouse mantido pelo Ministério do Planejamento, Desenvolvimento e Gestão, utilizando os dados transacionais do SIAPE) realizada em 29/4/2016. 
pagar o prêmio depende do segurado?

Essas instituições vêm tratando esse problema com a utilização de modelos estatísticos que aprendem com o histórico de transações e quantificam o peso de determinadas características na determinação do risco de um cliente ou processo específico. Assim, a empresa de seguros de automóveis sabe, por exemplo, que jovens solteiros do sexo masculino oferecem mais risco que senhoras casadas e com filhos.

Tais modelos, que são denominados no caso dos bancos como Credit Scoring (LESSMANN et al., 2015), na prática são aplicações de técnicas estatísticas de regressão e classificação utilizando bases de dados que possuem informações do histórico de transações, com marcação dos casos de sucesso e fracasso, ou com alguma variável dependente de medida contínua ou que defina categorias de risco. Em computação, esse processo é conhecido como Aprendizagem de Máquina Supervisionada (FRIEDMAN; HASTIE; TIBSHIRANI, 2001). Quando são utilizadas variáveis econômicas nos modelos, aproxima-se do conceito de Econometria (WOOLDRIDGE, 2015).

Uma condição facilitadora da construção desse tipo de modelo de análise de riscos é a existência de informações sobre o histórico de transações, com variáveis que representem diversas características de cada processo específico. Assim, podem distinguir-se grupos e identificar padrões, correlações e anomalias.

No âmbito governamental, o advento dos sistemas informatizados de registro dos processos de compras permitiu termos hoje um repositório de informações detalhadas sobre inúmeros processos de aquisição. Na realidade, até o final do ano de 2015, o sistema SIASG registra 4,7 milhões de processos de compra e 501 mil contratos ${ }^{6}$. As informações sobre cada um deles envolvem aspectos do processo em si (e.g. datas, pessoas responsáveis, participantes e valores) e contêm variadas informações cadastrais dos fornecedores, além de registrar ocorrências como multas aplicadas, penalidades aos contratantes e interrupção dos contratos.

Por outro lado, no campo acadêmico, há algum tempo, diversas pesquisas vêm sendo realizadas utilizando dados de contratações públicas, muitas vezes com o intuito de compreender o funcionamento dos pregões eletrônicos à luz de teorias oriundas da Administração, Contabilidade e Economia, como Teoria dos Leilões, Teoria dos Jogos, Teoria da Agência ou Teoria dos Custos de Transação (alguns desses trabalhos serão referenciados na Seção 2.1). Uma das questões recorrentes é a tentativa de quantificar o efeito de aspectos do pregão, como quantidade de fornecedores ou de lances, no "desconto" obtido pelo órgão licitador, normalmente calculado a partir da comparação do valor estimado com o efetivamente pago pelo produto.

De fato, as teorias econômicas que avaliam o comportamento racional de agentes

$\overline{6}$ Consulta ao DW-SIASG realizada em $29 / 4 / 2016$. 
oferecem um fértil campo de ideias para identificação de características que contribuem para um potencial risco em transações. Se compreendermos a relação contratual entre órgãos governamentais e agentes privados (fornecedores do governo) sob a ótica de um problema de agência, estando o governo no papel do principal, podemos enxergar cada uma das variáveis relativas aos fornecedores como componentes de uma espécie de equação que determinaria o risco de conflitos de agência, consubstanciados na potencial ocorrência de problemas contratuais. Se enxergarmos o contrato em si sob o prisma da Teoria dos Custos de Transação, podemos identificar características do próprio processo (ou mesmo dos agentes privados envolvidos) como elementos que contribuem para o aumento ou redução dos custos potenciais envolvidos no contrato, entendendo-se tais custos como assumíveis pela parte pública da relação contratual.

Este trabalho propõe integrar essas visões sob o campo mais amplo da análise preditiva de riscos, utilizando elementos das teorias econômicas que estudam o comportamento racional dos agentes para identificar características (na prática, variáveis disponíveis em bases de dados) dos processos de contratação pública que possam ser utilizadas como indicadoras do risco de execução do contrato, ou seja, como variáveis preditoras em modelos econométricos que mensurem esse risco.

O ambiente de potencial aplicação dos resultados desse estudo é a ControladoriaGeral da União (CGU), que, como já mencionado, tem a missão de auditar todo e qualquer uso de dinheiro público originário da União, com o grande desafio de adequar a efetividade dos trabalhos às limitações de pessoal, orçamentárias e logísticas.

Podemos definir como objetivo geral dessa pesquisa a proposta de uma metodologia de avaliação de riscos de contratos públicos pautada na compreensão da influência de determinadas características dos fornecedores do governo e dos processos de contratação no risco da ocorrência de problemas contratuais.

Isso foi viabilizado pela consecução de três objetivos específicos. O primeiro foi a criação de um modelo econométrico de avaliação de risco de fornecedores, que quantifica a propensão de um fornecedor do governo apresentar problemas em contratos com o governo, de acordo com as características da empresa. Esse modelo foi construído a partir de um processo de aprendizagem de máquina supervisionada e se baseia numa equação de regressão que tem como variável dependente a ocorrência de punição com impedimento de licitar para o fornecedor e como regressores características ligadas a sua capacidade operacional, histórico de punições, vinculação com servidores públicos e atuação política. A técnica de regressão utilizada, a Regressão Logística, resulta em um valor contínuo que mede essa propensão numa escala entre 0 e 1.

O segundo objetivo específico foi a criação de um modelo econométrico de classificação de contratos, que quantifica a propensão de um contrato apresentar problemas, de acordo com variáveis do próprio contrato, da licitação que o originou e da empresa 
contratada. Este modelo também utilizou a técnica de Regressão Logística e foi construído a partir de um processo de aprendizagem supervisionada. Tem como variável dependente a ocorrência de rescisão do contrato por descontinuidade na execução e também apresenta, como resultado, uma medida de risco com valores entre 0 e 1.

O terceiro objetivo específico foi a proposição de um modelo de decisão multicritério para priorização de auditorias, construído com a incorporação de variáveis logísticas e de capacidade operacional, e utilizando a própria opinião de auditores como insumo para a ponderação das variáveis. Nesse modelo, estão incorporados os resultados dos modelos anteriores, que quantificam o risco para o fornecedor e para o contrato. É especialmente importante esse terceiro passo, pois representa o caráter aplicado da pesquisa. A grande questão é ir além da simples compreensão da capacidade explicativa das variáveis utilizadas nos dois modelos de aprendizagem, e definir como esses resultados podem ser efetivamente utilizados para planejar as auditorias e melhorar sua efetividade.

Para os modelos econométricos, a escolha das variáveis foi, ao mesmo tempo, fundamentada na sua potencialidade de servir como proxy para variáveis econômicas oriundas das supracitadas teorias e também na sua relação com o que definimos aqui como dimensões de risco contratual afetas ao fornecedor e ao contrato em si, conforme é aprofundado na Seção 3.

Este trabalho está dividido em 5 seções. Além desta introdução, a Seção 2 apresenta o referencial teórico que apoia a ideia central do trabalho e a abordagem metodológica adotada. A Seção 3 contém o detalhamento da metodologia da pesquisa, passando pelas etapas de entendimento do negócio, entendimento dos dados e modelagem. A Seção 4 apresenta e discute os resultados obtidos para cada uma das abordagens, contando também com a validação final dos modelos. Por fim, a Seção 5 traz as conclusões e ponderações sobre lacunas e oportunidades de trabalhos futuros. 



\section{Referencial Teórico}

Esta seção está organizada em 3 partes. Na primeira, são abordados os aspectos mais negociais do trabalho, abrangendo as teorias econômicas que se relacionam e justificam as escolhas de parte das variáveis dos modelos econométricos, o tema das licitações públicas no Brasil e as normas que regem o processo de auditoria pública. Na segunda parte, são descritas questões técnicas da construção dos modelos, com explanações sobre técnicas estatísticas e tratamentos de dados necessários. A terceira parte trata dos trabalhos correlatos.

\subsection{Teorias econômicas, licitações públicas e auditoria}

Esta subseção aborda as teorias econômicas que estão relacionadas à escolha das variáveis para os modelos quantitativos (são elas: Teoria dos Leilões, Economia dos Custos de Transação, Teoria dos Jogos e Teoria da Agência), os aspectos teóricos e legais das licitações e da auditoria governamental no Brasil.

\subsubsection{Teoria dos Leilões}

A Teoria dos Leilões é a aplicação de teorias microeconômicas para a compreensão do comportamento estratégico de agentes racionais sob condições de informação assimétrica no contexto da venda de bens onde o valor real do item é incerto (KLEMPERER, 2004). Vários elementos da Teoria dos Leilões são advindos da Teoria dos Jogos, que tem seu escopo direcionado ao estudo do comportamento racional dos agentes, nesse caso, vendedores e compradores, sob condições de incerteza (KLEMPERER, 2004).

MCAFEE; MCMILLAN (1987) classifica os leilões, quanto à forma de disputa, em quatro tipos: O leilão Inglês (de lances ascendentes), o Holandês (de lances descendentes), o de primeiro preço com lance selado e o de segundo preço com lance selado (também chamado de leilão de Vickrey).

O Leilão Inglês é a forma mais comumente utilizada para venda de bens (MCAFEE; MCMILLAN, 1987). A partir de um valor mínimo pré-estabelecido são permitidos lances ascendentes até que não haja mais contrapropostas, sendo o objeto adjudicado ao comprador responsável pelo último (e maior) lance. A qualquer momento do certame, qualquer participante sabe exatamente em que nível de preço o objeto está sendo valorado e racionalmente compara esse valor com o que ele próprio atribui ao objeto, decidindo por dar um novo lance ou desistir. 
O chamado Leilão Holandês tem lances descendentes, partindo de um valor alto definido pelo leiloeiro, que vai reduzindo esse valor até que algum dos compradores aceitem o preço.

O Leilão de Primeiro Preço com Lance Selado, consiste em um único lance (secreto) de cada comprador, onde o responsável pelo maior preço é o vencedor. Uma diferença crucial em relação ao Leilão Inglês é que, nesse último, o comprador tem a oportunidade de rever seu próprio lance a depender dos demais lances, o que não ocorre no modelo de único lance selado, havendo maior obstáculo, no último caso, ao comportamento oportunista do agente, que será tratado mais adiante.

Por fim, o Leilão de Segundo Preço com Lance Selado, conhecido como Leilão de Vickrey, segue também uma estrutura de único lance selado, com a diferença de que o responsável pelo melhor lance paga pelo bem o valor do segundo maior lance.

Importante destacar que a utilização da Teoria dos Leilões no contexto das licitações públicas é recorrente e naturalmente válida. Não existe diferença, do ponto de vista teórico, entre uma situação em que um monopolista (ou único detentor de um bem, pelo menos no contexto de uma transação específica) possui um bem e o põe à venda através de um leilão e outra em que o chamado monopsista (único comprador) busca no mercado um bem que pode ser fornecido por vários vendedores (KLEMPERER, 2004; MCAFEE; MCMILLAN, 1987).

O modelo de Leilão Inglês é o que mais se aproxima do modelo de aquisições públicas brasileiro.

A Teoria dos Leilões traz algumas ideias de características das disputas que favoreceriam o benefício econômico do leiloeiro (leia-se, vender pelo maior preço possível). Uma dessas características é a quantidade de participantes. SILVA (2007) e CARTER et al. (2004) afirmam que o preço final de um leilão será maior na medida em que se aumente a quantidade de participantes. BARTOLINI; COTTARELLI (1994) afirma que, com um maior número de participantes, aumenta-se a probabilidade de participação de fornecedores mais qualificados, que podem, assim, oferecer melhores preços.

Outros estudos, agora mais focados no contexto das licitações públicas chegam a conclusão semelhante (mais participantes, menor o preço pago pelo governo). Além disso, o número de lances também é citado como uma característica que reduziria o preço pago pelos produtos. Destacamos os estudos de SANTOS; SILVEIRA (2010), SILVA (2007), MORAES (2012) e CORDERO; SILVEIRA; MOREIRA (2012).

Diversos trabalhos (SILVA, 2007; SANTOS; SILVEIRA, 2010; MORAES, 2012; CORDERO; SILVEIRA; MOREIRA, 2012) utilizam a teoria dos leilões buscando identificar os fatores predominantes na diferença entre o valor previsto para a aquisições de um item e o valor efetivamente pago pelo item, em aquisições governamentais. Pressupõe-se, 
naturalmente, que, quanto maior essa diferença, melhor economicamente para o governo. Isso de fato faz sentido, mas vale ponderar alguns pontos adicionais da Teoria dos Leilões e dos estudos que a aplicam ao contexto das licitações públicas que merecem atenção.

Primeiramente, é preciso diferenciar o preço de referência adotado nas licitações brasileiras (obrigatoriedade prevista no Inciso X do artigo 40 da Lei 8.666/93(MUKAI, 1994)) do preço mínimo (ou máximo, na analogia a um modelo monopsista) existente no modelo de Leilão Inglês. O preço de referência não é um preço máximo o qual representaria um limite a partir do qual se dariam os lances descendentes. A lei brasileira, claramente, posiciona-o como uma proxy do preço de mercado.

Assim, numa situação hipotética, uma grande diferença entre o preço de referência e o preço final de uma licitação pode estar relacionada tanto a um certame "bem sucedido", em que o órgão licitante conduziu a disputa de modo a extrair de cada participante o máximo possível em termos de redução de margem de lucro, quanto também pode significar um erro na estimação daquele preço de referência, havendo assim um ganho fictício para o governo. Obviamente, o não tratamento desse ponto na estimação de um modelo econométrico limita os resultados e as interpretações decorrentes.

Outro fator a se destacar, ainda quanto à interpretação da diferença entre preço de referência e preço final, é a chamada "praga do vencedor", definida por BARTOLINI; COTTARELLI (1994) como a situação em que, dada a assimetria de informação (ou a má especificação do bem), os licitantes valoram o objeto de maneira distinta, uns subestimando e outros superestimando, e obviamente, supondo um leilão, quem superestima acaba ganhando. Num contexto de licitação pública, o licitante acabaria dando um lance abaixo do razoável e a consequência disso podem ser futuros problemas que prejudicam ou até impedem a execução do compromisso com o governo. PEREIRA; LAGROTERIA; LEAL (2004) pondera que nos leilões ingleses, dada a publicidade dos lances, essa assimetria de valoração do bem estaria atenuada, já que os participantes conhecem os lances uns dos outros.

Conforme MATOSO (2009), outro ponto a ser observado é que todos os modelos básicos de leilão preveem a não cooperação entre os participantes, situação muitas vezes não existente no contexto das aquisições públicas no Brasil. Isso pode impactar diretamente os pressupostos de independência entre as avaliações e de simetria entre os licitantes, já que numa disputa com várias empresas podem haver pequenos grupos com mais informação do que os participantes sem conexão.

\subsubsection{Economia de Custos de Transação}

A chamada Economia de Custos de Transação (ECT), desenvolvida a partir dos trabalhos de WILLIAMSON (2008), aborda aspectos comportamentais das empresas 
quando da assunção de obrigações contratuais, incluindo a disputa pelos contratos. Partese do pressuposto de que todo contrato traz em si um custo de transação embutido. Os aspectos comportamentais dos agentes envolvem o comportamento oportunista e a racionalidade limitada. Outros atributos relacionados às transações propriamente ditas, e que impactam diretamente o custo de transação, são a especificidade do objeto, a frequência de transações com este ativo e a incerteza quanto à garantia de performance frente a eventos imprevisíveis.

Detalharemos cada um desses aspectos, indicando possíveis características das transações que podem ser utilizadas na construção de modelos econométricos dentro do contexto das licitações públicas.

Quanto aos aspectos comportamentais, o oportunismo dos agentes, segundo VALLE; BONACELLI; FILHO (2002), implica que estes buscarão maximizar o seu ganho, mesmo que isso represente perda aos demais participantes na transação. SANTOS; SILVEIRA (2010) afirma que, no contexto das licitações públicas, uma situação que provavelmente implicaria oportunismo por parte dos agentes seria a má especificação do objeto licitado. Adicionalmente, e com certo grau de incerteza, poderíamos supor que numa contratação pública determinados grupos de objetos seriam mais propensos a uma má especificação e, por conseguinte, ao maior oportunismo por parte dos licitantes. Pode-se acreditar também que fatores relacionados ao porte e à experiência da empresa em licitações contribuiriam para um maior potencial oportunista.

Outro aspecto comportamental oriundo da ECT é a racionalidade limitada dos agentes, que decorre da própria assimetria informacional e incerteza quanto aos eventos futuros. Mais uma vez fatores ligados à experiência das empresas e à qualidade da especificação dos objetos podem reforçar ou aliviar esse aspecto, aumentando ou reduzindo o espaço para o comportamento oportunista dos agentes.

A especificidade do objeto (não confundir com especificação do objeto, que se refere apenas à qualidade descritiva do item em referência) diz respeito ao grau de complexidade e peculiaridade do objeto de uma transação. No contexto das licitações públicas, seriam obras de engenharia especializada ou serviços de nível técnico muito específico. Segundo JUNIOR; MACHADO (2003), um ativo é específico quando a possibilidade de realocação contratual é praticamente inexistente. Tome-se como exemplo a suspensão de um contrato para a construção de uma usina nuclear. Uma vez que a empresa contratada alocou os recursos para o início das obras, não há, ou é muito pequena, a possibilidade de redirecionamento do esforço. Uma possível proxy para mapear objetos altamente especializados seria o valor da contratação, em se tratando se serviços.

A frequência das transações (quantas vezes ela ocorre, dado um período de tempo), se alta, é um fator dissuasivo de comportamentos oportunistas individuais por parte dos agentes. Essa é uma visão oriunda da Teoria dos Jogos, que prevê maior cooperação em 
jogos de repetição. O comportamento oportunista numa transação implicaria em provável perda (visto que quebraria a confiança numa possível relação de troca) numa transação idêntica no futuro. Uma frequência alta também pode reduzir os custos de transação, principalmente na formulação de contratos e propostas (SANTOS; SILVEIRA, 2010). No contexto das licitações, uma possível informação que capta esse aspecto é a quantidade de licitações com o mesmo objeto.

A incerteza gera insegurança e pouca estabilidade nas transações, aumentando os riscos de realocação e potencializando os custos de transação. Está relacionada à racionalidade limitada dos agentes (JUNIOR; MACHADO, 2003). No contexto das contratações públicas, um exemplo recorrente das consequências da incerteza nos custos transacionais é o valor adicional, abertamente declarado por empresas que negociam com o governo, posto nas negociações para cobrir futuros atrasos nos pagamentos (esses também recorrentes). Uma possível característica da licitação que captaria o efeito da incerteza, pelo menos quanto à efetivação da contratação, é a chamada "forma da compra", que diz se uma licitação é realizada nos moldes do Sistema de Preços Praticados (SISPP) ou do Sistema de Registro de Preços (SISRP), já que este último indica uma futura adesão ao contrato não apenas da unidade licitadora como também de outras unidades, sendo que esta adesão implica um custo transacional reduzido (já que pula-se a etapa da licitação).

\subsubsection{Teoria dos Jogos e aplicações na análise de cartéis}

A Teoria dos Jogos é a principal referência para a Teoria dos Leilões e uma das bases da ECT (MCAFEE; MCMILLAN, 1987). Além dos pontos já colocados anteriormente, vale destacar a sua aplicação no estudo sobre defesa da concorrência, especialmente quanto aos aspectos comportamentais de agentes privados na formação de cartéis no mercado de aquisições públicas.

Vale ressaltar que o Cartel é um esquema de colaboração, e a Teoria dos Jogos afirma que a colaboração tende a ser maior quanto maior repetição ocorrer no jogo (ou quanto mais incerto for o final dessa repetição) (THOMAS, 1995; MATOSO, 2009). MATOSO (2009) indica que nas licitações públicas os cartéis tendem a se manter em mercados fartos.

É importante este ponto na formulação de um modelo econométrico que analise os preços de um pregão, pois espera-se que produtos mais recorrentes possam favorecer o surgimento de ações colaborativas entre os licitantes.

\subsubsection{Teoria da Agência}

A Teoria da Agência é definida por JENSEN; MECKLING (1976) como o estudo dos conflitos interorganizacionais entre agentes econômicos denominados agentes (ou que recebem uma delegação) e principais (que delegam e fiscalizam o objeto delegado). Utiliza- 
se também dos pressupostos comportamentais de racionalidade limitada e oportunismo dos agentes.

Possui ampla aplicação no estudo de organizações públicas, tanto em nível mais amplo, onde se entende o cidadão (ou a sociedade) como principal e o governo como agente, quanto em nível de negócios intragoverno, onde o governo figura como principal e atores privados (empresas contratadas, por exemplo) como agentes (SLOMSKI, 2000; ALBUQUERQUE et al., 2007).

A Teoria da Agência é importante na avaliação da economicidade de pregões públicos, pois explica alguns problemas advindos das características comportamentais dos licitantes, na condição de agentes, durante uma contratação pautada no menor preço. Um desses problemas, conforme colocado por CARTER et al. (2004), seria que o critério do menor preço abriria espaço para ações oportunistas na fase de licitação e durante a execução do contrato, já que a empresa contratada buscaria economizar na medida do possível para fazer seu custo "caber" dentro do orçamento vencedor (mais barato), trazendo consequências para a qualidade do serviço prestado.

\subsubsection{Licitações Públicas no Brasil}

Todo o processo de compra de produtos ou contratação de serviços no governo federal ocorre segundo as regras da Lei 8.666/93 (MUKAI, 1994), denominada Lei de Licitações. Outros normativos complementam essa lei, como a Lei 10.520/05 (SCARPINELLA, 2003), que cria a modalidade do Pregão, e a Lei Complementar 123/06 (MAMEDE, 2007), que estabelece privilégios para as micro e pequenas empresas em licitações. A Lei 8.666/93 (MUKAI, 1994) detalha as fases do procedimento licitatório em si, as modalidades de licitação permitidas, os tipos de contratos, os aspectos da qualificação das empresas e também prevê sanções administrativas e penais a serem aplicadas a fornecedores no caso do seu descumprimento.

Conforme previsão da Lei 8666/93 (MUKAI, 1994), o processo de aquisição e contratação no governo federal é feito pelo Sistema de Adinistração de Serviços Gerais (SIASG). Cada compra ou contrato fica registrado no sistema desde a abertura do processo até a emissão do empenho. Durante a execução dos contratos, é possível ao gestor público atribuir, também pelo sistema, penalidades aos fornecedores, caso haja descumprimento de obrigações.

Existente desde 1994, o SIASG passou a ser utilizado pelo governo gradualmente e já registra mais de 5 milhões de compras ${ }^{1}$. Toda a administração federal direta, autárquica e fundacional é obrigada a utilizar esse sistema (MUKAI, 1994).

O Decreto 5.450/05 (BRASIL, 2005) incluiu a modalidade de licitação denominada

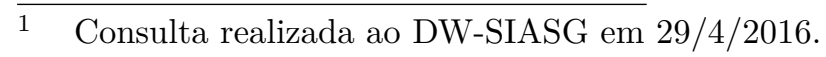


Pregão dentre as passíveis de utilização. A principal diferença do pregão em relação a uma licitação comum é a ordem das etapas de execução, já que a habilitação só é feita após o final da fase de lances. Essa inversão de fases busca simplificar o processo de aquisição, uma vez que apenas a empresa vencedora da fase de lances é convocada a apresentar os documentos de habilitação. Quanto aos requisitos para participação nos certames, uma vez que não é exigida habilitação prévia, é apenas necessário o cadastro no Sistema de Cadastro de Fornecedores do Governo, o SICAF. O Pregão deve ser necessariamente utilizado para a aquisião de bens de serviços comuns.

Outro avanço importante na normatização das compras públicas no Brasil foi a regulamentação do Sistema de Registro de Preços, já previsto na Lei 8.666/93, pelo Decreto 3.931 (BRASIL, 2001a). Esse sistema busca criar um modelo de simplificação das aquisições, uma vez que permite o cadastramento de produtos e fornecedores, mediante a realização de um único procedimento licitatório, que pode ser utilizado por toda a administração pública. Assim, desde que esteja vigente o registro de preços de determinado produto, o órgão público pode comprar diretamente do fornecedor cadastrado, sem necessidade de um novo processo de licitação.

São especialmente relevantes para este trabalho as previsões legais de aplicação de penalidades a fornecedores do governo, quando da execução de contratos públicos. Destacamos as penalidades previstas tanto na Lei de Licitações como na Lei 10520/01:

- Lei 8.666/93: Multa, que é aplicada no caso de atraso injustificado na execução do contrato;

- Lei 8.666/93: Advertência, que é aplicada nos casos de inexecução total ou parcial do contrato;

- Lei 8.666/93: Suspensão Temporária, que também é aplicada nos casos de inexecução total ou parcial do contrato, podendo ser cumulativa à multa, e limitada a dois anos;

- Lei 10.520/02: Impedimento de Licitar e Contratar, que é aplicada quando o fornecedor desiste da celebração do contrato ou apresenta dcumentação fraudulenta após vencer um pregão, com prazo de até cinco anos, e também cumulativa à multa;

- Lei 8.666/93: Declaração de Inidoneidade, que é aplicada em casos mais graves de inexecução total ou parcial do contrato, podendo também ser cumulativa à multa, sem limite de prazo (perdura enquanto não resolvida a situação ou ressarcido o governo).

\subsubsection{Auditoria Governamental e Controle Interno}

Auditoria Governamental é definida pela Instrução Normativa da Secretaria Federal de Controle (BRASIL, 2001b) como o conjunto de técnicas que se utiliza para avaliar a 
execução de programas de governo, quanto ao cumprimento das leis e normas ou de metas operacionais.

Além das atividades tradicionais de auditoria, de checagem documental, análise minuciosa de processos e acompanhamento presencial das unidades auditadas, outras técnicas mais modernas estão sendo utilizadas no processo de auditoria governamental, com o uso intensivo de Tecnologia da Informação e ferramentas de Análise de Dados (COSTA; DUTRA, 2014).

No Brasil, a implementação ao longo das últimas décadas de diversos sistemas informatizados para a gestão governamental, aliada à evolução tecnológica, permitiu a criação de um enorme repositório de dados de interesse dos órgãos de controle. Surge assim a necessidade ou oportunidade dessas instituições melhorarem o seu desempenho e reduzirem seus custos sem prejuízo da assertividade dos trabalhos.

Isso se dá a partir do desenvolvimento de técnicas que usam essa infinidade de registros como insumo para, com o auxílio de ferramentas de inteligência computacional, reproduzirem automaticamente a detecção de diversas situações que implicam fraudes ou falhas de gestão (COSTA; DUTRA, 2014).

Essas técnicas estão hoje consubstanciadas no conceito de Auditoria Contínua. Este processo, conforme entendimento dominante, tem como regra principal a possibilidade de verificação quase instantânea das transações. Necessita, portanto, de um processo concomitante denominado de auditoria computacional, definido como a atividade profissional de investigação, avaliação e recomendação centrada em Tecnologia da Informação (WEIGAND; ELSAS, 2012).

VASARHELYI; HALPER (1991) faz uma distinção entre Monitoramento Contínuo e Auditoria Contínua. O primeiro é a criação de alertas de transações suspeitas, com a utilização de ferramentas computacionais. A segunda é o processo mais amplo de checagem de casos, feedback e retroalimentação das regras definidas para o monitoramento (VASARHELYI; HALPER, 1991).

O Institute of Internal Auditors (IIA), no documento Six Steps to an Effective Continuous Audit Process (AQUINO et al., 2008), descreve o processo de funcionamento da Auditoria Contínua, mostrado na Figura 1. 


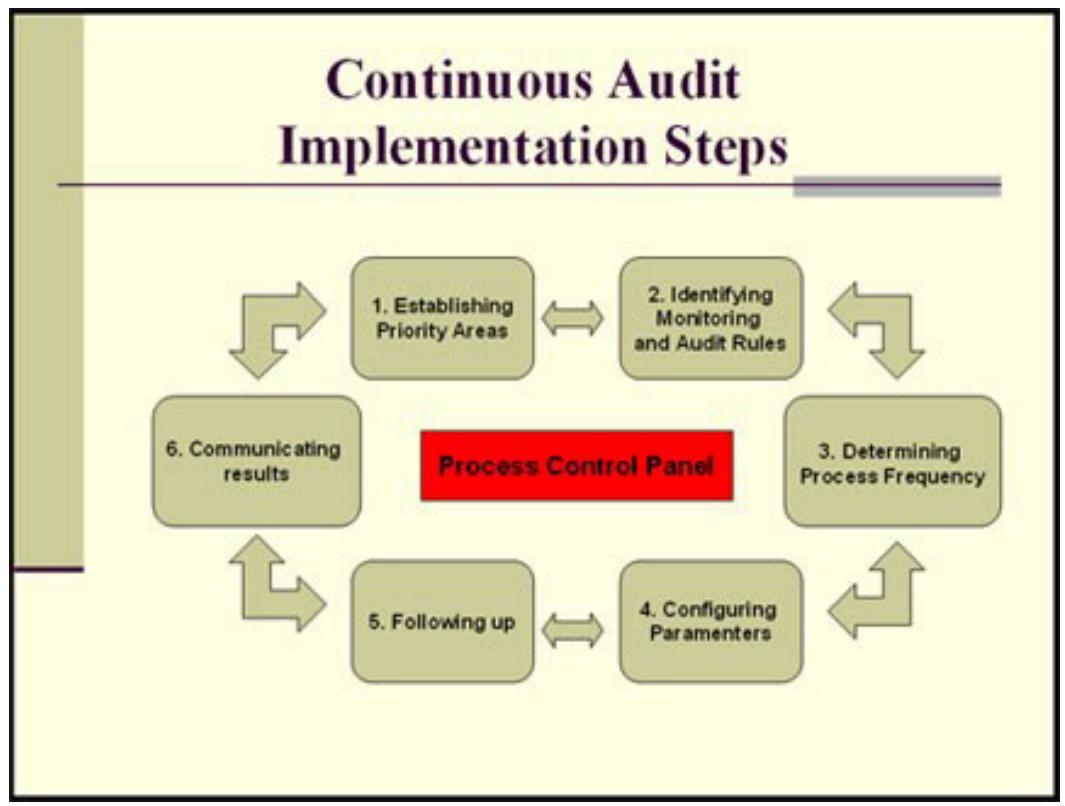

Figura 1: Processo de Auditoria Contínua

\subsection{Modelos de Regressão e de Decisão Multicritério}

Nesta subseção, primeiramente são abordadas as questões teóricas ligadas aos processos de modelagem de regressão (item 2.2.1), que são utilizados nos dois modelos. Em seguida, discorre-se sobre os procedimentos para tratamento de dados e validação dos modelos, quando também são trazidas as questões teóricas relacionadas à modelagem de Decisão Multicritério (item 2.2.2). Ao final, o foco é a modelagem de Decisão Multicritério (item 2.2.3).

\subsubsection{Modelos de Regressão}

Modelos de Regressão são amplamente utilizados para analisar relações entre variáveis, normalmente quando se pretende prever o valor de uma variável, dita dependente, a partir de um vetor de uma ou mais variáveis ditas independentes. Na prática, o que se estima é o quanto uma variação marginal em cada variável independente impacta no valor da variável dependente (WOOLDRIDGE, 2015).

Definindo-se como $y$ a variável dependente e como $x_{i}$ a única variável independente de um modelo desse tipo, a Equação 2.1 expressa um modelo de Regressão Linear Simples, onde se observa a relação entre uma única variável independente e a variável dependente.

$$
y_{i}=\beta_{0}+x_{i} \beta_{i}+u_{i}
$$


Esse modelo simplificado é útil para compreendermos a lógica desses modelos. O termo $y_{i}$ é a variável dependente do modelo, resultado da influência das demais variáveis. O termo $\beta_{0}$ é chamado de intercepto do modelo, representando o valor da variável dependente quando todo o vetor de variáveis independentes for nulo. O termo $\beta_{i}$ representa a variação em $y_{i}$ resultante de uma variação unitária em $x_{i}$. Nesse modelo linear, é o coeficiente de inclinação da reta. Quanto maior for em módulo maior é o poder da variável independente em influenciar a dependente. O termo $u_{i}$ é o termo de erro da equação, representando outros fatores não incluídos no vetor de variáveis independentes que influenciam a variável resposta.

Segundo WOOLDRIDGE (2015), a variável dependente $y$ também pode ser chamada de explicada, predita, resposta ou regressanda. As independentes, de explicativas, controle, preditoras, regressoras ou covariadas.

Na sua configuração primitiva, o modelo de regressão linear pressupõe relações lineares entre preditores e preditos, o que raramente ocorre. No modelo clássico de se prever o salário a partir da quantidade de anos de estudo, seria como se um ano a mais de estudo tivesse sempre o mesmo impacto na remuneração de uma pessoa, independentemente de ser uma variação de 0 para 1 ano de estudo ou de 20 para 21. Hodiernamente, os modelos de regressão linear incorporam transformações nas variáveis com vistas a captar relações não lineares (FRIEDMAN; HASTIE; TIBSHIRANI, 2001).

As mudanças mais utilizadas com esse objetivo são a transformação por log na variável resposta, o que faz com que o impacto das variáveis independentes seja medido em percentual de alteração na dependente (e.g. 1 ano a mais de estudo aumenta em 5\% o salário), e as transformações polinomiais em variáveis independentes, com vistas a captar relações quadráticas, por exemplo. (WOOLDRIDGE, 2015)

A estimação de um modelo de regressão linear é realizada por meio da otimização matemática (no caso, minimização) de alguma função de custo que mede o quanto os valores resultantes da aplicação da função criada se distanciam dos valores reais. A função de custo classicamente utilizada é a soma do quadrado dos resíduos (diferença entre valor real e estimado), quando a técnica de regressão recebe o nome de Regressão por Mínimos Quadrados Ordinários (MQO). Basicamente, o algoritmo que estima a função seleciona a equação linear que minimiza esse valor.

Uma limitação para o uso do MQO são os pressupostos que se deve assumir em relação aos dados. Segundo WOOLDRIDGE (2015), os pressupostos para garantir que o estimador é não-viesado num modelo de regressão linear múltipla são a linearidade dos parâmetros, a amostragem aleatória, a variabilidade da variável dependente, a não colinearidade perfeita entre covariadas e a média condicional nula, que significa que a esperança do erro é nula para qualquer valor da variável preditora. 
Para garantir que o estimador é consistente, é exigida homocedasticidade, que significa que a variância dos erros é constante em relação ao vetor de covariadas. Algumas técnicas buscam superar o não cumprimento de determinados pressupostos. Destacamos o método dos Mínimos Quadrados Generalizados, que reduz a possibilidade de inconsistência dos modelos quando não cumprido o pressuposto de homocedasticidade (WOOLDRIDGE, 2015).

\section{Trade-off entre Viés e Variância}

Uma questão importante quando se constroem modelos de regressão multivariada é a existência do chamado trade-off entre viés e variância do modelo, dada sua complexidade. Modelos mais complexos, com variáveis com alto grau de correlação, tendem a se ajustar muito bem aos dados (baixo viés), mas tendem a possuir fraca possibilidade de extrapolação para novos dados, dada a alta dependência dos dados usados na estimação e a consequente maior variância em novas distribuições. Dá-se a essa condição a denominação de overfitting (FRIEDMAN; HASTIE; TIBSHIRANI, 2001).

Quando se constroem modelos de regressão com o objetivo de se estabelecer previsões, deseja-se que tais modelos tenham uma boa capacidade de previsão para novos dados, mesmo que isso implique em modelos menos ajustados aos dados utilizados na modelagem. Isso faz com que muitas vezes modelos mais simples sejam mais eficazes, ao tempo em que também são mais fáceis de interpretar.

Por causa dessas questões é que normalmente modelos preditivos que usam regressão são construídos havendo primeiro a divisão de uma base de dados em dois conjuntos distintos, sendo um para treino e ajuste do modelo e outro para teste. Assim, a acurácia de um modelo é testada em um conjunto de dados diferente daquele utilizado para estimar os parâmetros. Desta maneira, um modelo perfeitamente ajustado aos dados de aprendizado mas com alta variabilidade apresentará, na base de teste, uma medida de erro elevada.

A Figura 2, utilizada por FORTMANN-ROE (2012), ilustra esse trade-off, contabilizando o erro total de modelos hipotéticos. 


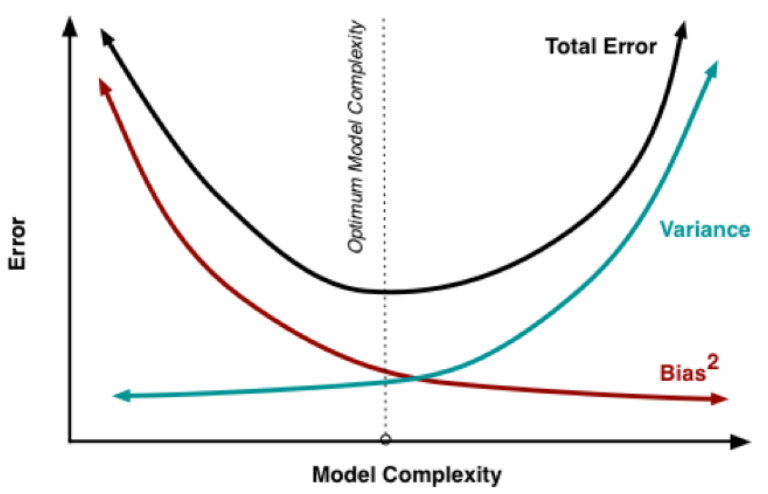

Figura 2: Trade-off viés x variância (FORTMANN-ROE, 2012)

A Figura 2 mostra que a modelagem, buscando apenas a redução do viés, pode gerar um modelo muito dependente dos dados e, na prática, inaplicável a novos dados, vide a alta variância. Por outro lado, um modelo que vise somente à redução da variância terá alto viés. O ponto ótimo de complexidade do modelo é aquele que equilibra esses dois objetivos, e minimiza o erro total.

\section{Regressão Logística}

Modelos de regressão linear não são bons para serem utilizados quando a variável dependente obedece a um intervalo restrito de valores. Isso porque os modelos lineares não limitam os resultados previstos (WOOLDRIDGE, 2015). Os chamados Modelos Lineares Generalizados utilizam funções de ligação para forçar a distribuição dos valores estimados a ficarem dentro de um intervalo definido. No caso de a variável dependente ser binária, e de querermos que o resultado do modelo apresente valores numa escala pré-definida (entre 0 e 1), pode-se usar a chamada Regressão Logística, cuja função de ligação mais amplamente usada é a função logit, apresentada na Equação 2.2.

$$
\operatorname{logistic}(\alpha)=\frac{\exp (\alpha)}{\exp (\alpha)+1}
$$

A Equação 2.2 é a função logística de uma variável $\alpha$ utilizando a função de ligação logit. Se trocarmos $\alpha$ pela função genérica de regressão linear, temos a esperança condicional de $y=1$, dado o vetor de covariadas $x$, como mostrado na Equação 2.3.

$$
E[y=1 \mid x]=\frac{\exp \left(\beta_{0}+\sum_{i=1}^{n} x_{i} \beta_{i}\right)}{\exp \left(\beta_{0}+\sum_{i=1}^{n} x_{i} \beta_{i}\right)+1}
$$

Usualmente, define-se que o valor unitário da variável dependente indica a presença ou ocorrência do evento monitorado. Assim, $y=1$ pode indicar presença de risco de inadimplência, de doença, de sinistro de automóveis etc. Dessa forma, o resultado de 
$E[y=1 \mid x]$ pode ser entendido como a probabilidade da ocorrência do evento. Esse é o valor obtido através da Equação 2.3.

\subsubsection{Procedimentos para tratamento dos dados e validação dos modelos de regressão}

\section{Balanceamento de dados}

Em modelos de regressão onde a variável dependente é binária e há grande desproporcionalidade entre os grupos, existe o risco de o algoritmo utilizado para a estimação ser desproporcionalmente influenciado pela classe majoritária, gerando uma boa acurácia geral do modelo, mas sob a pena de uma alta proporção de erros na classe minoritária. O maior problema disso é que normalmente essa classe minoritária é justamente a de maior interesse (JAPKOWICZ et al., 2000).

Para lidar com esse problema, costuma-se adotar uma das três medidas seguintes (GUO et al., 2008):

- a utilização de algoritmos específicos para modelagem nessas condições, sem mexer na proporção (GUO et al., 2008);

- o aumento fictício da classe minoritária, processo denominado oversampling, onde os elementos da menor classe são simplesmente repetidos como novos elementos tantas vezes quantas forem necessárias para se inflar a classe até o tamanho da classe maior (GUO et al., 2008);

- a redução da classe majoritária, denominada undersampling (JAPKOWICZ et al., 2000; GUO et al., 2008), onde se extrai uma amostra aleatória da classe majoritária com quantidade de elementos igual à da classe minoritária.

Alguns estudos comparam essas três abordagens, havendo razoável consenso de que o oversampling está ligado à existência de overfitting (JAPKOWICZ et al., 2000; WEISS; PROVOST, 2003).

Quanto à utilização do undersampling ou da distribuição inalterada, não existe consenso formado, mas, na prática, há uma clara preferência pelo undersampling, vide a quantidade de trabalhos que utilizam este tratamento (os trabalhos citados na Seção 2.3 que tratam de risco de crédito bancário, são exemplo).

Isso pode se dever a uma maior facilidade de interpretação dos resultados.

\section{Cross-validation}

Já foi dito que para se prevenir o overfitting do modelo, é comum a divisão da base em treino e teste, de maneira a ter conjuntos diferentes para ajuste do modelo e para medir 
a sua acurácia. Ainda assim, nesse momento de se estimar o modelo na base de treino, os algoritmos trabalham basicamente com o teste de inúmeras possibilidades de estimação (no caso da regressão logística, com o teste de diversas combinações de parâmetros da função) em busca de identificar o ponto de minimização da função de custo (i.e., soma dos resíduos quadrados).

Não havendo nenhum tratamento adicional, para fazer a comparação entre valores reais e estimados, estando restritos à base de treino, os algoritmos acabariam utilizando o mesmo conjunto de dados para estimar e medir o acerto dessas diversas combinações de parâmetros. Isso faria com que mais uma vez o modelo estimado na base de treino ficasse "viciado" aos dados de modelagem. Dessa forma, teríamos um modelo que dificilmente traria bons resultados quando apresentado a um novo conjunto de dados, a base de teste.

Uma maneira de se resolver isso seria criar uma nova divisão na base de treino, de maneira a separar um novo subconjunto para teste dentro da própria base que está sendo usada para validar o modelo. Em regra, dá-se o nome de conjunto de validação a essa nova divisão. Ocorre que isso só é eficiente quando se possui um número razoável de observações na base de treino, caso contrário, o conjunto a ser utilizado para estimação ficará muito pequeno, impactando na qualidade do modelo estimado (KOHAVI et al., 1995).

O processo de cross-validation visa resolver essa questão ao criar ciclos de estimação e validação na própria base de treino através do particionamento desse conjunto de dados em várias partes que são utilizadas a cada ciclo, sendo uma delas para validação e as demais para aprendizagem. Cada ciclo muda a ordem escolhendo uma nova partição para validação e as restantes para uma nova estimação. A minimização da função de custo é então realizada considerando o valor conjugado dos erros quantificados a cada ciclo (KOHAVI et al., 1995).

\section{Regularização e redução de variáveis}

Modelagens com quantidade muito grande de variáveis independentes podem ser muito custosas computacionalmente, além de serem uma potencial causa de overfitting, como já abordado em (FRIEDMAN; HASTIE; TIBSHIRANI, 2001). No caso extremo de o número de covariadas superar o número de registros na base, algumas técnicas de regressão simplesmente não funcionam (FRIEDMAN; HASTIE; TIBSHIRANI, 2001). Outro ponto importante é a interpretabilidade do modelo: modelos mais simples possuem um potencial de interpretação maior.

Algumas técnicas foram desenvolvidas para lidar com os impactos de um alto (ou desproporcional) número de covariadas em um modelo de regressão ou classificação. Quando o objetivo é prevenir o overfitting ou eliminar algumas das covariadas, utilizamse as chamadas técnicas de regularização, destacando-se a regressão Ridge (HOERL; KENNARD, 1970) e a Lasso (TIBSHIRANI, 1996). 
Essas duas técnicas funcionam por meio da inclusão, na função de custo da estimação, de um componente de penalização do vetor de coeficientes, proporcional a sua magnitude. Assim, quanto maiores os coeficientes estimados, maior a penalização, o que regulariza a medida de qualidade do modelo, antes dependente exclusivamente dos resíduos, e, consequentemente, reduz o valor dos parâmetros estimados. Basicamente, duas características diferenciam a Ridge da Lasso: enquanto a Ridge usa como parâmetro de penalização o somatório do quadrado dos parâmetros, a Lasso utiliza o somatório dos módulos desses parâmetros; e a Lasso, diferentemente da Ridge, pode reduzir alguns parâmetros a zero, portanto é bastante usada como meio de seleção de variáveis (TIBSHIRANI, 1996).

Outro método bastante utilizado é o chamado Stepwise, onde a estimação do modelo é feita com a inclusão (exclusão) de uma variável por vez a partir do modelo vazio (completo), até que a função de custo se estabilize, determinando o subconjunto a ser usado, processo denominado Forward Stepwise (Backward Stepwise)(BENDEL; AFIFI, 1977).

\section{Validação de resultados}

Diversos métodos podem ser utilizados para testar a significância de modelos de regressão de caráter preditivo. Destacaremos a medida do Pseudo-R2 e o teste de Wald, mais comumente usados em trabalhos desse tipo.

Diferentemente da regressão linear comum com a estimativa de mínimos quadrados ordinários, não há estatística $R 2$ que explique a proporção da variância na variável dependente relacionada aos preditores. No entanto, há uma série de métricas conhecidas como Pseudo-R2 que podem servir como proxy dessa medida. A mais utilizada é o $R 2$ de $M c F a d d e n$, que é definido pela Equação 2.4, onde $\ln (L M)$ é o valor de verossimilhança para o modelo ajustado e $\ln (L 0)$ é a verossimilhança para o modelo nulo com apenas o intercepto como preditor. A medida varia de 0 a pouco menos de 1 , com valores mais próximo de zero indicando baixo poder preditivo (HOETKER, 2007).

$$
\text { Pseudo-R2 }=1-\frac{\ln (L M)}{\ln (L 0)}
$$

O teste de Wald verifica se cada coeficiente estimado é significativamente diferente de zero, o que indica que a covariada serve de fato para diferenciar os grupos. É normalmente usado em modelos de regressão ou classificação com variável resposta binária (JR; DONNER, 1977).

Além dos testes de validação, a qualidade de um modelo de regressão desse tipo é frequentemente medida com métricas de acerto do modelo. Uma vez que a variável resposta que é utilizada para aprendizagem é binária, e que o valor previsto pelo modelo fica restrito a valores entre 0 e 1, pode-se estabelecer um threshold (normalmente 0.5) e classificar os elementos segundo a previsão criada. Assim, registros com valor previsto 
maior que 0.5 podem ser considerados como iguais a 1 e os demais como 0 .

Desta maneira, pode-se simplesmente comparar, para cada classe de resposta, os valores reais com os previstos pelo modelo. A Tabela 1 contém um exemplo da chamada matriz de confusão, normalmente utilizada para apresentar essa comparação.

Tabela 1: Matriz de confusão padrão.

\begin{tabular}{|c|c|c|}
\hline & Previsão 1 & Previsão 0 \\
\hline Valor Real 1 & Verdadeiro Positivo (VP) & Falso Negativo (FN) \\
\hline Valor Real 0 & Falso Positivo (FP) & Verdadeiro Negativo (VN) \\
\hline
\end{tabular}

Para explicar a Tabela 1, tomemos um exemplo de classificação de risco, onde, no modelo de aprendizagem construído, as empresas foram previamente identificadas como de "alto risco" (valor da variável resposta $=1$ ) ou de "baixo risco" (valor da variável resposta $=0)$. Após a estimação de um modelo de Regressão Logística, os valores previstos assumem valores entre 0 e 1, e as empresas são classificados de acordo com o threshold de 0.5, sendo 1 para valores maiores que 0.5, e 0, caso contrário.

Assim, os valores dispostos na Tabela 1 teriam o seguinte significado:

- Verdadeiros Positivos (VP): quantidade de empresas classificadas pelo modelo como de alto risco e que de fato são de alto risco.

- Falsos Positivos (FP): quantidade de empresas classificadas pelo modelo como de alto risco mas que na realidade são de baixo risco.

- Falsos Negativos (FN): quantidade de empresas classificadas pelo modelo como de baixo risco mas que na realidade são de alto risco.

- Verdadeiros Negativos (VN): quantidade de empresas classificadas pelo modelo como de baixo risco e que de fato são de baixo risco.

A partir desses valores, pode-se calcular as seguintes métricas da capacidade preditiva do modelo:

- Acurácia: Mede o percentual de acertos do modelo. É obtida pela Equação 2.5.

$$
\text { Acurácia }=\frac{V P+V N}{V P+F P+F N+V N}
$$


- Sensibilidade: Mede o percentual de casos classificados como 1, dentre os que realmente são da classe 1. É obtida pela Equação 2.6.

$$
\text { Sensibilidade }=\frac{V P}{V P+F N}
$$

- Especificidade: : Mede o percentual de casos realmente da classe 0, dentre os que foram previstos como 0. É obtida pela Equação 3.5.

$$
\text { Especificidade }=\frac{V N}{F N+V N}
$$

- Precisão: Mede os o percentual de casos realmente da classe 1, dentre os que foram previstos como 1. É obtida pela equação 2.8 .

$$
\text { Precisão }=\frac{V P}{V P+F P}
$$

A depender do objetivo do modelo criado, cada métrica ganha importância diferente. Num modelo cujo foco é identificar possíveis fraudes, por exemplo, pode ser mais importante a sensibilidade que a especificidade, já que a fraude é objeto a se prever e os registros da base de aprendizado que a apresentarem terão o valor 1 . Num diagnóstico médico que determine a realização de uma cirurgia de emergência, é fundamental a precisão, já que é absolutamente indesejável levar à realização de cirurgia um paciente são.

Uma medida que combina essas métricas em uma única medida de avaliação do modelo é a F-measure, apresentada na Equação 2.9, que é a média harmônica entre precisão e sensibilidade (POWERS, 2011).

$$
F-\text { Measure }=\frac{\left(1+\beta^{2}\right) \cdot \text { Precisão.Sensibilidade }}{\beta^{2} \cdot(\text { Precisão }+ \text { Sensibilidade })}
$$

Ajustando-se o valor de $\beta$, pode-se dar mais importância à sensibilidade $(\beta>1)$ ou à precisão ( $\beta$ entre 0 e 1 ). $\mathrm{O}$ valor de $\beta=1$ atribui igual importância às duas métricas.

O índice Kappa é comumente utilizado para medir o desempenho de modelos de predição e diferenciá-lo de um resultado obtível aleatoriamente (CARLETTA, 1996). Sua fórmula de cálculo é a mostrada na Equação 2.10.

$$
\text { Kappa }=\frac{\text { Acurácia_do_modelo }- \text { Aleatoriedade }}{1-\text { Aleatoriedade }}
$$

\subsubsection{Modelos de Decisão Multicritério}

Modelos de Decisão Multicritério são técnicas de ordenação lógica das alternativas para solução de um problema (ou busca de um objetivo) por meio da decomposição 
analítica do objeto de tomada de decisão, da ponderação de um conjunto de critérios e do aproveitamento da opinião de especialistas ou gerentes (STEWART, 2005). Existem diversos métodos de auxílio à decisão multicritério. Detalharemos o Analytic Hierarchy Process (AHP), que será utilizado neste trabalho.

Analytic Hierarchy Process (AHP)

O AHP existe desde 1970 e é um dos métodos de decisão multicritério mais utilizados no mundo. Funciona a partir da decomposição hierárquica do conjunto de ações possíveis para a solução do problema de tomada de decisão (GOLDEN; WASIL; HARKER, 2003). COSTA; MOLL (1999) define três etapas para a modelagem do AHP:

- Construção de Hierarquias: Nesta etapa, estrutura-se o problema em níveis hierárquicos, sendo o primeiro nível da hierarquia o problema central, ou objetivo geral. O segundo nível contém os critérios que são utilizados para a ponderação das alternativas. O terceiro nível contém as alternativas de atuação sobre o problema.

- Definição de Prioridades: É a comparação par a par, para todas as combinações possíveis, dos elementos de cada um dos níveis hierárquicos inferiores (critérios e alternativas). Essa comparação é realizada por meio da criação de uma matriz denominada Matriz de Julgamentos. Após a normalização da Matriz de Julgamentos, com a divisão de cada elemento da matriz pelo somatório da respectiva coluna, o coeficiente final de cada elemento do nível hierárquico (critério ou alternativa) é resultado da média da respectiva linha da matriz normalizada.

- Verificação da Consistência Lógica: O método utiliza uma equação de verificação de consistência dos julgamentos (vide Equação 2.11), que, basicamente, visa identificar a existência de contradições graves nas avaliações. Considera-se aceitável um valor inferior a 0.1 (SAATY, 1990).

$$
I C=\frac{(\lambda \max -n)}{(n-1)}
$$

Na Equação 2.11, IC é o índice de consistência, $\lambda$ max é o máximo dos autovalores da matriz de julgamentos e $n$ é o número de elementos da matriz de julgamentos.

\subsection{Trabalhos correlatos}

Existem estudos aplicados utilizando econometria ou aprendizagem de máquina em diferentes áreas. Especificamente quanto à criação de modelos preditivos de risco, as aplicações mais comuns são na área de crédito bancário (são citados alguns a seguir). Nesta seção, serão abordadas aplicações que usam técnicas similares nessa área, bem como 
outros trabalhos no âmbito governamental, mesmo usando técnicas diferentes, mas cujo objetivo seja a construção de modelos preditivos. Neste último caso, dar-se-á destaque para trabalhos que se respaldam em teorias econômicas para a construção dos modelos.

No âmbito da avaliação de risco de crédito bancário, a aplicação clássica do chamado Credit Scoring é a seleção de proponentes ao crédito (CAOUETTE et al., 2009). Além dela, existem, na literatura, exemplos de aplicações desses modelos em outras etapas do ciclo de vida do crédito. Dentre outros momentos, ele pode ser aplicado na prospecção de clientes, quando recebe o nome de Response Scoring, durante a execução do contrato (Behavioral Scoring) ou mesmo após já consumada a inadimplência (Collection Scoring), para identificar devedores mais propensos a quitar a dívida (SEMEDO, 2010).

Essas novas visões ampliam a utilidade da ferramenta que, além de prever problemas, passa também a ser utilizada para identificar oportunidades para a organização (THOMAS; EDELMAN; CROOK, 2002).

Como exemplo de aplicação tradicional do Credit Scoring, podemos citar VASCONCELLOS (2002), que propõe uma metodologia de análise da concessão de crédito a pessoas físicas, utilizando, como objeto de estudo, o histórico de operações e os dados cadastrais dos clientes de um popular banco brasileiro.

Na mesma linha, GEVERT et al. (2011) investiga o desempenho de diferentes técnicas estatísticas na predição de inadimplência em contratos de uma agência bancária.

Já ARAÚJO; CARMONA (2009), estudando uma instituição de microcrédito, aborda também a possibilidade de utilização do Credit Scoring na modalidade Behavioral Scoring e compara os desempenhos de duas técnicas estatísticas: Análise Discriminante e Regressão Logística.

No âmbito governamental, CARVALHO (2015) propõe um modelo de quantificação do risco de corrupção de servidores públicos, utilizando Regressão Logística e um conjunto grande de variáveis, atingindo bons resultados preditivos. SALES; CARVALHO (2016) utiliza um modelo de regressão bayesiana para classificação de fornecedores do governo entre problemáticos e não problemáticos, numa abordagem diferente, mas com finalidade semelhante à do primeiro modelo quantitativo utilizado neste trabalho. CARVALHO; CARVALHO (2016) aplica um modelo de regressão bayesiana para verificação do risco de corrupção de unidades administrativas governamentais no Brasil.

Dados de compras públicas no Brasil vêm sendo muito utilizados em trabalhos recentes de econometria aplicada. Diversos estudos abordam a Teoria dos Leilões, Teoria dos Jogos ou Economia dos Custos de Transações na sua relação com o contexto das aquisições públicas no Brasil. Alguns desses buscam aplicar modelos econométricos na previsão de determinadas métricas de uma licitação, como o valor "economizado", "descontado" ou "variação de preços" em pregões. Destacaremos aqui as principais referências para este 
trabalho, buscando pontuar lacunas e oportunidades de aprofundamento.

SILVA (2007) propôs modelo econométrico para previsão da "economia" (definida pelos autores como a diferença percentual entre o valor estimado e o pago) em 141 pregões realizados pela Prefeitura Municipal de Fortaleza no ano de 2006. Identificou os efeitos nessa economia apenas do quantitativo de participantes e de lances, destacando faixas onde se maximizaria o resultado.

SANTOS; SILVEIRA (2010) realizou pesquisa descritiva das licitações (pregões eletrônicos) feitas pela Universidade Federal de Viçosa no último quadrimestre de 2007, com o objetivo de determinar matematicamente os fatores que mais contribuíam para a "variação dos preços" nos pregões da universidade. Diferencia-se do modelo proposto por SILVA (2007), especialmente, por não considerar o preço estimado pelo órgão licitante e sim o preço praticado pela empresa vencedora. Essa mudança metodológica tem a vantagem de captar melhor o valor de mercado do bem e a possível redução decorrente do pregão, mas, visto que exige uma pesquisa documental não estruturada (posto que o dado do preço praticado pela empresa é obtido manualmente), torna muito dificultosa a ampliação da pesquisa para um quantitativo mais representativo de licitações.

MORAES (2012) faz análise descritiva, sem cunho preditivo, dos pregões realizados pela unidade regional de Tocantins do Departamento Nacional de Infraestrutura de Transporte. Estuda o efeito de fatores como a quantidade de participantes e o horário dos últimos lances no valor final do que chama de "desconto" (nesse caso também a diferença percentual entre valor previsto e pago).

CORDERO; SILVEIRA; MOREIRA (2012) analisa os pregões promovidos em 2010 pela Universidade Federal do Pampa e busca quantificar a "economia" (aqui entendida novamente como a diferença percentual entre valor previsto e pago), também por meio de uma análise puramente descritiva.

Outros trabalhos abordam mais especificamente a Teoria dos Jogos e sua relação com a formação de cartéis em licitações públicas, mas trazem elementos interessantes sobre aspectos comportamentais dos agentes nesse contexto. Podemos destacar CAMPOS (2016) e MATOSO (2009).

Os trabalhos que estudam as teorias ou modelos econômicos relacionando-os com licitações ou leilões têm abordado aspectos específicos dessas áreas, como variação nos preços ou concorrência e formação de cartéis. Como este estudo foca nos riscos contratuais de inadimplência com o governo, tais trabalhos são úteis para a criação dos indicadores de risco a serem utilizados como varáveis preditoras nos modelos.

No contexto dos contratos públicos no Brasil, alguns estudos já foram realizados com o objetivo de implementar modelos de predição de riscos envolvendo os fornecedores do governo. BALANIUK et al. (2012) utiliza algoritmos de Redes Bayesianas para uma 
abordagem não supervisionada que quantifica o risco conjunto de empresas e unidades governamentais na execução dos contratos. SALES (2014) constrói um modelo supervisionado de previsão (usando Árvores de Decisão) do risco de uma empresa ser declarada inidônea, com resultados medianos. 



\section{Metodologia}

Esta seção detalha o processo de construção dos modelos econométricos. Para melhor organização lógica, está dividida em quatro partes. A Subseção 3.1, de entendimento do negócio, contextualiza a pesquisa dentro da realidade da CGU e explica os âmbitos de risco que são abordados pelos modelos. A Subseção 3.2, de entendimento dos dados, detalha cada uma das bases de dados que são utilizadas e como cada grupo de informações se relaciona com as dimensões de riscos pensadas. A Subseção 3.3 diz respeito à formulação dos indicadores de risco, a partir dos dados disponíveis, visando a sua adequação às dimensões de risco e a sua fundamentação nas teorias econômicas que analisam o comportamento estratégico dos agentes.

Como mencionado na seção de introdução, o objetivo geral de criar uma metodologia para seleção de contratos para auditoria foi atingido a partir da construção de três modelos, sendo o primeiro de quantificação de riscos do fornecedor, o segundo de quantificação do risco do contrato e o terceiro de decisão multicritério para auditoria. Assim, a Subseção 3.4 traz o processo de modelagem para o risco do fornecedor (item 3.4.1), para o risco para o contrato (item 3.4.2) e o processo de construção do modelo de decisão multicritério (item 3.4.3).

\subsection{Entendimento do Negócio}

Esta seção descreve aspectos da estruturação das atividades da CGU e dos pontos de interesse dos trabalhos de auditoria que serviram para fundamentar a escolha das variáveis que compõem o modelo preditivo de risco construído. Divide-se em duas partes, tratando a primeira do posicionamento institucional e legal do órgão e da configuração administrativa interna e a segunda, das dimensões de risco contratuais mais afetas ao controle de contratações públicas realizado.

\subsubsection{Aspectos institucionais}

A CGU, como órgão central do Sistema de Controle Interno do poder executivo federal, tem suas atribuições previstas originalmente na Constituição Federal de 1988 (BULOS, 2002) e definidas na Lei Ordinária nº 10.683/03 (BRASIL, 2003). Assim determina o Artigo 70 da Constituição (BULOS, 2002):

Art. 70. A fiscalização contábil, financeira, orçamentária, operacional e patrimonial da União e das entidades da administração direta e indireta, quanto à 
legalidade, legitimidade, economicidade, aplicação das subvenções e renúncia de receitas, será exercida pelo Congresso Nacional, mediante controle externo, e pelo sistema de controle interno de cada Poder.

Dentre as competências atribuídas por lei à CGU, destacamos (BRASIL, 2003):

- Assistir direta e imediatamente o Presidente da República no desempenho de suas atribuições quanto aos assuntos e providências que, no âmbito do Poder Executivo, sejam atinentes à defesa do patrimônio público, ao controle interno, à auditoria pública, à correição, à prevenção e ao combate à corrupção, às atividades de ouvidoria e ao incremento da transparência da gestão no âmbito da Administração Pública Federal;

- Efetivar, ou promover, a declaração da nulidade de procedimento ou processo administrativo, bem como, se for o caso, a imediata e regular apuração dos fatos envolvidos nos autos, e na nulidade declarada;

- Requisitar, a órgão ou entidade da Administração Pública Federal ou, quando for o caso, propor ao Presidente da República que sejam solicitadas, as informações e os documentos necessários a trabalhos da Controladoria-Geral da União.

A estrutura interna da CGU é definida pelo Decreto no 8.109/13 (BRASIL, 2013a). Esse documento legal diz que as atividades da CGU serão exercidas por quatro grandes áreas: a Secretaria Federal de Controle Interno, responsável pelo planejamento e execução de auditorias e fiscalizações; a Corregedoria, responsável pela condução ou supervisão de procedimentos investigativos contra servidores ou empresas que se relacionam com o governo; a Ouvidoria, responsável pelo recebimento e triagem de denúncias e pelo atendimento aos cidadãos, nos temas relativos à prestação de serviços públicos; e a Secretaria de Transparência e Prevenção da Corrupção, que desenvolve projetos de fomento ao controle social, transparência e integridade.

A configuração do planejamento de auditorias do órgão, para avaliação da execução de ações e programas do governo está definida na Instrução Normativa $n^{\circ}$. 01/2001 (BRASIL, 2001b) e no Manual da Metodologia para Avaliação da Execução de Programas de Governo (CGU, 2015). Esses documentos determinam a lógica de hierarquização das grandes áreas a serem avaliadas a cada ano. É um planejamento em alto nível, que já define alguns fatores ou dimensões de risco considerados importantes.

A hierarquização das ações governamentais leva em conta três critérios: materialidade, relevância e criticidade. A materialidade diz respeito ao montante de recursos envolvidos na ação. A relevância não está objetivamente definida, leva em conta a existência de contexto específico que dê destaque à ação. A criticidade diz respeito às fragilidades já 
previamente identificadas pela CGU em relação às unidades governamentais responsáveis pela ação ou ao próprio objeto da ação.

Do ponto de vista de organização interna da área de auditoria, o Decreto $\mathrm{n}^{\circ}$ 8.109/13 define as divisões de auditoria de acordo com as pastas ministeriais, assim existem coordenações que tratam dos assuntos finalísticos e de gestão referentes a cada ministério (BRASIL, 2013b).

Do ponto de vista operacional, as atividades de auditorias a serem executadas são delimitadas em ordens de serviço específicas, e relacionadas a procedimentos pré-definidos (BRASIL, 2001b). Esses procedimentos são genéricos e perpassam todos os atos de gestão relacionados ao processo e etapas do gasto público.

Os procedimentos utilizados para auditoria de contratos e licitações são genéricos, de maneira a serem executados de forma padronizada por qualquer uma das unidades de auditoria e a serem aplicáveis a qualquer contrato, independentemente do seu objeto ou finalidade.

Vale levantar aqui algumas possíveis limitações dessa modelagem. A primeira delas é que a divisão de áreas de auditoria por pasta ministerial deixa uma grande lacuna: a perda de conhecimento técnico especializado e impossibilidade de ação focada em questões transversais, como contratos, licitações, convênios ou obras. A criação de procedimentos padronizados pode ser uma tentativa de suprir essa lacuna, com a criação de check-lists para a verificação de irregularidades ou pontos de análise em auditorias, mas esses procedimentos estão configurados de maneira bastante genérica. Esta seria a segunda limitação do modelo, pois da forma como foram criados, os procedimentos deixam pouca margem para a análise de questões particulares de cada contrato ou licitação.

Essas limitações, a inexistência de área transversal para tratar de contratações públicas e a utilização de procedimentos genéricos, dão maior importância à utilização de modelos de risco com foco nos processos, como o proposto neste trabalho. Tais modelos têm o potencial de agregar à análise das contratações aspectos de risco inerentes ao processo, sejam esses aspectos ligados ao procedimento em si ou mesmo à empresa envolvida.

\subsubsection{Dimensões do risco contratual}

As dimensões de risco podem ser aduzidas dos próprios trabalhos de auditoria realizados pela $\mathrm{CGU}^{1}$. A questão que se coloca é: Quais situações são mais recorrentes quando da caracterização de achados de auditoria? A partir dos trabalhos referenciados na Seção 2.3 que analisam achados de auditoria em relatórios da CGU ou que retratam os trabalhos de monitoramento contínuo de contratos é possível se ter uma ideia dos principais

1 Os relatórios de fiscalização da CGU estão disponíveis em <http://www.cgu.gov.br/assuntos/ auditoria-e-fiscalizacao/pesquisa-de-relatorios $>$. 
tipos de irregularidades encontradas. Além disso, buscou-se junto a especialistas em licitações e contratos compreender que fatores poderiam ainda contribuir subsidiariamente para uma modelagem de riscos nessa área.

Para organizar logicamente esses pontos, fazemos aqui uma divisão no que denominamos Dimensões do Risco Contratual, que nada mais são do que agrupamentos dos principais fatores de risco aduzidos das irregularidades verificadas pela CGU, dos monitoramentos realizados, ou da opinião dos especialistas. Dividimos em duas grandes classes, coerentes com os modelos econométricos propostos neste trabalho: Dimensões do risco do fornecedor e Dimensões do risco do contrato. A ideia é delinear o escopo da análise de risco para a posterior definição de variáveis que servirão para caracterizar cada dimensão.

Detalhamos abaixo as dimensões do risco do fornecedor, com exemplos das situações monitoradas e das irregularidades encontradas e possíveis vulnerabilidades decorrentes.

- Capacidade operacional: Irregularidades que apontam para a inexistência ou insuficiente estrutura física e operacional da empresa contratada. Em muitos casos, a empresa não se encontra no endereço cadastrado ou possui apenas o que se denomina estrutura de "fachada". Os achados normalmente apontam para problemas posteriores de descontinuidade ou má prestação dos serviços.

- Histórico de punições e constatações: Ocorre a firmatura de contratos com empresas já punidas pelo governo e até impedidas de licitar. Empresas já recorrentes em infrações contratuais, ou que já apresentaram indícios de fraudes nas ações de monitoramento realizadas pela CGU, podem estar mais propensas a cometer novas irregularidades.

- Perfil de participação em licitações: O monitoramento realizado pela CGU avalia o perfil de participação em licitações, como o quantitativo médio de lances, e o grau de sucesso das empresas, mapeando situações anômalas, como as que participam de inúmeras licitações e nunca vencem ou as que sempre são vencedoras.

- Conflito de interesses: Vinculação da empresa com servidores públicos. Empresa que recebe recursos em convênios, como Entidade Sem Fins Lucrativos, é contratada em procedimentos licitatórios comuns, onde se visa lucro.

- Vinculação política: Vínculo da empresa com políticos, via filiação partidária ou doações realizadas em campanhas. Normalmente verificado em fiscalizações em municípios, algumas vezes representando o repasse indireto de recursos do governo federal para empresas de políticos locais.

As dimensões de risco relacionadas ao contrato são as seguintes: 
- Irregularidades na licitação: Questões formais, como o desrespeito ao limite financeiro da modalidade, vinculação entre licitantes, dispensa sem justificativa, fracionamento da compra, entre outras. Muitas dessas situações são monitoradas pela CGU, por meio do Observatório da Despesa Pública $(\mathrm{ODP})^{2}$, com a utilização de trilhas computacionais que analisam periodicamente os dados das licitações (GAL et al., 2015).

- Competitividade do processo licitatório: Situações que podem indicar direcionamento dos contratos, como por exemplo a criação de justificativa de emergência falsa para justificar a contratação direta das empresas. Mesmo quando há a licitação, fatores como a baixa quantidade de lances podem indicar baixa competitividade do processo.

- Características gerais da licitação: Aspectos gerais do processo de compra, não enquadrados como irregularidades ou dentre os indicativos de competitividade, como a qualidade na especificação do objeto e a especificidade do serviço contratado.

- Ocorrências do contrato: Aditamentos do contrato, alterações de prazo e de objeto. Essas situações podem representar o descumprimento frontal da lei (como aditamentos acima do limite) e também servem de indicativo do risco na execução.

- Fornecedor Contratado: Características do fornecedor contratado, como os já mencionados previamente.

\subsection{Entendimento dos Dados}

Nesta seção estão descritos os dados utilizados para a construção dos indicadores de risco. Para facilitar a compreensão, as informações estão agrupadas nas seguintes áreas temáticas: contratações públicas, cadastro de empresas, vínculos empregatícios públicos, vínculos empregatícios privados, pagamentos e transferências da União e vinculação política. Para cada uma dessas áreas, informamos as bases de dados utilizadas e as dimensões de risco que abarcam. Além disso, é feita uma pequena análise descritiva dos dados, naqueles pontos de maior interesse para este trabalho.

\subsubsection{Contratações Públicas}

A base de dados que traz informações sobre contratações públicas no Governo Federal é a base do Sistema de Administração de Serviços Gerais (SIASG). Este sistema registra toda e qualquer licitação, compra direta (sem licitação, por dispensa ou inexigibilidade) ou contrato de unidades da hierarquia dos ministérios, autarquias e fundações

2 Mais informações sobre o ODP estão disponíveis em urlhttp://www.cgu.gov.br/assuntos/informacoesestrategicas/observatorio-da-despesa-publica 
públicas. Estatais (Empresas Públicas e Sociedades de Economia Mista) não são obrigadas a utilizar o sistema (FERNANDES, 2008).

O SIASG contém registros desde o ano de 1997, mas, como a utilização do sistema provavelmente se deu de forma gradual, devemos olhar com parcimônia os dados dos primeiros anos.

O sistema está dividido em 5 módulos: Compras, Contrato, Cronograma, Empenhos e Fornecedor ${ }^{3}$. O módulo de empenho apenas complementa as informações dos pagamentos oriundos das compras. Detalharemos as informações disponíveis nos demais módulos.

O módulo de Compras registra informações sobre processos de licitação ou aquisição direta (sem licitação) de bens e serviços. Contém informações sobre identificação da compra (número do processo e objeto), modalidade de disputa utilizada (concorrência, tomada de preços, pregão, convite, dispensa ou inexigibilidade), identificação dos itens adquiridos (descrição dos materiais ou serviços), dos responsáveis pela compra (unidades gestoras, autorizadores e homologadores), valores estimados e finais, informações dos participantes (como quantidade de lances dada, valor da proposta inicial e valor do último lance) e das datas de cada fase do processo.

O módulo de Contratos registra informações posteriores sobre o subconjunto de compras que geraram contratos ${ }^{4}$. Contém informações sobre a unidade responsável pelo contrato, dados básicos da empresa contratada, objeto do contrato, dados de alterações no valor ou nos prazos (termos aditivos) e de mudanças de texto ou objeto (apostilamento) (MPOG, 2006).

Para explicitar o volume de registros envolvidos e a diferenciação que o sistema faz entre compras e contratos, a Figura 3 traz a evolução do quantitativo de compras registradas no sistema e dos contratos que decorreram delas, de 1997 a 2016 (atualizado até abril).

3 Mais informações sobre os módulos do SIASG em <http://comprasnet.gov.br/publicacoes/manual siasg $>$.

4 O SIASG só registra contratos para compras que demandam prestação continuada de serviços ou entrega de bens. Assim, todas as compras que consistem na pronta entrega de bens e serviços são registradas apenas no módulo de compras (MPOG, 2006). 


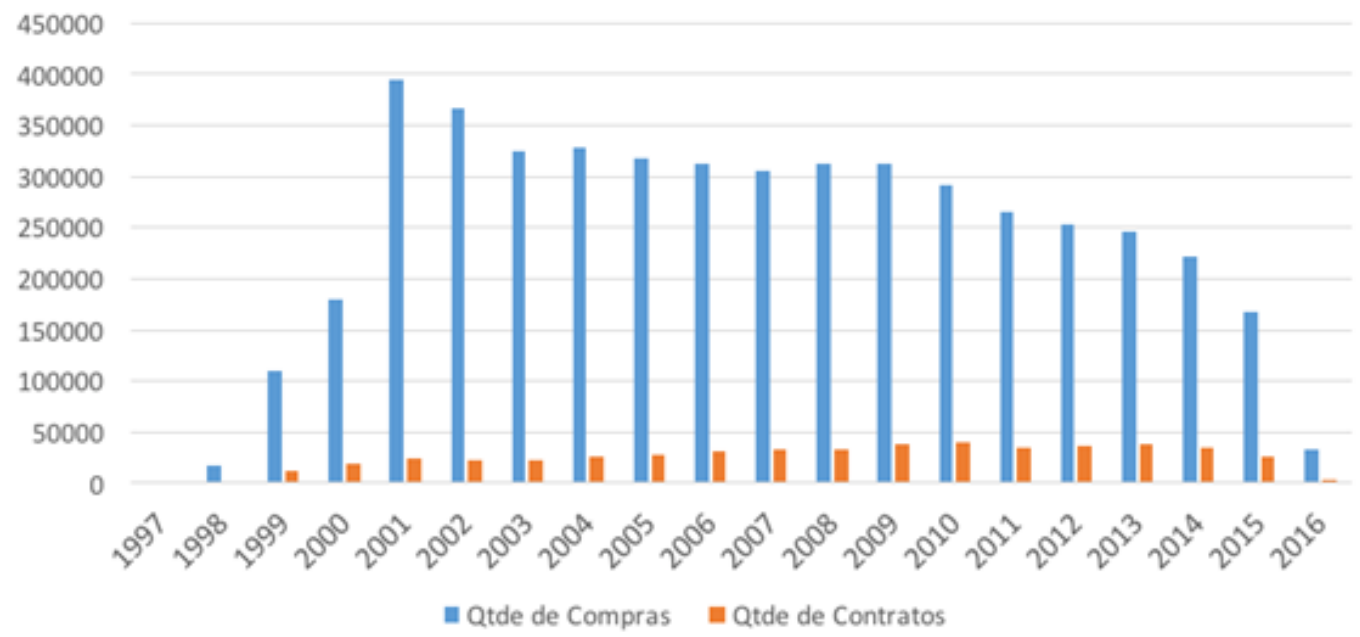

Figura 3: Evolução da quantidade de compras e contratos

Pela análise da Figura 3, percebe-se que o SIASG passou a ser utilizado efetivamente a partir de 2001, e que a quantidade de compras vem sofrendo uma redução nos últimos anos, possivelmente devido aos recorrentes cortes orçamentários.

O módulo de Cronograma traz importantes informações sobre o acompanhamento da execução dos contratos. Nele estão dados de servidores da unidade governamental responsáveis por fiscalizar o contrato, informações sobre planejamento e cumprimento de etapas, indicadores sobre a existência de garantia contratual ou alterações de objeto, ocorrências de descumprimento do objeto, interrupções, tipos de interrupção e motivo das interrupções (MPOG, 2006).

Por ser de especial importância para este trabalho, a distribuição das ocorrências contratuais por tipo é apresentada na Figura 4. O período considerado também foi o de 1997 a 2016 (atualizado até abril). 


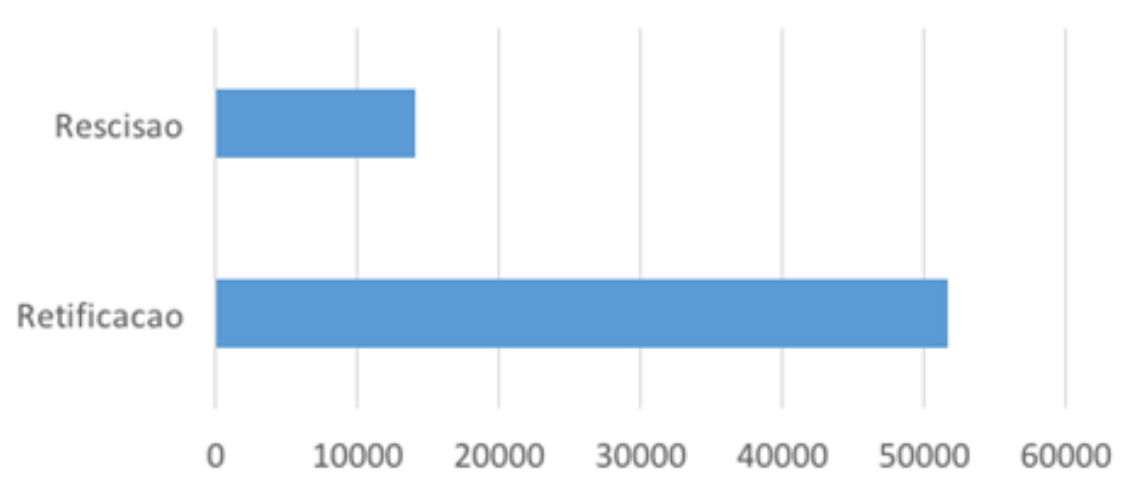

Figura 4: Distribuição das ocorrências de interrupção contratual por tipo

A Figura 4 mostra que a maior parte das ocorrências são retificações no contrato (correção de falhas no texto, a princípio não alterando valor ou prazo).

O sistema registra ainda a motivação das rescisões. Não existe uma categorização dessa informação, já que o campo é de texto livre. Para facilitar o entendimento e tendo em vista a utilização de tipos específicos de justificativa, foi realizada, com o apoio de especialistas da CGU, uma categorização dessa informação, apresentada na Figura 5, referente às rescisões registradas em 2015 e 2016 (dados atualizados até abril).

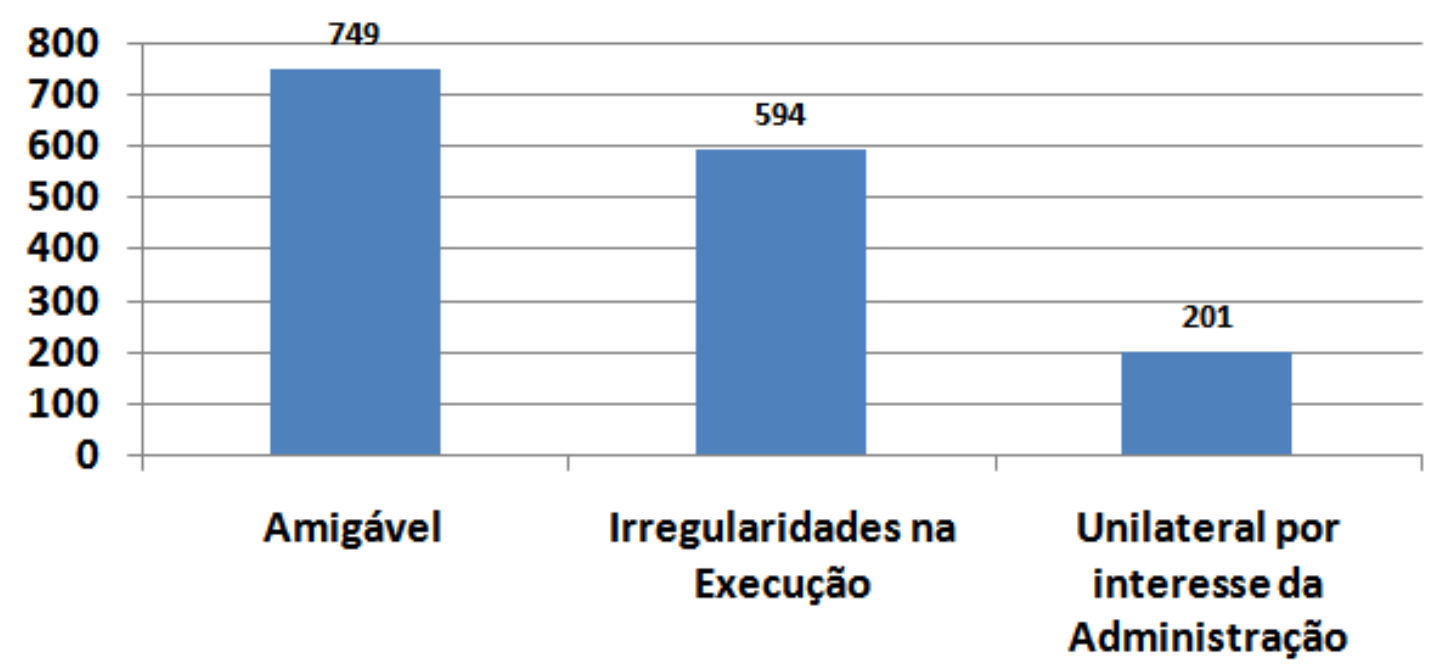

Figura 5: Motivação das rescisões de 2015 e 2016

O foco deste trabalho, especialmente no segundo modelo quantitativo, são as as rescisões causadas por irregularidades na execução (das quais pode-se concluir que há culpa 
do fornecedor e prejuízo à administração pública), que somam 594 ocorrências, conforme mostrado na Figura 5.

O módulo de Fornecedor traz dados cadastrais do fornecedor (como localidade, porte, identificação de sócios, representantes e endereço) e, mais importante no contexto deste trabalho, registra as penalidades a ele aplicadas, abrangendo das mais leves (advertência e multa) às mais graves (suspensão e impedimento de licitar).

A Figura 6 mostra a distribuição dos tipos de penalidade dentre os registros da base.

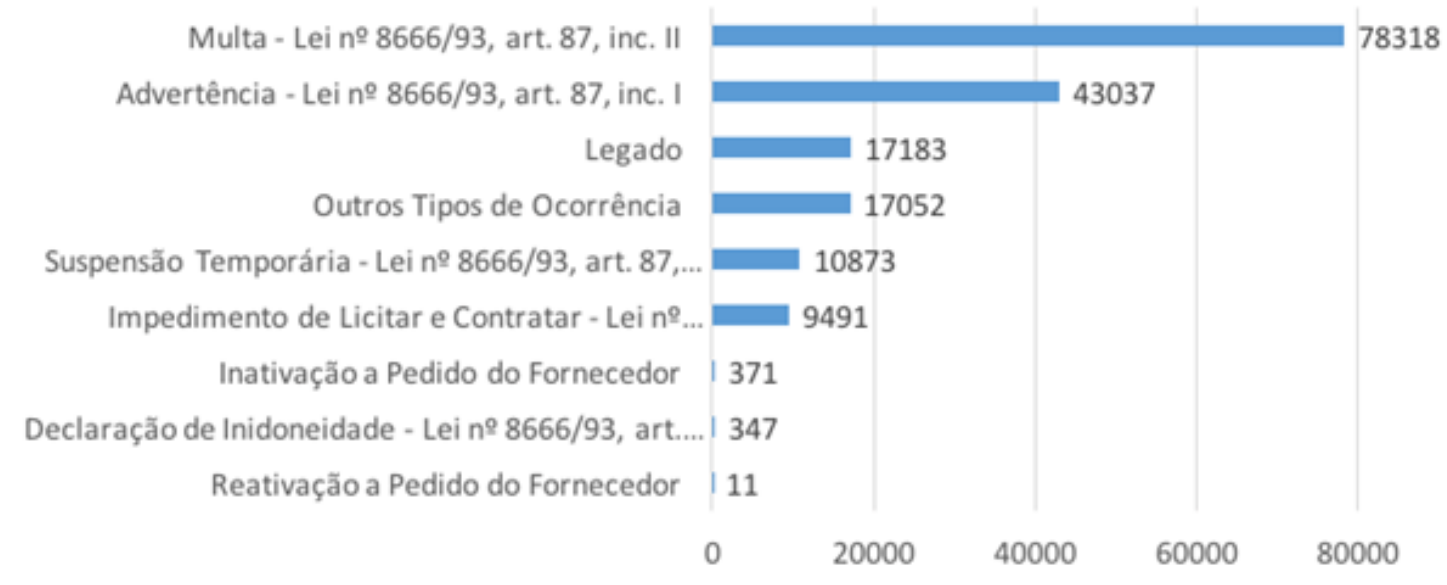

Figura 6: Distribuição dos tipos de penalidade

A Lei de Licitações estabelece como menos graves a multa e a advertência, e como mais graves a suspensão, o impedimento de licitar e a declaração de inidoneidade. Pode-se observar que penalidades menos severas são mais frequentes, o que é natural, uma vez que normalmente elas antecedem a aplicação de penalidades mais graves (MPOG, 2006).

A causa prevista na lei que justifica a aplicação dessas penalidades é a inexecução total ou parcial do contrato (MUKAI, 1994).

As informações sobre contratações públicas estão relacionadas às dimensões de Histórico de Punições e Constatações e de Perfil de Participação em Licitações, no âmbito do Risco do Fornecedor e a todas as dimensões do Risco do Contrato, já que contempla informações sobre as principais irregularidades na compra, possui dados que permitem inferir o grau de competitividade da licitação, e trazem registros detalhados da execução dos contratos. 


\subsubsection{Cadastro de Empresas}

Uma das bases de dados que fornece informações do cadastro de empresas brasileiras é o Cadastro Nacional de Pessoas Jurídicas (CNPJ), da Receita Federal do Brasil. Lá estão registradas mais de 30 milhões de pessoas jurídicas ${ }^{5}$, com informações de código de CNPJ, endereço, sócios, contadores, responsáveis, porte (empresa comum, Microempresa ou Empresa de Pequeno Porte) e mercado de atuação. Por serem especialmente importantes para este trabalho, descreveremos aqui alguns atributos.

O porte da empresa é dado pelo seu faturamento anual. Admite três valores: Microempresas (ME), com faturamento até R\$ 360 mil, Empresas de Pequeno Porte (EPP), com faturamento até $\mathrm{R} \$ 3,6$ milhões,po e outras, que seriam as empresas maiores, com faturamento maior que o último limite (MAMEDE, 2007).

Outro importante dado dessa base é a Classificação Nacional de Atividade Econômica $(\mathrm{CNAE})^{6}$, que representa o mercado onde atua a empresa, segundo declarado no momento da inscrição no cadastro. É classificado em CNAE principal (atividade principal da empresa) e secundário (outras atividades subsidiárias).

Outra informação útil diz respeito à área de atuação das empresas é o atributo de Natureza Jurídica. Nele, as empresas são separadas entre Empresas Públicas ou Sociedades de Economia Mista, organizações sem fins lucrativos e empresas comuns. As informações oriundas do cadastro de empresas se relacionam com o grupo de dimensões do Risco do Fornecedor, uma vez que oferecem dados relacionados a vínculos (o que abrangeria as dimensões de Conflito de Interesses e de Vinculação Política) e ao tamanho da empresa, além de outras informações que podem servir como proxy para caracterizar a Capacidade Operacional.

\subsubsection{Vínculos empregatícios públicos}

Os vínculos funcionais de servidores públicos federais estão registrados no Sistema Integrado de Administração de Recursos Humanos (SIAPE) ${ }^{7}$. O SIAPE foi estruturado com foco no pagamento das remunerações dos servidores, mas possui também muitas informações a respeito do vínculo funcional, como datas de admissão e de saída e ocupação de cargos e funções de confiança . Essa base conta hoje com mais de 1,1 milhão registros de servidores públicos federais, sendo aproximadamente 643 mil ativos e 392 mil aposentados ${ }^{8}$.

As informações de vínculos empregatícios públicos podem ser usadas para caracterizar a dimensão de risco de Conflito de Interesses (no âmbito do Risco do Fornecedor).

5 Consulta à base de dados com atualização de março de 2016.

6 Mais informações sobre o cadastro de atividades econômicas em < http://www.receita.fazenda.gov.br/ PessoaJuridica/CNAEFiscal/cnaef.htm>.

7 Mais informações sobre o SIAPE em urlhttp://www.siapenet.gov.br

8 Consulta ao DW-SIAPE em 29/4/2016. 


\subsubsection{Vínculos empregatícios privados}

Os dados sobre vínculos de emprego formal privado são declarados anualmente pelas empresas privadas e ficam registrados na Relação Anual de Informações Sociais (RAIS), do Ministério do Trabalho e da Previdência Social ${ }^{9}$. A base de dados do sistema que recebe as declarações contém informações sobre todos os vínculos trabalhistas formais (que tenham sido declarados).

Somente os dados de 2014 trazem 200 milhões de vínculos empregatícios. As principais informações são os dados do empregador, dos empregados, de início e final do vínculo, da qualificação da ocupação, do salário e benefícios recebidos e também do nível de escolaridade dos empregados.

Os vínculos privados ajudarão a caracterizar a capacidade operacional da empresa (quantidade e qualificação dos funcionários), no âmbito de Risco do Fornecedor.

\subsubsection{Pagamentos e transferências da União}

Os pagamentos realizados pela União a fornecedores e as transferências obrigatórias ou voluntárias de recursos a estados, municípios e organizações sem fins lucrativos são públicas e estão disponíveis no Portal da Transparência do Governo Federal ${ }^{10}$. A base que alimenta o que está disponível no site é oriunda do Sistema Integrado de Administração Financeira (SIAFI) ${ }^{11}$, de responsabilidade da Secretaria do Tesouro Nacional (STN).

\subsubsection{Vinculações políticas}

Os dados de registro em partidos políticos, de candidaturas e de doações efetuadas para candidatos, comitês partidários ou partidos políticos também são públicos e estão disponíveis no site do Tribunal Superior Eleitoral (TSE) ${ }^{12}$.

A seção de prestações de contas eleitorais apresenta todas as doações feitas a partidos, comitês partidários e candidatos. Estão disponíveis dados desde o ano de 2002. Além disso, existem informações mais gerais das eleições desde o ano de 1994.

A Figura 7 apresenta os valores doados nas eleições de 2014 por destinação do recurso (candidato, comitê ou partido).

9 Mais informações sobre a RAIS em < http://www.rais.gov.br/sitio/sobre.jsf $>$.

10 Mais informações sobre o Portal da Transparência em <http://transparencia.gov.br/ $>$.

11 Mais informações sobre o SIAFI em < http://www.tesouro.fazenda.gov.br/siafi $>$.

12 Mais informações sobre os dados de vinculação política e doações de campanha em <http://www.tse. jus.br $/>$. 


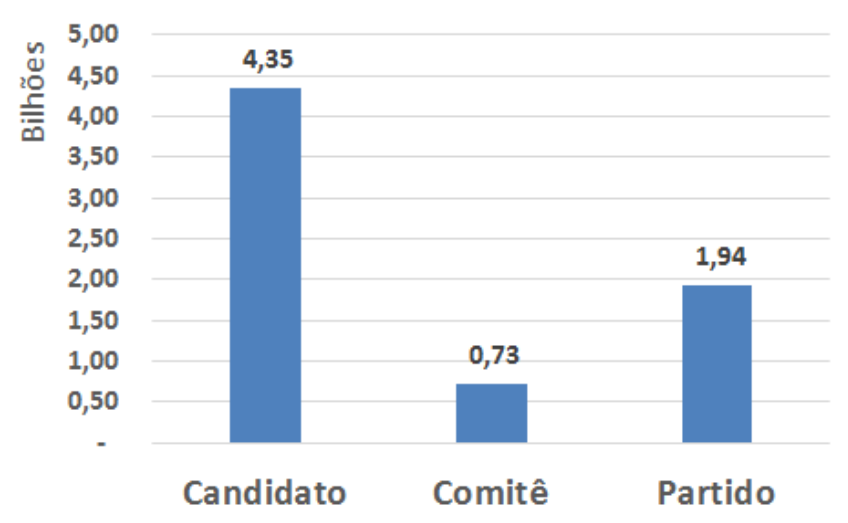

Figura 7: Doações eleitorais em 2014

Os dados de vínculos partidários e doações efetuadas caracterizam a dimensão de risco de Vinculação Política, no âmbito do Risco do Fornecedor.

\subsubsection{Indícios mapeados pela CGU}

A CGU monitora periodicamente os registros de licitações do governo federal, por meio de cruzamentos de dados que buscam verificar nos dados a ocorrência de determinadas irregularidades. Esse trabalho gera um banco de dados de "alertas" de transações potencialmente irregulares para posterior atuação da auditoria. Esse trabalho é parte de um processo de Auditoria Contínua desenvolvido pelo órgão com a participação de diversas áreas.

A Figura 8 apresenta a distribuição das transações qualificadas como "alerta" no ano de 2015, por tipologia de fraude.

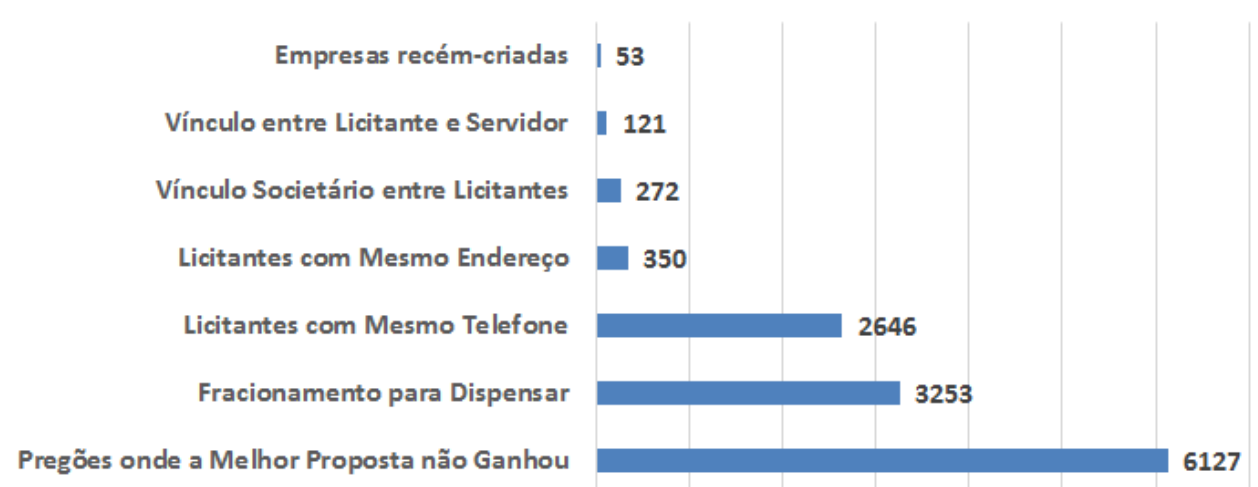

Figura 8: Alertas do monitoramento de licitações realizado pela CGU 
A CGU atualmente disponibiliza para o gestor público os dados analíticos do monitoramento, por meio de um site denominado Portal ODP ${ }^{13}$.

\subsection{Formulação dos indicadores de risco}

Os indicadores de risco estão formulados de maneira a: 1) caracterizarem uma ou mais dimensões de risco; 2) serem obtidos mediante utilização direta ou por meio de combinação das variáveis disponíveis nas bases citadas; e 3) na medida do possível, estarem relacionados às teorias econômicas que analisam o comportamento estratégico de agentes racionais.

Para facilitar o entendimento, os indicadores serão detalhados seguindo a mesma estrutura apresentada na Subseção 3.1.2, que descreve as dimensões de risco.

Para cada dimensão de risco, os indicadores estão separados em dois tipos: centrais e acessórios. Os indicadores centrais buscam resumir a questão central da dimensão de risco em uma única métrica. Os indicadores acessórios trazem informações subsidiárias sobre a dimensão servindo para complementar o entendimento do indicador central.

Nesta subseção, são descritos os indicadores centrais, com o detalhamento de sua fórmula de construção. Os acessórios serão somente exemplificados ${ }^{14}$. Complementarmente, será apresentado de que maneira o indicador está relacionado com as teorias econômicas, se este for o caso.

\subsubsection{Indicadores do risco do fornecedor}

Os indicadores estão agrupados segundo as dimensões de risco do fornecedor descritas na Subseção 3.1.2.

\section{Capacidade Operacional}

Esses indicadores visam medir a capacidade da empresa executar contratos governamentais. Estão relacionados a sua estrutura física e ao volume de recursos governamentais geridos.

- Indicador central 1: Valor por Funcionário.

Significado: Representa o montante recebido do governo para cada funcionário que a empresa possui, com vistas a destacar empresas que estariam recebendo recursos desproporcionalmente a sua capacidade funcional.

$\overline{13}$ O acesso a esse portal é atualmente restrito a gestores públicos que são indicados pelo ministro ou secretário-executivo da pasta

14 Para um entendimento completo, o Anexo A conterá todos os indicadores relacionados com as dimensões de risco. 


\section{Cálculo:}

$$
\text { Valor por Funcionário }=\frac{\text { valor_total_recebido_do_governo }}{\text { quantidade_média_de_funcionários }}
$$

- Indicador central 2: Valor por Sócio.

Significado: Representa o montante recebido do governo para cada sócio que a empresa possui, com vistas a destacar empresas de estrutura pequena que estariam recebendo grande volume de recursos.

Cálculo:

$$
\text { Valor por Sócio }=\frac{\text { valor_total_recebido_do_governo }}{\text { quantidade_média_de_sócios }}
$$

- Indicadores acessórios (exemplos): quantidade de funcionários, valor recebido do governo, grau de instrução dos funcionários, salário médio dos funcionários, quantidade de sócios.

- Relação com a Teoria da Agência: Contratações que utilizam como critério o menor preço induzem a um comportamento oportunista dos agentes, que tentarão ajustar sua estrutura de custos ao orçamento proposto, o que pode implicar em queda na qualidade do serviço. Uma das consequências disso é que empresas com estrutura pior tenham mais chance de vencer as disputas.

\section{Histórico de Punições e Constatações}

Esse conjunto de indicadores representa o histórico da relação da empresa com o próprio governo (problemas pré-existentes na execução de contratos) e indícios de irregularidades monitorados pela CGU.

- Indicador central 1: Quantidade de punições recebidas.

Significado: Representa o quantitativo de punições recebidas pela empresa em seu histórico de contratações com o governo federal.

Cálculo: Somatório da quantidade de punições.

- Indicador central 2: Quantidade de alertas no monitoramento realizado pela CGU.

Significado: Representa o quantitativo de vezes em que alguma licitação ganha pela empresa foi mapeada nas trilhas de monitoramento contínuo utilizadas pela CGU (descritas na subseção anterior).

Cálculo: Somatório da quantidade de alertas.

- Indicadores acessórios (exemplo): Quantitativo médio (por ano) de punições. 


\section{Perfil de Participação em Licitações}

Esses indicadores quantificam as características do fornecedor quando da participação em licitações.

- Indicador central 1: Percentual de sucesso em licitações.

Significado: Razão entre o número de disputas vencidas e o número total de disputas.

Cálculo:

$$
\text { Percentual de Sucesso }=\frac{\text { quantidade_total_de_itens_vencidos }}{\text { quantidade_total_de_itens_disputados }}
$$

- Indicador central 2: Quantidade média de lances.

Significado: Representa o quantitativo médio de lances dados nas disputas.

Cálculo:

Quantidade Média de Lances $=\frac{\text { quantidade_total_de_lances_dados }}{\text { quantidade_total_de_itens_disputados }}$

- Indicadores acessórios (exemplos): quantidade de desclassificações, quantidade de compras, quantidade de órgãos para os quais vende, quantidade de Unidades da Federação para os quais vende.

- Relação com Economia dos Custos de Transação: As variáveis de perfil de participação têm relação com os custos assumidos pelas empresas quando da disputa por um item, custos esses que tendem a ser embutidos nos preços ofertados.

\section{Conflito de Interesses}

Esses indicadores identificam relações potencialmente conflituosas envolvendo a empresa, como a relação com servidores públicos.

- Indicador central 1: Quantidade de Sócios Servidores.

Significado: Representa o quantitativo de sócios que são servidores públicos.

Cálculo: Quantitativo de sócios com vínculo funcional com o governo federal.

- Indicador central 2: Valor Recebido em Convênios

Significado: Valor total que a empresa recebeu via transferência voluntária de recursos, na qualidade de Organização sem Fins Lucrativos.

Cálculo: Soma do valor total recebido do governo em convênios. 
- Indicadores acessórios: quantidade de sócios que exercem função de confiança em órgãos públicos, quantidade de funcionários servidores.

\section{Vinculação Política}

Esses indicadores informam os valores doados pela empresa nas campanhas eleitorais de 2010, 2012 e 2014.

- Indicador central 1: Valor doado em campanhas eleitorais.

Significado: Valor total das doações efetuadas pela empresa em eleições, segundo dados das prestações de contas de candidatos, partidos e comitês, fornecidos pelo TSE.

Cálculo: Somatório das doações.

\subsubsection{Indicadores do risco do contrato}

Os indicadores estão agrupados segundo as dimensões de risco do fornecedor descritas na Subseção 3.1.2.

\section{Irregularidades na Licitação}

Esses indicadores quantificam problemas existentes na licitação que deu origem ao contrato.

- Indicador central 1: Quantidade de alertas gerados.

Significado: Representa o quantitativo de ocorrências monitoradas pela CGU referentes à licitação que originou o contrato. Significa que a licitação que deu origem ao contrato apresenta determinadas características que representam indícios de fraude, segundo essas regras. O indicador é a soma de ocorrências distintas ligadas à licitação.

Cálculo: Somatório do quantitativo de ocorrências relacionadas.

- Indicadores acessórios (exemplo): Valor dos alertas gerados.

\section{Competitividade do processo}

Esses indicadores dizem respeito à modalidade de licitação utilizada, focando naquelas que premitem pouca ou nenhuma competição (casos das dispensas e inexigibilidades), bem como ao grau de competição ocorrida no caso de pregão.

- Indicador central 1: Modalidade de licitação. 
Significado: Indica a utilização de modalidades de licitação onde existe pouca ou nenhuma competição (dispensa e inexigibilidade).

Cálculo: Variável binária, que assume 1 para as modalidades dispensa e inexigibilidade e 0 para as demais.

- Indicador central 2: Quantidade de lances.

Significado: Quantitativo de lances dados na licitação.

Cálculo: Somatório dos lances dados por todos os participantes.

- Indicadores acessórios (exemplos): número de participantes, média de lances por participante.

- Relação com a Teoria dos Leilões: A competitividade, idealmente, proporciona uma escolha melhor. Além disso, inúmeros trabalhos quantificam a proporcionalidade inversa do quantitativo de lances e de participantes, por exemplo, com preço obtido em pregões.

\section{Aspectos gerais da licitação}

Esse grupo de indicadores captam outros aspectos relevantes da licitação, como a qualidade na especificação do objeto.

- Indicador central 1: Forma da compra.

Significado: Indica se a compra foi realizada utilizando o Sistema de Preços Praticados (SISPP) ou o Sistema de Registro de Preços (SISRP)

Cálculo: É uma variável dummy que assume valor 1 para o item de compra de um pregão realizado pelo SISRP e 0 caso contrário.

- Indicador central 2: Qualidade na especificação do objeto.

Significado: Busca medir o quanto o objeto do item de compra está bem descrito. Utiliza um campo de texto livre do SIASG, que é preenchido pela unidade governamental responsável pelo pregão, e utilizado pelos licitantes para fundamentar suas propostas iniciais.

Cálculo: Esse indicador utiliza algoritmos de contagem de palavras-chave do campo, após eliminar palavras sem significado, e desprezando termos redundantes ou repetidos.

- Indicador central 3: Frequência do item comprado.

Significado: Indica a quantidade de vezes em que o objeto do item de compra já foi adquirido. 
Cálculo: É calculado pela contagem da ocorrência do material em tela em licitações anteriores. Essa contagem é feita a partir da busca na base de dados por outros registros de aquisições com o mesmo material cadastrado, utilizando o catálogo de materiais do SIASG.

- Indicador central 4: Especificidade do objeto.

Significado: Indica se um objeto possui alto nível de complexidade, resultando de uma análise combinada do valor do item e da frequência com que é comprado pelo governo. Para se aproximar desse conceito um tanto subjetivo, partimos do pressuposto de que a complexidade de um item de compra seria: a) Diretamente proporcional a seu valor; b) Inversamente proporcional a sua frequência.

Cálculo:

$$
\text { especificidade }=\frac{\text { valor }}{\text { frequêencia_do_item_de_compra }}
$$

- Indicador central 5: Desconto.

Significado: Diferença percentual entre o valor previsto e o efetivamente obtido após a disputa.

Cálculo:

$$
\text { desconto }=\frac{\text { valor_estimado_valor_homologado }}{\text { valor_estimado }}
$$

- Indicadores acessórios (exemplo): Indicador de material ou serviço (indica se a finalidade do contrato é a entrega continuada de bens ou a prestação continuada de bens.

\section{Ocorrências do Contrato}

Esse grupo de indicadores visa identificar alterações no contrato, como aditamentos de valor, mudanças no prazo e na responsabilidade pela execução.

- Indicador central 1: Quantidade de Termos Aditivos de Valor.

Significado: Indica a quantidade de vezes em que o contrato teve seu valor modificado.

Cálculo: Contagem dos aditivos de valor.

- Indicador central 2: Quantidade de Termos Aditivos de Vigência.

Significado: Indica a quantidade de vezes em que o contrato teve o prazo de vigência alterado.

Cálculo: Contagem dos aditivos de vigência. 
- Indicadores acessórios (exemplo): Quantidade de retificações.

\section{Fornecedor Contratado}

Esse grupo de indicadores capta as variáveis a serem selecionadas dentre as descritas nas dimensões de risco do fornecedor, relativas ao fornecedor responsável pelo contrato. A seleção dessas variáveis decorrerá do processo de identificação do grupo de variáveis mais importantes ${ }^{15}$ na modelagem de risco do fornecedor, a ser descrita na Subseção 3.4.1.

\subsection{Modelagem}

Para os dois modelos supervisionados, o processo de modelagem seguiu o fluxo comum utilizado em modelos de aprendizagem de máquina supervisionada. Uma vez que o objetivo da modelagem, além da compreensão de como as variáveis preditoras impactam o risco calculado, também é a utilização do modelo para prever o risco de novos contratos, é fundamental que se busque garantir a capacidade do modelo de ser assertivo na presença de novos dados. Por isso, o processo de modelagem começou com a separação da base de dados em dois conjuntos: um para treino e validação e outro para teste. Assim, o conjunto de teste foi usado para simular a capacidade preditiva na presença de dados futuros. A Figura 9, retirada de RASCHKA(2015) apresenta o fluxo padrão da construção de um modelo de aprendizagem supervisionada.

15 Na Subseção 3.4.1.1 é utilizado um algoritmo específico para seleção das variáveis mais importantes para o cálculo do risco do fornecedor. 


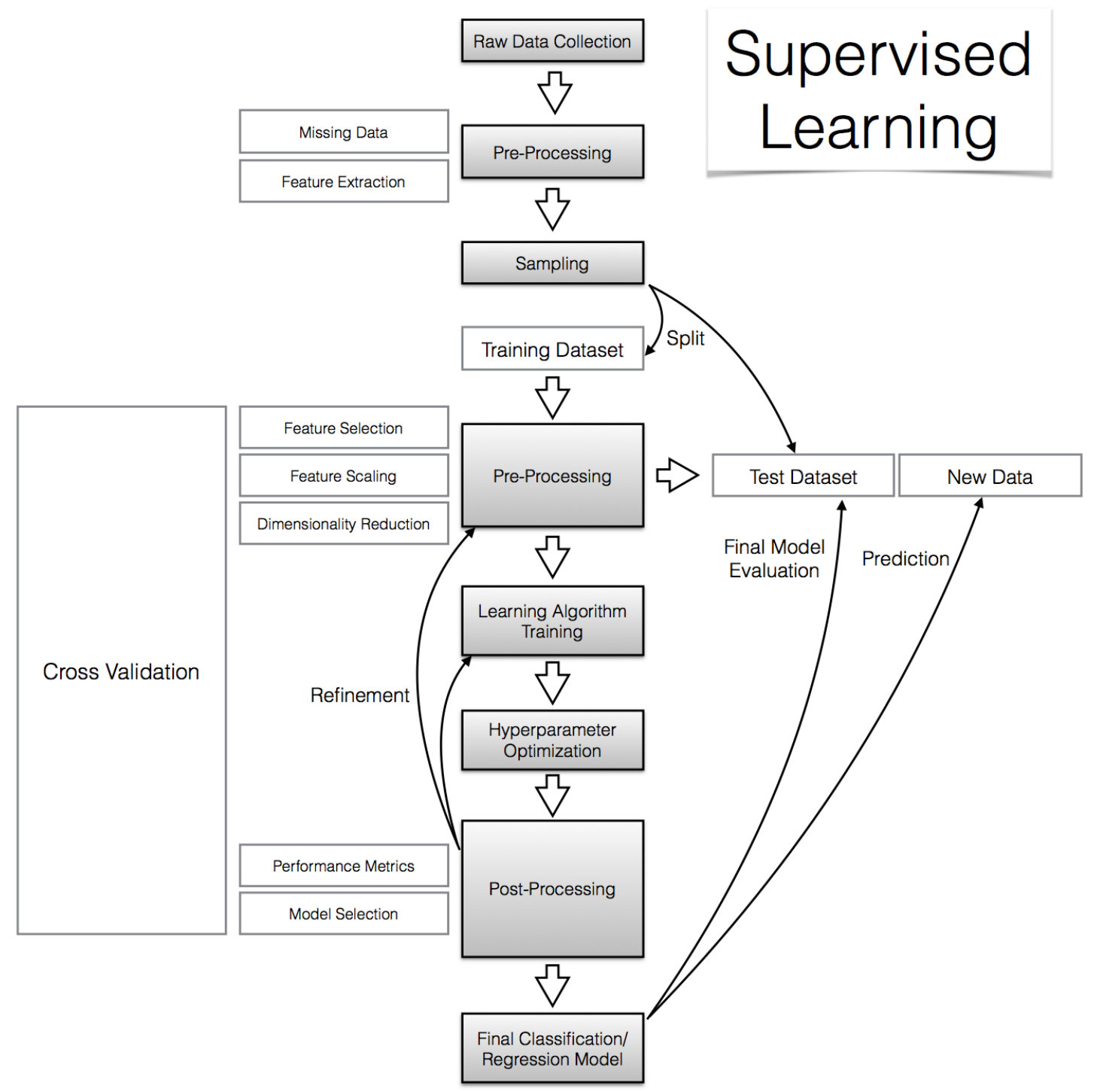

Figura 9: Fluxo padrão da Aprendizagem Supervisionada (RASCHKA, 2015)

Após separada a base de teste, a base de treino foi utilizada para parametrização e ajuste fino do modelo. Conforme mencionado, este trabalho resultou na construção de dois modelos de aprendizagem supervisionada, um para previsão do risco de empresas e outro mais amplo para a previsão de riscos de contratos. Ambas as modelagens seguiram em linhas gerais o fluxo da Figura 9, abrangendo as seguintes etapas:

- Definição dos critérios de definição das classes da variável resposta (criação dos labels da variável dependente, sendo 1 para "Alto Risco" e 0 para "Baixo Risco"). Esta etapa corresponde ao estágio de Pre-Processing da Figura 9.

- Montagem da base de dados a partir dos critérios definidos e da inclusão dos indicadores (etapa também incluída no estágio de Pre-Processing). 
- Balanceamento da base através de processo de undersampling. Optou-se pelo undersampling por ser a técnica de balanceamento mais comumente utilizada em trabalhos de classificação de risco, além de ser adequada à maior parte dos algoritmos de classificação (esta etapa está relacionada com os estágios de Pre-Processing e Sampling).

- Separação da base em 2 partes: $70 \%$ para treino e validação e $30 \%$ para teste.

- Seleção das variáveis mais importantes com a utilização de algoritmo de stepwise (estágio de Feature Selection).

- Utilizando apenas as variáveis selecionadas pela aplicação do stepwise, testam-se diversas parametrizações da modelagem usando um algoritmo de Regressão Logística (RL). Esta etapa corresponde ao estágio de Hyperparameter Optimization da Figura 9 .

- Utilização da melhor parametrização para a construção do modelo final com a base de treinamento completa (Model Selection e Final Classification/Regression Model).

- Aplicação do modelo na base de teste para quantificação da acurácia, sensibilidade, especificidade e precisão (Final Model Evaluation).

Convém detalhar melhor o sexto passo. Primeiramente, optou-se pela utilização da técnica de Regressão Logística porque ambos os modelos contam com uma variável dependente binária. Além disso, é importante que o resultado final do score de risco calculado fique dentro de um intervalo limitado entre 0 e 1 , de maneira a permitir inferir probabilidades de risco. O algoritmo utilizado para modelar a RL é o glmnet, do $\mathrm{R}^{16}$. Ele permite configurar um fator de penalização dos parâmetros estimados pelo modelo, de maneira a reduzir sua magnitude e prevenir a ocorrência de overfitting. Esse fator de panalização utiliza os métodos denominados Ridge e Lasso, abordadas na Seção 2.2.2.

A configuração do fator de penalização consiste em escolher entre utilizar Ridge ou Lasso, ou algum mix entre os dois métodos, e definir o parâmetro (lambda), que representa um multiplicador do fator de penalização.

Assim, nessa etapa, verifica-se a capacidade preditiva do modelo diante de diversas configurações de penalização, e a escolha da formatação final se baseia nesse resultado conjugadamente com a perspectiva de resultado para novos dados. Por isso, dá-se preferência a modelos com mais penalização, pois estes tendem a gerar equações mais simples, portanto com maior perspectiva de eficácia diante de novos dados.

16 Mais informações sobre o algoritmo glmnet em < https://cran.r-project.org/web/packages/glmnet/ index.html>. 
Para o modelo de decisão multicritério, foi utilizado o método denominado Analytic Hierarchy Process (AHP) descrito na Seção 2.2.3. Foram incorporados os resultados dos dois modelos supervisionados como parte dos critérios de decisão, juntamente com os aspectos logísticos da unidade de auditoria.

As próximas subseções detalham o processo de modelagem para as três abordagens.

\subsubsection{Estimação do modelo de risco do fornecedor}

Como dito, um passo fundamental na construção de um modelo de aprendizagem desse tipo é a definição da variável dependente do modelo. Ou seja, se o que se quer é quantificar a contribuição de cada característica dos fornecedores para aumentar seu risco de apresentar problemas em contratos, há de se definir qual variável será indicativa desse risco. Para tanto, foi construída uma variável binária que indica presença (1) ou ausência (0) de alto risco. Um fornecedor foi considerado como de alto risco (1) de acordo com os seguintes critérios:

- Ter tido contrato vigente em 2015 ou 2016.

- Ter sido punido nesses anos com uma das seguintes penalidades:

Suspensão temporária de licitar (previsto na Lei no 8.666/93);

Impedimento de licitar e contratar (previsto na Lei $\left.\mathrm{n}^{\circ} 10.520 / 02\right)$;

Declaração de inidoneidade (previsto na Lei $n^{\circ} 8.666 / 93$ ).

- Não ter tido qualquer dessas punições entre os anos de 2011 e $2014^{17}$.

Para classificação como de baixo risco (0), o fornecedor obedeceu aos seguintes critérios:

- Ter tido contrato vigente em 2015 ou 2016.

- Nunca ter sido punido com as penalidades suspensivas anteriormente citadas.

As variáveis utilizadas como preditoras do risco do fornecedor correspondem aos indicadores da dimensão de risco do fornecedor, descritos na Subseção 3.3.1. Ao todo foram utilizadas na modelagem 47 variáveis preditoras, descritas no Anexo A.

O escopo geral considerado para a coleta dos dados foram as licitações e contratos ocorridos entre 2011 e 2016. Os registros de 2015 e 2016 foram utilizados apenas para

17 Essa restrição se deve ao fato de que é fundamental que a empresa estivesse "ativa" nos anos anteriores à punição, de maneira que se pudesse observar o comportamento dela nesse período. Caso não se fizesse tal restrição, correr-se-ia o risco de embutir no modelo de aprendizagem empresas já suspensas e sem negócios ativos com o governo, havendo completa ausência dos dados que pudessem mensurar seu comportamento prévio à punição. 
identificação das empresas. As variáveis preditoras foram todas construídas com base nos dados de 2011 a 2014. A ideia é simples: entender o que ocorreu no passado recente das empresas que possa ter contribuído para os problemas apresentados em 2015/16.

O critério de qualificação do risco das empresas resultou num quantitativo de 723 empresas previamente classificadas como de alto risco e 41.287 empresas previamente classificadas como de baixo risco. Como é comum em modelos de aprendizagem desse tipo, buscou-se balancear a base a ser utilizada para a modelagem, selecionando-se aleatoriamente dentre as empresas de baixo risco o quantitativo idêntico ao de empresas de alto risco (723), no processo conhecido como undersampling ${ }^{18}$.

Assim, a base utilizada para o processo de aprendizagem consistiu num banco de dados de 1.446 empresas (metade pré-qualificadas como de alto risco e metade como de baixo risco), 47 potenciais indicadores de risco sendo utilizados como variáveis preditoras e 1 variável dependente indicando a pré-qualificação.

Após a criação da base balanceada, dividiu-se os 1.446 registros em dois subconjuntos, mantida a proporcionalidade das classes, sendo um subconjunto para treinamento e validação $(70 \%)$ e o outro para teste $(30 \%)$. O modelo reservado para teste não passa pelo processo de modelagem, de maneira a se manter como proxy do "dado futuro" e explicitar o verdadeiro poder preditivo do modelo.

Como a base de dados tem um número não muito grande de observações, utilizou-se um processo de estimação com cross-validation no subconjunto de treino. O procedimento de cross-validation aplicado consistiu na divisão aleatória da base de treino em 10 partições amostrais de tamanhos iguais, para repetidas estimações em ciclos onde 9 partições são utilizadas para treino e 1 para teste. As medidas de erro de cada ciclo são então combinadas resultando em uma medida única de acurácia.

A ideia central da modelagem foi observar o comportamento da empresa nos anos anteriores à punição para responder à seguinte pergunta: Que características do seu passado recente contribuem mais para ela apresentar problemas em contratos com o governo? O modelo responde isso através da quantificação do poder dessas variáveis em diferenciar os dois grupos pré-qualificados de empresas com alto e baixo risco.

\subsubsection{Seleção de variáveis - método Forward Stepwise}

A etapa de seleção de variáveis visou escolher o conjunto delas que minimizasse o erro de predição numa regressão, mantendo o modelo o mais simples possível. O método Stepwise testa diversos conjuntos através da inclusão de variáveis uma a uma no modelo, até que a função de erro se estabilize, descartando as variáveis menos importantes (BENDEL;

18 Conforme explicado na Subseção 2.2.2, o processo de undersampling é utilizado para corrigir problemas de desbalanceamento de classes, em modelos de aprendizagem. Consiste reduzir a classe majoritária selecionando aleatoriamente uma amostra de igual tamanho à classe minoritária. 
AFIFI, 1977). Do conjunto inicial de 47 variáveis, o processo selecionou 29, conforme descrito na Tabela 2.

É interessante destacar que foram selecionadas variáveis de todas as dimensões de risco idealizadas, o que de certa forma confirma a intuição que respalda sua escolha.

Tabela 2: Variáveis selecionadas - Forward Stepwise.

\begin{tabular}{|c|c|}
\hline Nome da Variável & Significado \\
\hline TSE-VALOR-DOADO-TOTAL & $\begin{array}{l}\text { Valor total doado em campanhas eleitorais, em 2010, } 2012 \\
\text { e } 2014 \text {. }\end{array}$ \\
\hline TRILHAS-VALOR-ALERTAS-2014 & $\begin{array}{l}\text { Valor dos alertas monitorados pela CGU, de licitações } \\
\text { ganhas pela empresa. }\end{array}$ \\
\hline TRILHAS-QTDE-ALERTAS-2014 & $\begin{array}{l}\text { Quantidade total dos alertas monitorados pela CGU, de } \\
\text { licitações ganhas pela empresa. }\end{array}$ \\
\hline RFB-QTDE-SOCIOS-MEDIA & $\begin{array}{l}\text { Quantidade média de sócios da empresa, entre } 2011 \text { e } \\
2014 \text {. }\end{array}$ \\
\hline RFB-QTDE-SOCIOS-2014 & Quantidade de sócios em 2014 \\
\hline RFB-qtde-atividades & $\begin{array}{l}\text { Quantidade de atividades desenvolvidas pela empresa, se- } \\
\text { gundo cadastro da Receita Federal. }\end{array}$ \\
\hline RFB-PAGTO-POR-SOCIO-MEDIA & $\begin{array}{l}\text { Razão entre o valor total recebido do governo e a quanti- } \\
\text { dade média de sócios. }\end{array}$ \\
\hline RFB-PAGTO-POR-SOCIO-2014 & $\begin{array}{l}\text { Razão entre o valor total recebido do governo e a quanti- } \\
\text { dade de sócios em } 2014 .\end{array}$ \\
\hline RFB-PAGTO-TOTAL & Valor total recebido do governo. \\
\hline RFB-PAGTO-2014 & Valor recebido do governo em 2014. \\
\hline RFB-IDADE-EMPRESA-2015 & Idade da empresa no ano de 2015. \\
\hline RAIS-QTDE-LARANJAS-2014 & $\begin{array}{l}\text { Quantidade de sócios com baixa qualificação, no ano de } \\
2014 \text {. }\end{array}$ \\
\hline $\begin{array}{l}\text { RAIS-QTDE-FUNCIONARIOS- } \\
\text { MEDIA }\end{array}$ & Quantidade média de funcionários da empresa. \\
\hline $\begin{array}{l}\text { RAIS-QTDE-FUNCIONARIOS- } \\
2014\end{array}$ & Quantidad \\
\hline $\begin{array}{l}\text { RAIS-MEDIA-SALARIO-SOCIO- } \\
\text { MEDIA }\end{array}$ & $\begin{array}{l}\text { Média do salário dos sócios (valor médio entre } 2011 \text { e } \\
2014 \text { ) }\end{array}$ \\
\hline $\begin{array}{l}\text { RAIS-MEDIA-SALARIO-SOCIO- } \\
2014\end{array}$ & Média do salário dos sócios no ano de 2014 . \\
\hline $\begin{array}{l}\text { RAIS-MEDIA-SALARIO- } \\
\text { FUNCIONARIOS-2014 }\end{array}$ & Média do salário dos funcionários em 2014 \\
\hline dummie-PF & Indicador de fornecedor Pessoa Física. \\
\hline CONVENIOS-valor-favorecido & $\begin{array}{l}\text { Valor recebido pela empresa enquanto subcontratada em } \\
\text { convênios. }\end{array}$ \\
\hline CONVENIOS-valor-convenente & $\begin{array}{l}\text { Valor recebido pela empresa enquanto convenente em con- } \\
\text { vênios. }\end{array}$ \\
\hline $\begin{array}{l}\text { COMPRAS-soma-valor-homologado- } \\
\text { TOTAL }\end{array}$ & Valor total vencido em licitações, entre 2011 e 2014. \\
\hline $\begin{array}{l}\text { COMPRAS-soma-valor-homologado- } \\
2014\end{array}$ & Valor vencido em licitações em 2014. \\
\hline COMPRAS-soma-qtde-lances-2014 & $\begin{array}{l}\text { Quantidade total de lances dados em licitações no ano de } \\
2014 \text {. }\end{array}$ \\
\hline COMPRAS-qtde-orgaos-MEDIA & $\begin{array}{l}\text { Quantidade média de órgãos governamentais para os } \\
\text { quais vende, de } 2011 \text { a } 2014 .\end{array}$ \\
\hline COMPRAS-qtde-orgaos-2014 & $\begin{array}{l}\text { Quantidade de órgãos governamentais para os quais ven- } \\
\text { deu no ano de } 2014 . .\end{array}$ \\
\hline $\begin{array}{l}\text { COMPRAS-qtde-itens-compra- } \\
\text { WIN-TOTAL }\end{array}$ & $\begin{array}{l}\text { Quantidade de itens de licitação vencidos entre } 2011 \text { e } \\
2014 \text {. }\end{array}$ \\
\hline COMPRAS-qtde-itens-compra-2014 & Quantidade de itens de licitação disputados em 2014. \\
\hline $\begin{array}{l}\text { COMPRAS-qtde-desclassificacao- } \\
\text { TOTAL }\end{array}$ & $\begin{array}{l}\text { Quantidade de itens de licitação em que a empresa foi } \\
\text { desclassificada, entre } 2011 \text { e } 2014 \text {. }\end{array}$ \\
\hline COMPRAS-qtde-compras-TOTAL & Quantidade de licitações disputadas entre 2011 e 2014. \\
\hline
\end{tabular}




\subsubsection{Teste de parâmetros para modelagem utilizando Regressão Logística}

A parametrização (tunning) do modelo de Regressão Logística foi realizada com o pacote caret $^{19}$ do R, aplicando a função train ${ }^{20}$. O algoritmo utilizado permite parametrizar rotinas de regressão ou classificação e testar vários ajustes, avaliando-os por meio de alguma medida de erro. Os parâmetros de configuração do algoritmo incluem: 1) a definição do modelo de regressão ou classificação usado; 2) o que se denomina família da função de regressão; 3) o controle de treinamento a ser utilizado; e 4) e a medida de erro que será usada para avaliar a capacidade de predição.

Uma vez que se trata de uma Regressão Logística com variável dependente binária, o modelo foi configurado com o algoritmo de ajuste glmnet $^{21}$, que permite estimar um modelo generalizado de regressão com penalização, e família binomial. Para reduzir a possibilidade de overfitting do modelo, e consequente perda da capacidade de generalização, utilizou-se o controle de treinamento por cross-validation, processo explicado na Subseção 2.2 .2 .

A medida de erro adotada foi a acurácia no conjunto de validação. Uma vez que o modelo resulta em valores previstos entre 0 e 1, define-se um ponto de corte a partir do qual se considera a empresa como de "Alto Risco" (label 1), ficando as demais classificadas como "Baixo Risco" (label 0). A acurácia é medida comparando-se cada label previsto com o real. Por padrão, o algoritmo utiliza o ponto de corte de 0,5 para exibição dos resultados na base de treino.

Os componentes variáveis do algoritmo são os parâmetros de penalização. No caso específico, o glmnet permite ajustar dois parâmetros, um que define a métrica de penalização (Ridge ou Lasso), dados pelo parâmetro alpha e outro que define o multiplicador (parâmetro lambda).

Utilizando o subconjunto de variáveis selecinadas pelo algoritmo stepwise, o modelo de regressão foi inicialmente testado com 50 combinações diferentes dos parâmetros de penalização, de maneira a se ter uma visão geral da acurácia. A escolha inicial desses parâmetros é feita automaticamente pelo algoritmo seguindo heurística específica.

A Figura 10 apresenta esses resultados. Vemos que com o parâmetro alpha livre o modelo admite desde o alpha igual a 0 (Ridge) quanto igual a 1 (Lasso). Vemos também que o multiplicador lambda é mantido sempre em níveis baixos, o que decorre da escolha automática, provavelmente porque os coeficientes estimados têm magnitude normal. A linha de acurácia se mantém no patamar acima de 80\%, salvo com alpha próximo de 1, quando cai abruptamente, o que é esperado devido à eliminação de variáveis.

19 Documentação do pacote caret em < https://cran.r-project.org/web/packages/caret/index.html>.

20 Documentação da função train em < http://www.inside-r.org/packages/cran/caret/docs/train>.

21 Mais informações sobre o algoritmo glmnet em < https://cran.r-project.org/web/packages/glmnet/ index.html >. 


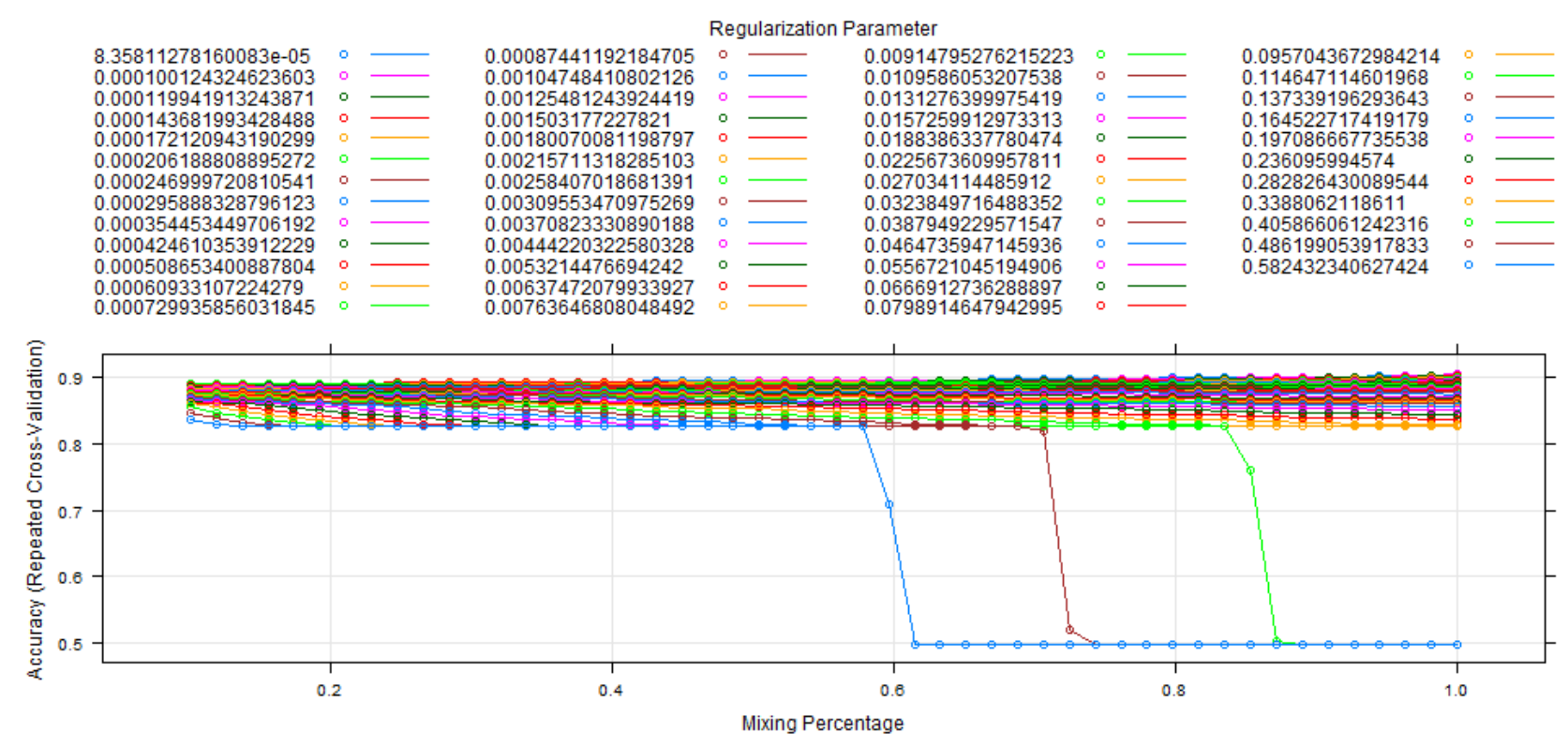

Figura 10: Acurácia para diversas configurações

A primeira decisão tomada a partir dessa análise foi deixar fixo o parâmetro alpha em 0, direcionando para um modelo de penalização Ridge. Isso porque a quantidade de variáveis que restaram após o stepwise foi de apenas 29, não sendo desejado um modelo mais simples do que isso. Como já explicado, a penalização Ridge não elimina variáveis, mas a Lasso sim.

Tomada essa decisão, uma segunda configuração é testada, agora fixando alpha em 0 e definido um intervalo para lambda entre 0 e 500, para se ter uma visão ampla do comportamento da curva de acurácia.

A Figura 11 apresenta esse resultado. Observa-se que existe uma queda regular da acurácia até um valor de lambda pouco acima de 300, e depois uma queda abrupta. Faz-se então uma nova configuração deixando lambda entre 0 e 10, visando detalhar o patamar superior da curva de acurácia. A Figura 12 mostra que a acurácia cai regularmente na medida em que se aumenta o fator de penalização. 


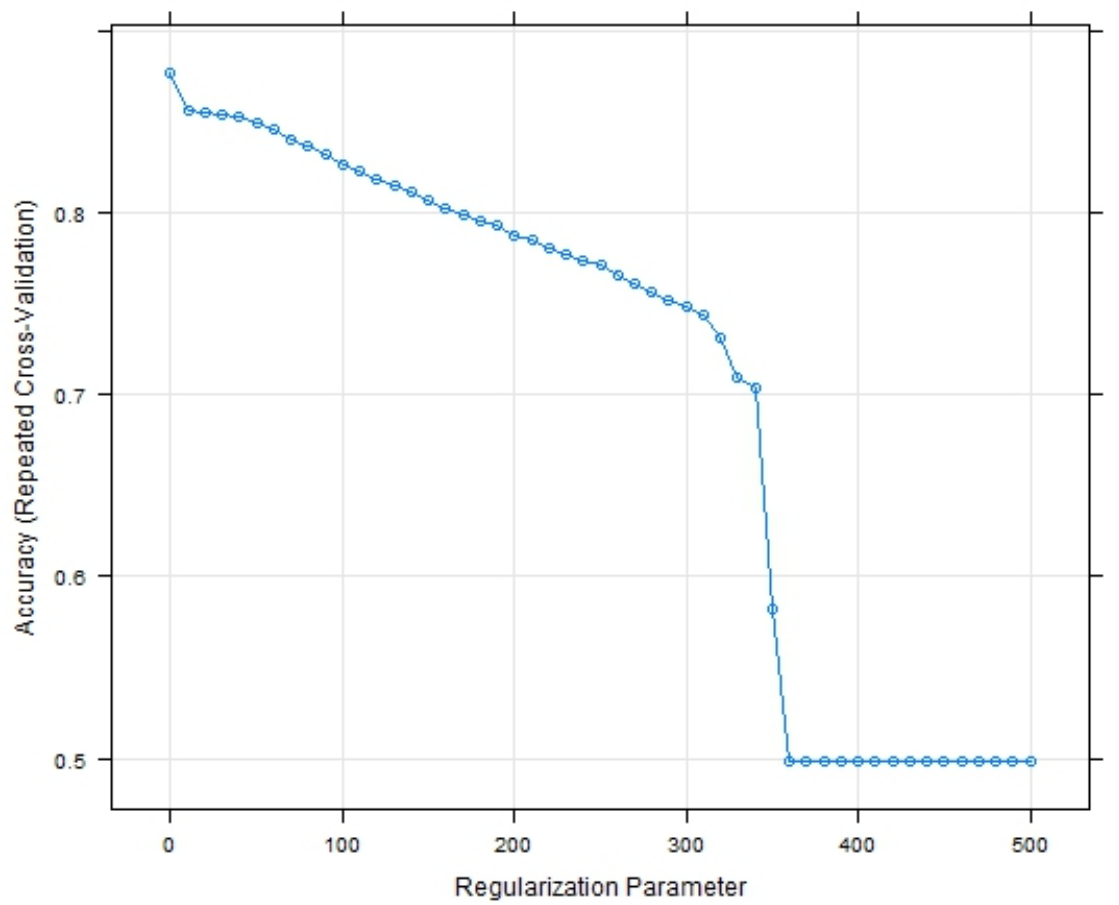

Figura 11: Acurácia para diversas configurações

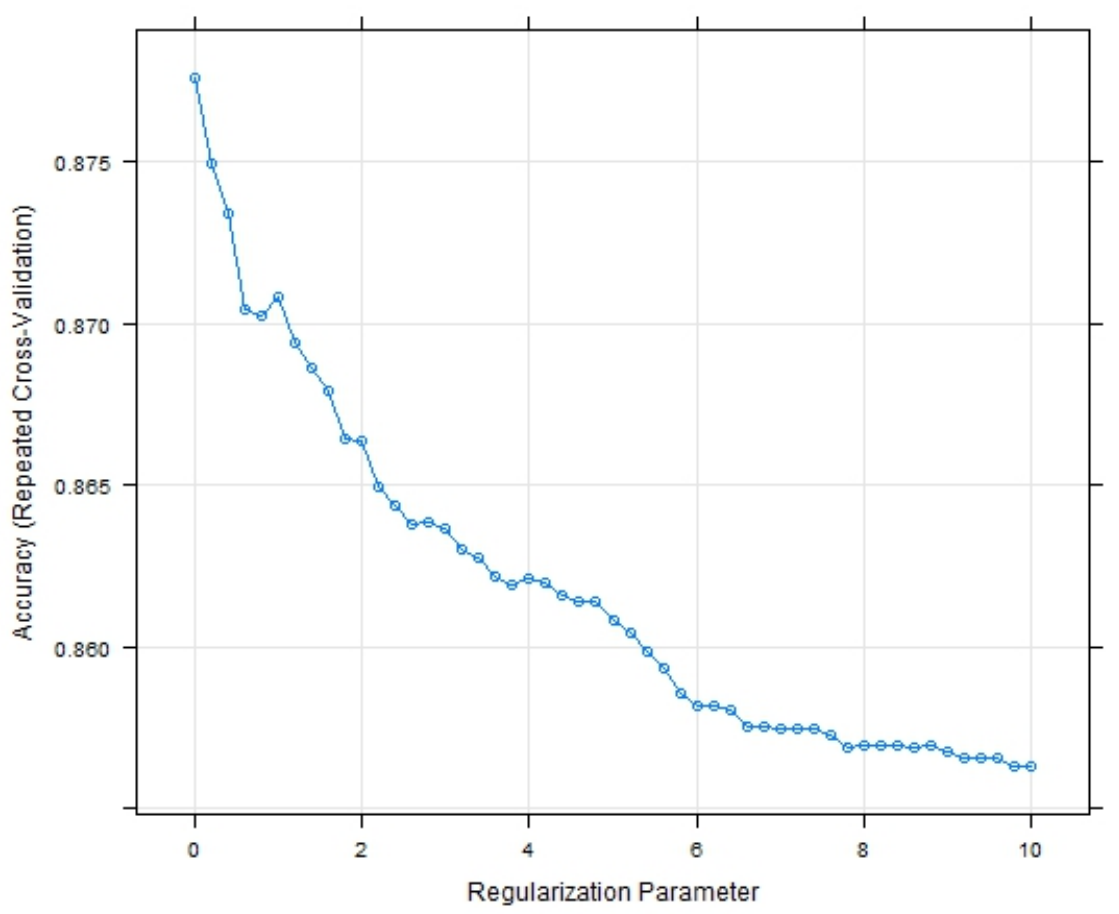

Figura 12: Acurácia para diversas configurações 


\subsubsection{Criação do modelo final na base de treinamento}

Essa visão geral, e o aprofundamento da análise do comportamento da curva de acurácia no conjunto de validação diante de diversas configurações de penalização, é útil para a tomada de decisão sobre o modelo final. O que se quer, em resumo, é um modelo com o máximo de penalização (para prevenção do overfitting) dentro de uma perspectiva de acurácia aceitável.

Dessa maneira, a configuração final escolhida para a modelagem foi alpha igual a 0 e lambda igual a 1, o que mantém a perspectiva de acurácia acima de $87 \%$.

Com essa configuração o modelo de Regressão Logística foi construído utilizando a base de treinamento completa. A Tabela 3 apresenta os coeficientes estimados para as variáveis. A Seção de Resultados (4.1) apresentará a interpretação desses coeficientes, bem como a acurácia obtida com a aplicação do modelo na base de teste.

Tabela 3: Parâmetros Estimados - Modelo de Risco do Fornecedor

\begin{tabular}{|l|l|}
\hline Nome da Variável & Parâmetro Estimado \\
\hline TSE-VALOR-DOADO-TOTAL & 0.0000001410631 \\
\hline TRILHAS-VALOR-ALERTAS-2014 & 0.00000001292902 \\
\hline TRILHAS-QTDE-ALERTAS-2014 & 0.00002914072 \\
\hline RFB-QTDE-SOCIOS-MEDIA & -0.006977492 \\
\hline RFB-QTDE-SOCIOS-2014 & -0.004208786 \\
\hline RFB-qtde-atividades & 0.003828594 \\
\hline RFB-PAGTO-POR-SOCIO-MEDIA & -0.0000000001352726 \\
\hline RFB-PAGTO-POR-SOCIO-2014 & 0.000000005733377 \\
\hline RFB-PAGTO-TOTAL & 0.000000005157193 \\
\hline RFB-PAGTO-2014 & -0.0000000004129853 \\
\hline RFB-IDADE-EMPRESA-2015 & -0.006548038 \\
\hline RAIS-QTDE-LARANJAS-2014 & 0.02987819 \\
\hline RAIS-QTDE-FUNCIONARIOS- & -0.00001928377 \\
MEDIA & \\
\hline RAIS-QTDE-FUNCIONARIOS- & -0.00002451413 \\
2014 & \\
\hline RAIS-MEDIA-SALARIO-SOCIO- & -0.000006606303 \\
MEDIA & \\
\hline RAIS-MEDIA-SALARIO-SOCIO- & -0.000004700092 \\
2014 & \\
\hline RAIS-MEDIA-SALARIO- & -0.00004687442 \\
FUNCIONARIOS-2014 & \\
\hline dumMie-PF & -0.005969864 \\
\hline CONVENIOS-valor-favorecido & 0.00000004145842 \\
\hline CONVENIOS-valor-convenente & -0.000000002070004 \\
\hline COMPRAS-soma-valor-homologado- & 0.00000000002353047 \\
TOTAL & \\
\hline COMPRAS-soma-valor-homologado- & 0.000000001365422 \\
2014 & \\
\hline COMPRAS-soma-qtde-lances-2014 & 0.000002072065 \\
\hline COMPRAS-qtde-orgaos-MEDIA & 0.002161472 \\
\hline COMPRAS-qtde-orgaos-2014 & 0.002063101 \\
\hline COMPRAS-qtde-itens-compra- & 0.00001414373 \\
WIN-TOTAL & \\
\hline COMPRAS-qtde-itens-compra-2014 & 0.0000100916 \\
\hline COMPRAS-qtde-desclassificacao- & 0.00001446886 \\
TOTAL & \\
\hline COMPRAS-qtde-compras-TOTAL & 0.0000730513 \\
\hline
\end{tabular}




\subsubsection{Estimação do modelo de risco do contrato}

Para construção do modelo de risco do contrato, muda-se a granularidade da base de dados. Neste caso, os indicadores são todos calculados a nível de contrato e a base de dados a ser utilizada conterá dois grupos de contratos, pré-qualificados como de alto ou baixo risco.

Seguindo a mesma lógica da estimação do modelo de risco do fornecedor, a variável dependente do modelo, que indica a presença ou ausência de risco, é definida por uma variável binária que assume 1 para presença e 0 para ausência de alto risco. Os critérios adotados para pré-qualificação são descritos a seguir.

Para ser qualificado como de alto risco, o contrato:

- Deve ter sido rescindido nos anos de 2015 ou 2016;

- Não deve apresentar como justificativa da rescisão fatores que indiquem mera conveniência ou oportunidade da unidade governamental ${ }^{22}$.

Para ser qualificado como de baixo risco, o contrato:

- Deve ter estado vigente por pelo menos 1 ano entre 2015 e 2016;

- Não deve apresentar ocorrência de rescisão.

Mais uma vez, tendo em vista que a variável resposta do modelo é binária, optou-se por se criar um modelo de Regressão Logística.

Com relação às variáveis preditoras a serem utilizadas, vale ressaltar que a abordagem utilizada considerará a construção do modelo de risco do contrato de maneira parcialmente dependente da modelagem realizada para o fornecedor. Serão aproveitados o conjunto de indicadores pré-selecionados na modelagem stepwise realizada para cálculo do risco do fornecedor, mas não será considerado o score de risco já modelado.

Assim, as variáveis utilizadas como preditoras do risco do contrato correspondem aos indicadores da dimensão de risco do contrato, descritos na Seção 3.3.2, também sendo incorporadas as variáveis mais importantes ligadas ao risco do fornecedor (que resultaram do processo de seleção descrito na Subseção 3.4.1.1. Ao todo, foram utilizadas na modelagem 55 variáveis preditoras, sendo 29 relativas às empresas e 26 propriamente dos contratos.

22 É possível haver rescisão de contratos por mera conveniência ou oportunidade da unidade governamental responsável, vide Artigo 79, Inciso I, da Lei 8.666/93. Esses casos não são relevantes para o modelo preditivo pretendido, uma vez que se visa compreender os fatores que influenciam a interrupção dos contratos por falhas na sua execução. A Figura 5 apresenta a distribuição das rescisões ocorridas em 2015 e 2016 por motivo. 
Obedecidas as restrições que definem as classes da variável dependente, tem-se um escopo de 85.110 contratos, sendo 506 pré-qualificados como de alto risco e 84.604 pré-qualificados como de baixo risco. Tal como adotado na modelagem do risco dos fornecedores, também foi feito o balanceamento da base por meio de undersampling.

Dessa forma, a base utilizada para o processo de aprendizagem consistiu num banco de dados de 1.012 contratos (metade pré-qualificados como de alto risco e metade como de baixo risco), 55 potenciais indicadores de risco sendo utilizados como variáveis preditoras e 1 variável dependente indicando a pré-qualificação. Essa base foi separada em dois subconjuntos, sendo um (de 70\%) para treino e validação e outro (de 30\%) para teste, de maneira a preservar a possibilidade de mensuração da acurácia do modelo aprendido numa proxy do "dado futuro".

O controle do processo de modelagem na base de treino e validação foi feito utilizando a técnica de cross-validation.

A ideia central da consturção desse modelo de risco é compreender que características do contrato, relacionadas a fatos do seu ciclo de vida, desde a licitação que o originou até a execução, contando prorrogações e alterações de curso, e ligadas também à própria empresa que o executa, contribuem mais para o surgimento de problemas futuros que ensejam a ocorrência da rescisão.

\subsubsection{Seleção de variáveis - método Forward Stepwise}

O processo de Regressão utilizando o método stepwise foi utilizado para selecionar o conjunto mais relevante de variáveis. Do quantitativo inicial de 55 preditoras, o modelo final resultou em um subconjunto de 24. A Tabela 4 descreve cada uma delas. 
Tabela 4: Variáveis selecionadas - Forward Stepwise.

\begin{tabular}{|c|c|}
\hline Nome da Variável & Significado \\
\hline RFB-QTDE-SOCIOS-2014 & Quantidade de sócios em 2014 \\
\hline RFB-qtde-atividades & $\begin{array}{l}\text { Quantidade de atividades desenvolvidas pela empresa, se- } \\
\text { gundo cadastro da Receita Federal. }\end{array}$ \\
\hline RFB-PAGTO-POR-SOCIO-2014 & $\begin{array}{l}\text { Razão entre o valor total recebido do governo e a quanti- } \\
\text { dade de sócios em } 2014 .\end{array}$ \\
\hline RFB-PAGTO-TOTAL & Valor total recebido do governo. \\
\hline RFB-IDADE-EMPRESA-2015 & Idade da empresa no ano de 2015. \\
\hline $\begin{array}{l}\text { RAIS-QTDE-FUNCIONARIOS- } \\
\text { MEDIA }\end{array}$ & Quantidade média de funcionários da empresa. \\
\hline $\begin{array}{l}\text { RAIS-QTDE-FUNCIONARIOS- } \\
2014\end{array}$ & Quantidade de funcionários no ano de 2014. \\
\hline $\begin{array}{l}\text { RAIS-MEDIA-SALARIO-SOCIO- } \\
\text { MEDIA }\end{array}$ & $\begin{array}{l}\text { Média do salário dos sócios (valor médio entre } 2011 \text { e } \\
\text { 2014) }\end{array}$ \\
\hline $\begin{array}{l}\text { COMPRAS-soma-valor-homologado- } \\
\text { TOTAL }\end{array}$ & Valor total vencido em licitações, entre 2011 e 2014. \\
\hline COMPRAS-soma-qtde-lances-2014 & $\begin{array}{l}\text { Quantidade total de lances dados em licitações no ano de } \\
2014 .\end{array}$ \\
\hline COMPRAS-qtde-orgaos-MEDIA & $\begin{array}{l}\text { Quantidade média de órgãos governamentais para os } \\
\text { quais vende, de } 2011 \text { a } 2014 .\end{array}$ \\
\hline COMPRAS-qtde-compras-TOTAL & Quantidade de licitações disputadas entre 2011 e 2014. \\
\hline i-dummie-servico & Variável binária que indica 1 para contratação de serviço. \\
\hline i-dummie-inexigibilidade & $\begin{array}{l}\text { Variável binária que indica } 1 \text { para inexigibilidade de lici- } \\
\text { tação. }\end{array}$ \\
\hline i-dummie-dispensa & Variável binária que indica 1 para dispensa de licitação. \\
\hline i-desconto & $\begin{array}{l}\text { Diferença percentual entre o valor estimado e o final da } \\
\text { licitação. }\end{array}$ \\
\hline i-especificidade & Razão entre o valor do contrato e a frequência do item. \\
\hline i-frequencia-item & $\begin{array}{l}\text { Quantidade de vezes que o item foi contratado em outros } \\
\text { processos. }\end{array}$ \\
\hline i-lances-por-participante & $\begin{array}{l}\text { Razão entre a quantidade total de lances na licitação e o } \\
\text { número de participantes }\end{array}$ \\
\hline i-qtde-participantes & Quantidade de participantes na licitação. \\
\hline i-qtde-lances & Quantidade de lances da licitação. \\
\hline i-qtde-TA-fornecedor & Quantidade de termos aditivos do contrato. \\
\hline i-qtde-TA-vigencia & $\begin{array}{l}\text { Quantidade de termos aditivos de vigência (prorrogações } \\
\text { de prazo) }\end{array}$ \\
\hline i-qtde-ocorrencias-compra & $\begin{array}{l}\text { Quantidade de ocorrências monitoradas pela CGU na li- } \\
\text { citação que originou o contrato. }\end{array}$ \\
\hline
\end{tabular}

\subsubsection{Teste de parâmetros para modelagem utilizando Regressão Logística}

O processo de tunning foi realizado tal qual no modelo de risco do fornecedor, utilizando o pacote caret do R, com a função train. A parametrização inicial utilizou o algoritmo de ajuste glmnet, família binomial (dada a variável dependente binária) e o controle de treinamento por cross-Validation. A medida de erro definida para avaliar a capacidade de predição foi a acurácia na aplicação na base de validação.

Como detalhado na Seção 3.4.1.2, o algoritmo glmnet permite a construção de modelo com penalização Ridge ou Lasso, ou uma combinação das duas técnicas. Assim, os parâmetros a serem combinados e variados para o teste de diversas configurações são o alpha (que define a combinação entre Ridge e Lasso) e o lambda (que define o multiplicador utilizado para a penalização).

Com o subconjunto de variáveis selecionadas na etapa do stepwise, o primeiro teste 
realizado foi com o alpha e lambda livres, com a parametrização automática realizada pelo glmnet. Com a definição do limite de 50 parametrizações distintas, foram testadas ao final configurações com alpha variando de 0 (Ridge puro) a 1 (Lasso puro) e com o multiplicador lambda variando de 0 a 9. A Figura 13 resume os resultados de acurácia obtidos. Observa-se que para grande parte das configurações de penalização o nível de acurácia se mantém estável acima de $80 \%$.

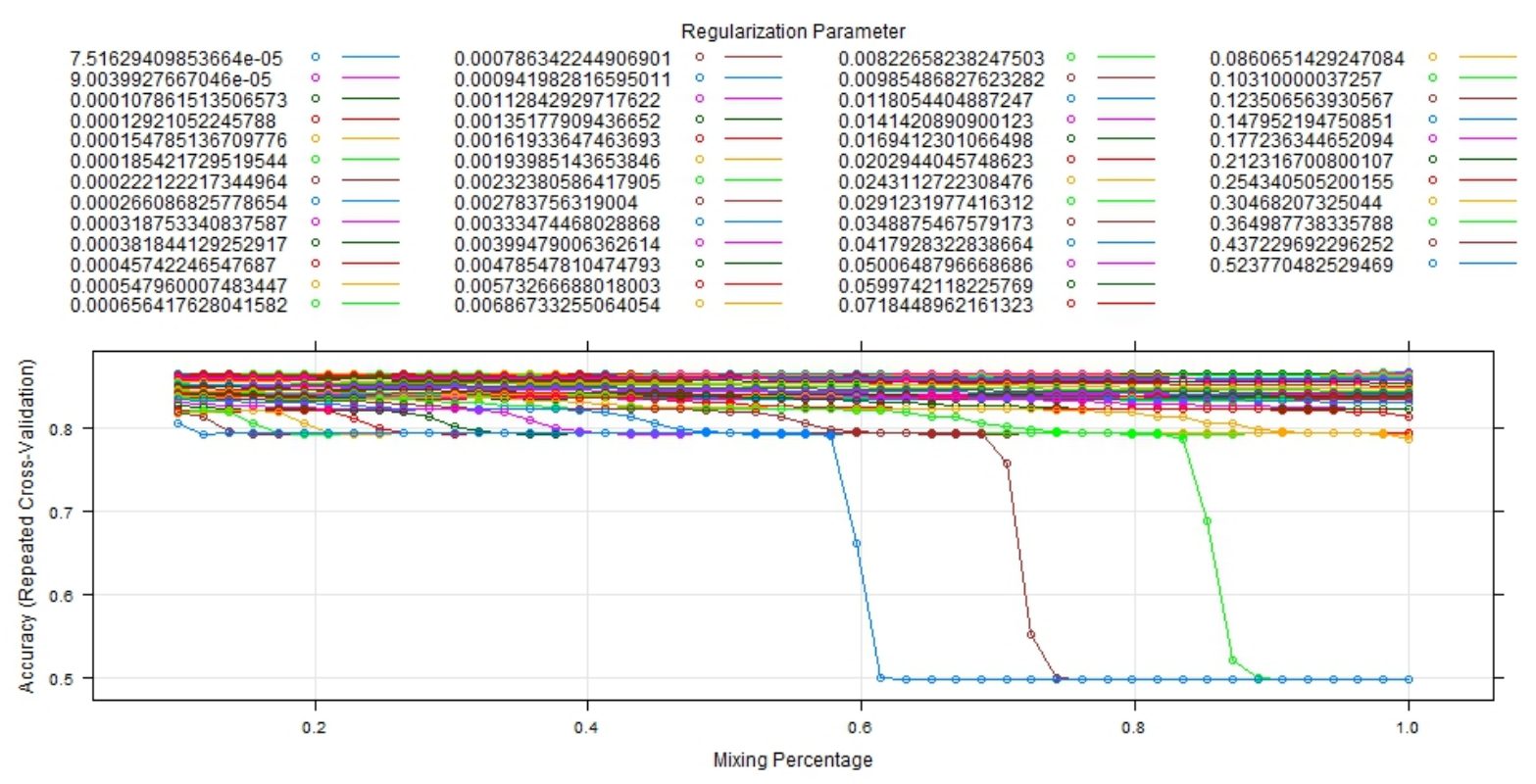

Figura 13: Acurácia para diversas configurações

A partir dessa análise inicial, foram feitos alguns testes alterando esses parâmetros com vistas a observar o comportamento da curva de acurácia. Um primeiro passo foi restringir o parâmetro alpha a 0 (penalização Ridge). Isso é importante porque o modelo resultante do stepwise já conta com um número reduzido de variáveis, não sendo desejadas novas exclusões provocadas pela penalização Lasso.

Com o tipo de penalização fixo, restou testar algumas configurações para o multiplicador lambda. A primeira delas foi limitá-lo ao intervalo de 0 a 500. A Figura 14 apresenta os resultados. 


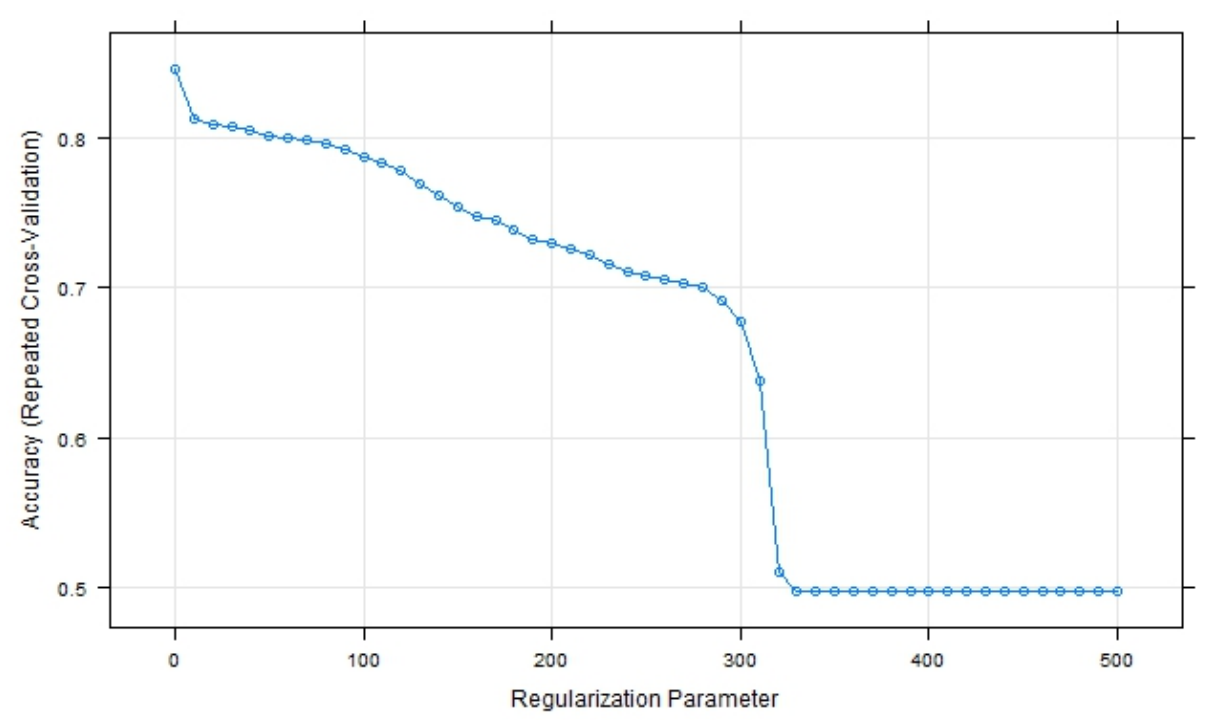

Figura 14: Acurácia para diversas configurações

Percebe-se que o intervalo onde se mantém uma acurácia acima de $80 \%$ é muito pequeno. Assim, fazemos uma nova aproximação limitando lambda entre 0 e 10. A Figura 15 mostra uma queda abrupta já no início.

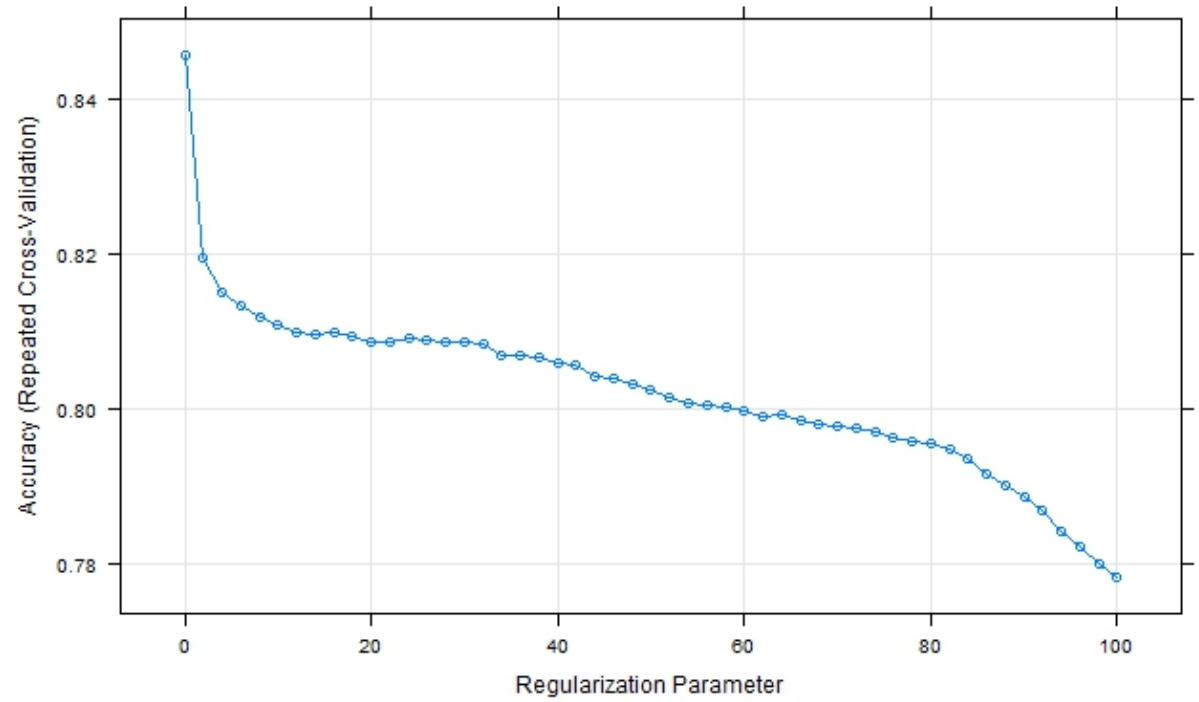

Figura 15: Acurácia para diversas configurações

Considerando a tendência de queda abrupta da acurácia diante das diversas configurações de penalização, e levando-se em conta ainda a aparente normalidade dos parâmetros 
estimados na etapa do stepwise, decidiu-se pela configuração final do modelo sem penalização. Ou seja, aplicando-se diretamente o modelo selecionado na etapa de escolha de variáveis. A Tabela 5 apresenta os parâmetros oriundos do stepwise e que foram utilizados como modelo final.

Tabela 5: Parâmetros Estimados - Modelo de Risco do Contrato

\begin{tabular}{|l|l|}
\hline RFB-QTDE-SOCIOS-2014 & -0.2611 \\
\hline RFB-qtde-atividades & 0.05473 \\
\hline RFB-PAGTO-POR-SOCIO-2014 & 0.0000001168 \\
\hline RFB-PAGTO-TOTAL & -0.00000003841 \\
\hline RFB-IDADE-EMPRESA-2015 & -0.03889 \\
\hline $\begin{array}{l}\text { RAIS-QTDE-FUNCIONARIOS- } \\
\text { MEDIA }\end{array}$ & 0.001443 \\
\hline $\begin{array}{l}\text { RAIS-QTDE-FUNCIONARIOS- } \\
\text { 2014 }\end{array}$ & -0.001201 \\
\hline RAIS-MEDIA-SALARIO-SOCIO- \\
MEDIA & 0.00003768 \\
\hline COMPRAS-soma-valor-homologado- \\
TOTAL & 0.0000000171 \\
\hline COMPRAS-soma-qtde-lances-2014 & 0.0003334 \\
\hline COMPRAS-qtde-orgaos-MEDIA & 0.07683 \\
\hline COMPRAS-qtde-compras-TOTAL & -0.005512 \\
\hline i-dummie-servico & 0.004563 \\
\hline i-dummie-inexigibilidade & -0.3318 \\
\hline i-dummie-dispensa & -0.2437 \\
\hline i-desconto & -0.06254 \\
\hline i-especificidade & 0.00005356 \\
\hline i-frequencia-item & 0.000004483 \\
\hline i-lances-por-participante & -0.0639 \\
\hline i-qtde-participantes & -0.008272 \\
\hline i-qtde-lances & 0.005765 \\
\hline i-qtde-TA-fornecedor & -0.009087 \\
\hline i-qtde-TA-vigencia & -0.2444 \\
\hline i-qtde-ocorrencias-compra & 0.8416 \\
\hline & \\
\hline
\end{tabular}

O modelo estimado será discutido na seção de resultados, assim como a acurácia resultante da sua aplicação na base de testes.

\subsubsection{Proposta de modelo de decisão multicritério para seleção dos contratos a serem auditados}

O modelo final de seleção de contratos foi construído a partir dos resultados dos dois modelos de aprendizagem supervisionada (risco do fornecedor e risco do contrato) e com a incorporação de variáveis relativas ao planejamento das unidades de auditoria. A ideia é a de calibrar o ranking obtido inicialmente pelo modelo do risco de contrato com a incorporação de aspectos relativos à conveniência, oportunidade e relevância da realização da auditoria.

Essa ponderação é necessária uma vez que o score de risco obtido do modelo supervisionado atribui ao contrato um valor que indica sua propensão a apresentar problemas no futuro. No entanto, mesmo contratos com alta propensão de problemas 
podem não ser relevantes quando da decisão de auditoria. Outras variáveis devem ser consideradas, como o valor envolvido, os custos potenciais da auditoria e a viabilidade da mesma. Assim, é possível que um contrato de alto risco tenha um valor muito pequeno, ou esteja sendo executado numa região do país onde o deslocamento da equipe de auditores ofereceria um custo muito alto, inviabilizando a auditoria.

O método de decisão multicritério utilizado foi o Analytic Hierarchy Process (AHP), descrito na Subseção 2.2.3. Para auxílio nos cálculos, foi utilizada a planilha disponibilizada por GOEPEL (2013).

As variáveis ou critérios ponderados foram os seguintes:

- Risco do Fornecedor (C1): variável resultado da aplicação do modelo de risco do fornecedor, que resulta num índice entre 0 e 1.

- Risco do Contrato (C2): variável resultado da aplicação do modelo de risco do contrato, que resulta num índice entre 0 e 1.

- Valor do Contrato (C3): medida normalizada ${ }^{23}$ do valor do contrato, em comparação com os demais contratos do ranking, apresentando valores entre 0 e 1.

- Indicador de Capital (C4): variável binária que apresenta 1 para contrato em execução por unidade gestora situada em capital e 0 caso contrário.

- Indicador de Plano de Auditoria (C5): variável binária que apresenta 1 para contrato em execução por unidade gestora que já consta do plano anual de auditoria do órgão de controle e 0 caso contrário.

- Indicador de Ação Priorizada (C6): variável binária que apresenta 1 para contrato relativo a ação governemental priorizada pelo órgão de controle e 0 caso contrário.

- Indicador de Estrutura da Unidade de Auditoria (C7): variável contínua entre 0 e 1 que indica a qualidade da estrutura administrativa da unidade de auditoria.

Essa etapa da modelagem se dispõe a apresentar um modelo parcialmente simulado, uma vez que não foram buscados de fato os valores para as últimas 4 variáveis apresentadas acima. Assim, valores aleatórios foram considerados nesses casos para permitir uma primeira aplicação do modelo.

Estando todas as variáveis na escala de 0 e 1, o objetivo da modelagem AHP é criar um score único com a utilização de pesos para cada critério. Esses pesos são dados segundo ponderação fornecida por especialistas, por meio da comparação de todos os critérios, dois a dois, utilizando a Matriz de Julgamentos descrita na Seção 2.2.3.

23 Para normalização foi utilizada a razão entre o valor do contrato e o maior valor dentre os demais. 
Os julgamentos paritários na Matriz de Julgamentos foram realizados por uma equipe de 5 auditores da CGU utilizando a escala proposta por SAATY (1990), apresentada na Tabela 6 .

Tabela 6: Escala numérica da Matriz de Julgamentos

\begin{tabular}{|l|l|}
\hline Escala Numérica & Descrição \\
\hline $\mathbf{1}$ & Ambos os critérios têm igual importância. \\
\hline $\mathbf{3}$ & Moderada importância de um elemento sobre o outro. \\
\hline $\mathbf{5}$ & Forte importância de um elemento sobre o outro. \\
\hline $\mathbf{7}$ & Importância muito forte de um elemento sobre o outro. \\
\hline $\mathbf{9}$ & Máxima importância de um elemento sobre o outro \\
\hline $\mathbf{2 , 4 , 6 , 8}$ & Valores intermediários dos níveis anteriores. \\
\hline
\end{tabular}

Os resultados desses julgamentos estão apresentados na Tabela 7 .

Tabela 7: Resultado da Matriz de Julgamentos

\begin{tabular}{|l|l|l|l|l|l|l|l|}
\hline & C1 & C2 & C3 & C4 & C5 & C6 & C7 \\
\hline C1 & 1 & 0,33 & 0,5 & 0,33 & 0,5 & 2 & 0,5 \\
\hline C2 & 3 & 1 & 0,5 & 2 & 1 & 1 & 1 \\
\hline C3 & 2 & 2 & 1 & 2 & 2 & 2 & 3 \\
\hline C4 & 3 & 0,5 & 0,5 & 1 & 1 & 0,5 & 3 \\
\hline C5 & 2 & 1 & 0,5 & 1 & 1 & 1 & 1 \\
\hline C6 & 0,5 & 1 & 0,5 & 2 & 1 & 1 & 1 \\
\hline C7 & 2 & 1 & 0,33 & 0,33 & 0,5 & 1 & 1 \\
\hline
\end{tabular}

A Tabela 8 apresenta a Matriz de Julgamentos normalizada (obtida pela divisão de cada elemento pelo somatório da respectiva coluna).

Tabela 8: Matriz de Julgamentos Normalizada

\begin{tabular}{|l|l|l|l|l|l|l|l|}
\hline & C1 & C2 & C3 & C4 & C5 & C6 & C7 \\
\hline C1 & 0,0741 & 0,0488 & 0,1304 & 0,0385 & 0,0714 & 0,2353 & 0,0435 \\
\hline C2 & 0,2222 & 0,1463 & 0,1304 & 0,2308 & 0,1429 & 0,1176 & 0,0870 \\
\hline C3 & 0,1481 & 0,2927 & 0,2609 & 0,2308 & 0,2857 & 0,2353 & 0,2609 \\
\hline C4 & 0,2222 & 0,0732 & 0,1304 & 0,1154 & 0,1429 & 0,0588 & 0,2609 \\
\hline C5 & 0,1481 & 0,1463 & 0,1304 & 0,1154 & 0,1429 & 0,1176 & 0,1739 \\
\hline C6 & 0,0370 & 0,1463 & 0,1304 & 0,2308 & 0,1429 & 0,1176 & 0,0870 \\
\hline C7 & 0,1481 & 0,1463 & 0,0870 & 0,0385 & 0,0714 & 0,1176 & 0,0870 \\
\hline
\end{tabular}

Os coeficientes finais para cada critério (também chamados de prioridades médias locais), obtidos pela média da linha respectiva da matriz normalizada, foram os seguintes:

- Risco do Fornecedor (C1): 0,090.

- Risco do Contrato (C2): 0,157. 
- Valor do Contrato (C3): 0,242.

- Indicador de Capital (C4): 0,145.

- Indicador de Plano de Auditoria (C5): 0,139.

- Indicador de Ação Priorizada (C6): 0,128.

- Indicador de Estrutura da Unidade de Auditoria (C7): 0,099.

Esses coeficientes irão compor a equação final que calcula o índice de propensão para auditoria, a ser apresentada na Seção 4.3. 



\section{Resultados}

Esta seção descreve os resultados dos processos de modelagem. A Subseção 4.1 detalha o resultado do modelo quantitativo de estimação do risco dos fornecedores, a Subseção 4.2 faz o mesmo para o risco dos contratos, e, por último, a Subseção 4.3 discorre sobre o resultado do modelo de decisão multicritério.

\subsection{Modelo de risco do fornecedor}

Os resultados estão divididos em duas partes. A primeira (item 4.1.1) contém a interpretação dos coeficientes obtidos no modelo final utilizado, visando identificar a direção do influência da variável preditora e sua magnitude. A segunda parte (item 4.1.2) detalha os resultados em termos de medidas de qualidade e validação do modelo.

\subsubsection{Interpretação dos coeficientes obtidos}

A Tabela 3 apresentou os coeficientes estimados para cada variável do modelo de Regressão Logística para o risco do fornecedor. Nesta seção discorreremos sobre a direção e a magnitude de alguns desses parâmetros, fazendo sua conversão para valores que representem o percentual de aumento ou redução do risco mantidas as demais variáveis constantes $^{1}$.

Um primeiro destaque é a variável TSE-VALOR-DOADO-TOTAL, cujo parâmetro convertido resulta num odds ratio igual a 1,000000141, o que significa que a cada $\mathrm{R} \$ 1,00$ doado em campanhas políticas aumenta o risco calculado em 0,000014\%. Mais clara a interpretação se pensarmos que a cada $\mathrm{R} \$ 100$ mil em doações (valor comumente doado por empresas) o fornecedor aumenta seu risco de apresentar problemas contratuais em 1,42\%. Essa relação confirma o entendimento existente entre especialistas de que vinculações políticas aumentam a probabilidade de irregularidades nas relações de empresas com o governo.

Outro resultado interessante é o coeficiente da variável RFB-IDADE-EMPRESA2015, cujo valor do odds ratio é de 0,9934733, o que nos diz que 1 ano de idade a mais implica numa queda do risco de $0,65 \%$.

Também é esperado que a experiência da empresa seja um ponto positivo nas suas relações com o governo, afinal se espera que para empresas mais antigas o custo de uma

1 Os valores dos estimadores fornecem uma estimativa do logaritmo natural do odds ratio ajustado para todas as variáveis do modelo. É possível obter o valor do odds ratio através da exponenciação do logaritmo natural pelo coeficiente estimado. 
penalização seja mais crítico.

Outras variáveis também apresentam relação positiva com o índice de risco, estando de acordo com o efeito esperado: quantidade e Valor dos alertas de monitoramento em 2014; quantidade de atividades cadastradas na Receita Federal; razão entre valores recebidos e sócios; valores totais recebidos; quantidade de sócios com baixa qualificação; valor ganho em licitações anteriores; valor ganho em licitações em 2014; quantidade de órgãos distintos para os quais vende; e quantidade de desclassificações em pregões. Todas essas variáveis provocam um aumento no risco de uma empresa apresentar problemas graves no futuro.

Também vale destacar as seguintes variáveis que impactam negativamente o risco e confirmam as expectativas: média salarial dos sócios; quantidade de sócios em 2014, quantidade média de sócios; quantidade de funcionários no ano de 2014; e média salarial dos funcionários em 2014. O aumento no valor dessas medidas tende a reduzir o risco da empresa.

Algumas variáveis, porém, apresentam uma relação contraintuitiva com o risco calculado. O sinal do coeficiente demonstra uma relação inesperada. Uma dessas é a razão média histórica entre valores recebidos do governo e o quantitativo de sócios. Esperava-se um sinal positivo desse coeficiente, tal como ocorreu com o indicador específico do ano de 2014. É possível que essa contradição indique o risco de uma mudança de comportamento da empresa, ou seja, quando ela passa a reduzir a quantidade de sócios mantidos os pagamentos. Outra variável aparentemente contraditória e que potencializa a contraintuição anterior é a que mede os pagamentos recebidos pela empresa em 2014, e aponta para uma redução do risco ao aumentar esse valor.

\subsubsection{Desempenho preditivo na base de teste}

Os resultados do modelo de classificação de fornecedores são mensurados inicialmente pelos índices de Acurácia, Sensibilidade, Especificidade, Precisão e F-Measure obtidos ao aplicá-lo na base separada para teste.

Após a aplicação do modelo na base de teste, esses indicadores são obtidos a partir da comparação do índice de risco calculado para cada empresa (que está limitado no intervalo de 0 a 1) com a classificação prévia feita. Retomando a seção de modelagem, as empresas foram classificadas, seguindo os critérios dispostos na Seção 3.4.1, como de alto risco (label 1) ou baixo risco (label 0) e essa classe foi utilizada como variável dependente no modelo de Regressão Logística. Para realizar a comparação estabeleceu-se a fronteira de 0.5 para o índice de risco calculado. Dessa forma, ele foi igualado a 1 para valores de risco maiores que 0.5 e a 0 caso contrário.

A Tabela 9 apresenta a matriz de confusão resultante dessa comparação na base de teste. 
Tabela 9: Matriz de confusão - Risco do Fornecedor.

\begin{tabular}{|c|c|c|}
\hline & Previsão 1 & Previsão 0 \\
\hline Valor Real 1 & 208 & 9 \\
\hline Valor Real 0 & 54 & 163 \\
\hline
\end{tabular}

Com base nesses valores, chegamos aos seguintes índices:

- Acurácia: 85,5\%

- Sensibilidade: $95,9 \%$

- Especificidade: $75,1 \%$

- Precisão: $79,4 \%$

Observa-se que modelo tem uma sensibilidade muito boa, o que significa que dos contratos pré-qualificados como de alto risco, 95,9\% foram previstos pelo modelo dessa forma. Mas isso por si só não é suficiente para verificar a qualidade do modelo de previsão. Poderíamos supor um modelo que previsse $100 \%$ dos casos como de uma classe. Obviamente teria uma sensibilidade de $100 \%$ mas uma acurácia de 50\% (caso as classes sejam perfeitamente balanceadas), ou seja, seria inútil. Há que se observar também os outros índices. Percebe-se que a precisão e a especificidade ficaram abaixo de 80\%, o que demonstra que o modelo de fato tende a prever os contratos como de alto risco (pela tabela, foram 262 contratos previstos como de alto risco e 172 como de baixo).

Pode ser feito um ajuste na fronteira criada para a classificação final do índice de risco calculado. Se pusermos um limite ligeiramente superior (por exemplo, 0.53), teríamos um resultado mais equilibrado, como visto na Tabela 10.

Tabela 10: Matriz de confusão - Risco do Fornecedor, com threshold alterado.

\begin{tabular}{|c|c|c|}
\hline & Previsão 1 & Previsão 0 \\
\hline Valor Real 1 & 174 & 43 \\
\hline Valor Real 0 & 26 & 191 \\
\hline
\end{tabular}

Isso alteraria os valores de Acurácia, Sensibilidade, Especificidade e Precisão para respectivamente $84,1 \%, 80,2 \%, 88,0 \%$ e 87,0\%. Esse tipo de ajuste é importante especialmente quando algum dos índices é mais valioso a depender o contexto de aplicação do modelo preditivo. No caso de seleção de casos para auditoria, como é o caso específico desse trabalho, a precisão é fundamental, visto que não se quer gastar recursos da unidade de auditoria sem uma confiança razoável de que o objeto auditado realmente oferece riscos. 
Outra maneira de lidar com a necessidade de maior precisão é dividir as empresas em classes de risco, e calcular a precisão para cada classe. Por exemplo, se considerássemos como passíveis de atuação apenas as empresas com risco superior a $80 \%$ teríamos um conjunto de 10 empresas, todas com previsão correta, ou seja, precisão de $100 \%$.

O índice F-Measure combina as métricas de sensibilidade e precisão. Essas duas medidas são as mais importantes quando existe uma classe mais relevante que a outra. No caso específico, a de alto risco. Esse índice é a média harmônica entre precisão e sensibilidade (ver Equação 2.9).

Para o modelo gerado teríamos um F-Measure de 0,86 com o treshold de 0,5 ou 0,83 com o treshold de 0,53 .

O índice Kappa também é utilizado para medir o quanto o modelo de predição é melhor do que um resultado obtível aleatoriamente. Aplicando-se a Equação 2.10, obtivemos o valor de 0,71, considerado "substancial", segundo o padrão de interpretação mais utilizado (LANDIS; KOCH, 1977), apresentado na Tabela 11.

Tabela 11: Valores do índice x Interpretação (LANDIS; KOCH, 1977)

\begin{tabular}{|c|c|}
\hline Valur do Kappa & Interpretação \\
\hline menor que 0,01 & Equivalente à aleatoriedade \\
\hline $0,01-0,20$ & Levemente ajustado \\
\hline $0,21-0,40$ & Suficientemente ajustado \\
\hline $0,41-0,60$ & Moderadamente ajustado \\
\hline $0,61-0,80$ & Substancialmente ajustado \\
\hline $0,81-1,00$ & Ajuste quase perfeito \\
\hline
\end{tabular}

A Validação final do modelo foi feita com o cálculo do Pseudo-R2 para verificação da consistência do modelo em relação a um modelo vazio, nesse caso tendo como preditor apenas o intercepto. Para validação do poder preditivo de cada variável independente foi utilizado o teste de Wald.

O Pseudo-R2 obtido foi de 0.32 . Isso demonstra que o modelo de fato é significativamente melhor do que um modelo vazio (VEALL; ZIMMERMANN, 1996).

O teste de Wald confirmou a significância de todas as variáveis, com exceção da variável que indica se o fornecedor é pessoa física e das que informam os valores recebidos como subcontratada ou convenente em convênios. Apesar da não significância estatística desses três preditores, deve-se mantê-los na aplicação final com fins de predição, como é comum em trabalhos de aprendizagem supervisionada do tipo, uma vez que estão contidas no modelo final resultado de um processo de otimização que maximizou a acurácia. 


\subsection{Modelo de risco do contrato}

Os resultados estão divididos em duas partes. A primeira (item 4.2.1) contém a interpretação dos coeficientes obtidos no modelo final utilizado, visando identificar a direção do influência da variavel preditora e sua magnitude. A segunda parte (item 4.2.2) detalha os resultados em termos de medidas de qualidade e validação do modelo.

\subsubsection{Interpretação dos coeficientes obtidos}

Os coeficientes estimados para cada variável do modelo de Regressão Logística para o risco do contrato estão apresentados na Tabela 5. Discorremos aqui sobre esses resultados, outra vez convertendo (via exponenciação do logaritmo natural) os estimadores para valores que representem um percentual de aumento ou redução do risco mantidas as demais variáveis constantes.

Destacamos inicialmente a variável $i$-qtde-participantes, que representa a quantidade de empresas que disputaram a licitação que originou o contrato. O parâmetro estimado para essa variável, se convertido, resulta num odds ratio igual a 0,991762, o que significa que 1 fornecedor a mais participando da licitação reduz o risco calculado em 0,82\%. Dez participantes a mais reduzem esse risco em 7,9\%. Essa relação vai ao encontro do entendimento geral, inclusive manifestado na própria lei de licitações, em seus princípios gerais (MUKAI, 1994), de que uma maior competição na licitação tende a gerar contratos melhores.

Outro resultado interessante é o coeficiente da variável $i$-qtde-ocorrencias-compra, cujo valor do odds ratio é de 2,32, o que nos diz que 1 ocorrência verificada na licitação (dentro do monitoramento realizado pela CGU) ocasiona um acréscimo de $132 \%$ no risco (em relação a um contrato sem ocorrências). Essa também é uma relação condizente com nossa expectativa quando da inclusão desse indicador. De fato uma licitação problemática favorece contratos problemáticos.

Outras variáveis também apresentam relação positiva com o índice de risco, e também condizem com nossa expectativa: quantidade de atividades exercidas pela empresa contratada; razão entre o valor recebido em 2014 e a quantidade de sócios; quantidade de órgãos distintos para os quais a empresa contratada vende; e indicador de serviço (contrato é uma prestação de serviço e não uma entrega de bens).

Também vale destacar as seguintes variáveis que impactam negativamente o risco, também confirmando as expectativas: quantidade de sócios em 2014 da empresa contratada; valores recebidos pelo governo; idade da empresa; quantidade de funcionários em 2014; quantidade total de compras da empresa contratada; e razão entre o número de lances da licitação e a quantidade de participantes. 
Contudo, o modelo gerado também apresenta relações contraintuitivas. Uma dessas é a variável de frequência do item, que mede a quantidade de vezes que o mesmo produto foi contratado. Esperava-se contratações de produtos adquiridos com maior frequência fossem menos propensas a riscos. Essa intuição tem relação com a Teoria dos Custos de Transação, no âmbito do oportunismo dos agentes, uma vez que se espera haver mais espaço para oportunismo no caso de produtos raros. Na verdade, o que pode ser deduzido do sinal positivo do estimador é que essa condição não se reflete em problemas futuros no contrato.

Outro exemplo é a variável de temos aditivos de vigência, que apresenta coeficiente com sinal negativo. Esperava-se que contratos com mais aditamentos fossem mais propensos a problemas, pois refletem falta de planejamento por parte do órgão. Na verdade, o efeito identificado na modelagem foi o inverso. Um aditamento provoca uma queda de $21 \%$ no risco do contrato, em relação a outro sem mudanças. De fato, o que se pode supor é que o mal planejamento não está se refletindo na ocorrências de falhas contratuais, talvez funcionando o aditamento como um saneador dos problemas.

\subsubsection{Desempenho preditivo na base de teste}

A Tabela 12 apresenta a matriz de confusão obtida comparando os resultados preditos do modelo com os reais na base de teste. Para tanto, utilizou-se o threshold de 0,5 (contratos com risco maior que 0,5 são classificados como de alto risco e, caso contrário, como de baixo risco).

Tabela 12: Matriz de confusão - Risco do Contrato.

\begin{tabular}{|c|c|c|}
\hline & Previsão 1 & Previsão 0 \\
\hline Valor Real 1 & 133 & 18 \\
\hline Valor Real 0 & 24 & 127 \\
\hline
\end{tabular}

Com base nesses valores, chegamos aos seguintes índices:

- Acurácia: $86,1 \%$

- Sensibilidade: $88,1 \%$

- Especificidade: $84,1 \%$

- Precisão: $84,7 \%$

Observa-se que o modelo tem uma sensibilidade e precisão boas, acima de $80 \%$, o que é importante tendo em vista que essas medidas medem o acerto na classe mais 
relevante (alto risco). As outras métricas também demonstram que o modelo está bem ajustado aos dados, com boa capacidade preditiva.

Pode-se obter maior precisão dividindo os contratos em classes de risco, testando acerto apenas para a classe de risco mais alto. Por exemplo, se considerássemos como passíveis de atuação apenas os contratos com risco superior a $90 \%$ teríamos um conjunto de 87 contratos, sendo 78 com previsão correta, o que eleva a precisão para $90 \%$.

O índice F-Measure, que combina as métricas de sensibilidade e precisão resultou em 0,86 .

O índice Kappa, que mede o quanto o modelo de predição é melhor do que um resultado obtível aleatoriamente resultou no valor de 0,72, também considerado "substancial", segundo o padrão de interpretação mais utilizado(LANDIS; KOCH, 1977), apresentado anteriormente na Tabela 8.

Tal como feito no modelo de fornecedores, a validação final foi realizada com o cálculo do Pseudo-R2 para medir a diferença estatística entre o modelo de contratos e um modelo vazio, tendo como preditor apenas o intercepto. Aplicou-se também o teste de Wald para verificação do poder preditivo de cada preditora.

O Pseudo-R2 obtido foi de 0.61. Isso demonstra que o modelo de fato é significativamente melhor do que um modelo vazio (VEALL; ZIMMERMANN, 1996).

O teste de Wald confirmou a significância de todas as variáveis, com exceção das de desconto na compra, especificidade do objeto e indicação de alteração do fornecedor. A não-significância dessas variáveis já havia sido constatada pela análise do p-valor na etapa de modelagem.

Contudo, uma vez que estão contidas no modelo final, que maximizou a acurácia, foram mantidas na aplicação final com fins de predição, como é comum em trabalhos de aprendizagem supervisionada do tipo.

\subsection{Modelo de decisão para auditoria}

O processo de modelagem de decisão multicritério realizado resultou na obtenção dos coeficientes de importância de cada critério adotado, conforme apresentado na Seção 3.4.3.

Esses coeficientes compõem a equação que calcula a propensão de auditoria (dora- 
vante denominada Índice de Auditoria), apresentada na Equação 4.1.

$$
\begin{gathered}
\text { Índice de Auditoria }=0,090 * C 1+0,157 * C 2+0,242 * C 3 \\
+0,145 * C 4+0,139 * C 5+0,128 * C 6+0,099 * C 7
\end{gathered}
$$

A coerência dos coeficientes calculados é medida pelo Índice de Consistência, calculado pela Equação 2.11. O índice obtido foi de 0.083, dentro do limite em que se pode considerar a ponderação consistente (SAATY, 1990).

Para verificar o potencial impacto de se utilizar essa abordagem sobre os contratos com risco já calculado, aplicamos o modelo de decisão multicritério final sobre os contratos com índice de risco calculado (no segundo modelo de aprendizagem supervisionada) superior a 0,8. A ideia é verificar as alterações que o modelo que incorpora a opinião de especialistas quanto a aspectos logísticos da auditoria provocaria na importância desse grupo restrito de contratos de alto risco.

A Tabela 13 detalha os cinco contratos com maior Índice de Auditoria, apresentando também a colocação original considerando apenas o índice de risco do contrato.

Tabela 13: Aplicação da equação de Índice de Auditoria nos contratos com risco maior que 0,8 .

\begin{tabular}{|l|l|l|l|l|l|l|l|l|l|l|}
\hline Contrato Valor & C1 & C2 & C3 & C4 & C5 & C6 & C7 & $\begin{array}{l}\text { Índice } \\
\text { Auditoria }\end{array}$ & $\begin{array}{l}\text { Colocação } \\
\text { anterior }\end{array}$ \\
\hline $\mathbf{1}$ & $\begin{array}{l}\mathrm{R} \$ 138,5 \\
\text { milhões }\end{array}$ & 0,50 & 0,99 & 1 & 1 & 1 & 1 & 0,53 & 0,91 & 15 \\
\hline $\mathbf{2}$ & $\mathrm{R} \$ 774$ mil & 0,60 & 0,97 & 0,03 & 1 & 1 & 1 & 0,75 & 0,70 & 32 \\
\hline $\mathbf{3}$ & $\begin{array}{l}\mathrm{R} \$ 16,05 \\
\text { milhões }\end{array}$ & 0,69 & 1 & 0,50 & 0 & 1 & 1 & 0,76 & 0,68 & 1 \\
\hline $\mathbf{4}$ & $\begin{array}{l}\mathrm{R} \$ \quad 672,5 \\
\text { mil }\end{array}$ & 0,56 & 0,89 & 0,03 & 1 & 1 & 1 & 0,62 & 0,67 & 92 \\
\hline $\mathbf{5}$ & $\begin{array}{l}\mathrm{R} \$ 898,9 \\
\text { mil }\end{array}$ & 0,55 & 0,81 & 0,04 & 1 & 1 & 1 & 0,69 & 0,67 & 123 \\
\hline
\end{tabular}

Observa-se que a aplicação da função de cálculo do Índice de Auditoria sobre os contratos com risco alto (calculado pelo segundo modelo de aprendizagem supervisionada) gera uma reordenação nas prioridades originais. Isso ocorre porque o risco contratual está agora combinado com outros atributos importantes para a tomada de decisão da auditoria. Um deles é o risco inerente ao fornecedor (calculado pelo primeiro modelo), e os demais dizem respeito a questões logísticas da unidade de auditoria.

Tomemos alguns exemplos. O contrato com maior Índice de Auditoria era originalmente o $15^{\circ}$ em risco contratual. Sua progressão de importância deve-se ao fato de ele ser o contrato com maior valor do grupo considerado ( $\mathrm{R} \$ 138,5$ milhões), combinado com a condição de que a unidade a ser auditada (gestora do contrato) se localiza numa 
capital e já está no Plano de Auditoria do órgão (iria ser auditada de qualquer maneira, não oferecendo nenhum custo adicional). Além disso, o objeto do contrato se refere a uma ação governamental priorizada para controle.

Outro "upgrade" com explicação similar ocorreu com o $5^{\circ}$ contrato da lista, que originalmente era apenas o $123^{\circ} \mathrm{em}$ risco.

O contrato com o terceiro maior Índice de Auditoria era originalmente o contrato de maior risco calculado pelo modelo supervisionado. A pequena "queda" de importância ocorreu provavelmente porque a unidade a ser auditada não está localizada numa capital, demandando um custo maior para realização da auditoria.

Vale destacar também o $2^{\circ}$ colocado em risco contratual, não exibido na Tabela 13 pois ocupa apenas a $35^{\mathrm{a}}$ colocação pelo Índice de Auditoria. Apesar do alto score de risco, esse contrato tem valor muito baixo (apenas $\mathrm{R} \$ 48$ mil), além de não contemplar uma ação priorizada. 



\section{Conclusões}

Modelos preditivos utilizando aprendizagem supervisionada são largamente utilizados no âmbito privado, especialmente por instituições que buscam prevenir fraude ou medir o risco de transações financeiras. No escopo governamental ainda são poucas as experiências consolidadas de uso efetivo de tais técnicas. No Brasil, especificamente, há uma visível subutilização dos dados relativos a contratações públicas, em que pese haver, pelo menos em nível federal, uma razoável estruturação dos registros dos sistemas transacionais de compras públicas.

Este trabalho buscou suprir essa lacuna a partir da utilização massiva dos dados do Sistema de Administração de Serviços Gerais (SIASG) do Governo Federal, com o complemento de diversas bases que se relacionam indiretamente com o processo de aquisições governamentais. O objetivo foi criar um modelo de quantificação do risco de contratações públicas e de suporte ao processo de planejamento de auditorias no âmbito da Controladoria-Geral da União (CGU), órgão central de controle interno do governo federal.

A abordagem híbrida adotada, que consistiu na criação de dois modelos de aprendizagem de máquina supervisionada (utilizando a técnica de Regressão Logística para cálculo do risco de fornecedores e contratos) e de um modelo de decisão multicritério incorporando variáveis relativas ao planejamento operacional das auditorias, possibilita a disponibilização aos planejadores das áreas fins da CGU de uma ferramenta com potencial de adicionar grande valor ao processo de tomada de decisão no âmbito operacional. Esse é o caráter aplicado da pesquisa realizada.

No âmbito teórico, a utilização, na construção das variáveis de predição, de teorias econômicas que abordam o comportamento racional dos agentes em face de relações contratuais ou de disputa, provê uma clara inovação na junção entre teoria econômica e política pública na área de auditoria governamental.

Os resultados alcançados pelos modelos de Regressão Logística foram significativos. Se observarmos a métrica de precisão, que na área de auditoria, considerando a finalidade de selecionar processos para atuação, tende a ser mais importante (uma vez que não se deseja gastar recursos com falsos positivos), os dois modelos criados foram certamente bem sucedidos. O primeiro modelo, que calcula o risco do fornecedor (em suma, o risco de apresentar problemas futuros que ensejem as punições mais graves), resultou em 79,4\% de precisão. Significa dizer que das empresas previstas como de alto risco, quase $80 \%$ de fato pertenciam à classe das mais problemáticas. Considerando-se apenas os casos com índice de risco maior (acima de 0,8), essa precisão seria de $100 \%$. 
O segundo modelo, que prevê o risco de contratos serem interrompidos a despeito do interesse da administração pública, foi ainda mais preciso, com um índice de 84,7\%. Selecionando-se somente contratos com alto índice previsto (acima de 0,9, por exemplo) a precisão do modelo seria de $90 \%$.

Fundamental também é o ganho na compreensão de como determinadas características das empresas que negociam com o governo ou dos processos de contratação impactam nos riscos que o contratante público assume. A interpretação dos coeficientes estimados nos modelos de Regressão Logística permitiu confirmar algumas hipóteses já intuídas por muitos especialistas da área, como, por exemplo, o fato de que empresas doadoras de campanha política ou com poucos funcionários oferecem maior risco, que empresas mais antigas seriam mais confiáveis ou que o quantitativo de lances (mais competição) da licitação reduz o risco do contrato resultante.

Outras relações foram clarificadas, agregando conhecimento sobre a relação dessas características com o risco esperado. Contratos que apresentam problemas durante a fase de formação (licitação) tendem a ter problemas graves de execução. Empresas com número maior de atividades cadastradas na junta comercial tendem a ser mais problemáticas, empresas que vendem para uma variedade maior de órgãos públicos também. Contratos com itens menos frequentes (mais raros) oferecem menor risco. Contratos aditados também, de maneira contraintuitiva, reduzem os riscos de interrupção. Seria o aditivo o "salvador" do contrato?

Observando algumas dessas relações pode-se arriscar o seguinte raciocínio: futuras empresas problemáticas pecam por assumir mais compromissos do que aparentam suportar, e isso resulta na sua punição. Emerge da análise dos coeficientes a ideia de que empresas com pouca capacidade operacional e experiência se arriscam mais em contratações com o governo (seria a "bala de prata" contra as firmas maiores?), fazem contratos com uma variedade maior de órgãos, atuam em áreas das mais diversas (vide o impacto positivo no risco da quantidade de atividades), e não possuem habilidade negocial (ou poder de pressão) com os órgãos públicos suficiente para engendrar uma alteração no contrato.

Um estudo mais qualitativo sobre casos de contratos abandonados ou com graves problemas na execução poderia explicar melhor os porquês que surgiram da interpretação dos modelos econométricos. Sugere-se tal abordagem como trabalho futuro.

O modelo de decisão multicritério vem fazer a conexão necessária entre o resultado dos modelos de quantificação do risco e a realidade administrativa das unidades de auditoria. Seria utópico e um tanto ingênuo pensar que resultados de modelagens preditivas como as realizadas nos dois primeiros modelos viessem a ser incorporados diretamente ao planejamento operacional de um órgão de controle governamental. Isso porque o modelo econométrico possibilitou a criação de um índice de risco limitado aos dados utilizados pelo modelo de regressão. Compreender um contrato como de alto risco é importante, mas 
é apenas uma parte da problemática do planejamento da auditoria.

Um exemplo claro: a variável de valor do contrato não apresentou significância estatística para separar os dois grupos de contratos de alto risco ou baixo risco do segundo modelo. Do ponto de vista do modelo de regressão, isso significa que existem contratos de alto ou baixo valor em ambos os grupos, não servindo essa variável para diferenciá-los. Mas do ponto de vista da decisão sobre auditar ou não um contrato, essa variável é crucial.

Retomando a justificativa para este estudo, apresentada na seção de introdução, a razão central para a construção de modelos de risco é que existe limitação dos recursos de auditoria frente ao escopo de atuação do órgão. Assim, como não se pode verificar tudo, que se verifique o mais importante. O modelo de decisão multicritério aprofunda-se nas questões referentes à logística da auditoria para buscar o conjunto mais relevante de objetos auditáveis. Tal conceito de relevância admite o score de risco como um componente a ser combinado e ponderado com outros aspectos não considerados pelos modelos quantitativos.

O exercício de simulação de um ranking de contratos a serem auditados utilizando os resultados dos modelos supervisionados juntamente com os critérios ponderados pela técnica de Analytic Hierarchy Process (AHP) mostra que a inclusão da opinião de especialistas ou planejadores corrige distorções e aproxima o modelo quantitativo da desejada efetividade no planejamento dos trabalhos de auditoria. Esse modelo certamente pode ser aperfeiçoado, com a participação de mais especialistas contribuindo com sugestões de novos critérios e com a reavaliação de importância dos mesmos.

Além da potencial aplicação imediata dessa pesquisa na melhora do processo de planejamento operacional das auditorias, espera-se que a melhor compreensão sobre a influência de cada variável no nível de risco de contratações possa influenciar, mesmo indiretamente, na formulação de regras para o setor de contratações públicas. Por isso, estudos futuros devem abordar mais profundamente essas relações, com análises tanto quantitativas quanto qualitativas.

É razoável também buscar melhorar os resultados dos modelos supervisionados de previsão do risco com a inclusão de novas variáveis, transformações das existentes e principalmente com o teste de novas técnicas de classificação ou regressão.

O aperfeiçoamento dos processos de gestão de riscos na área pública governamental deve ser encarado, e essa foi a ideia fundamental que justificou essa pesquisa, como uma parte crítica da busca constante pela melhor utilização dos recursos públicos, para que a atuação governamental cumpra sua função de prover crescimento social e serviços públicos condizentes com o que a população entrega ao estado e demanda como retorno. 



\section{Referências}

ALBUQUERQUE, J. H. et al. Um estudo sob a óptica da teoria do agenciamento sobre a accountability e a relação estado-sociedade. In: Congresso USP de Controladoria e Contabilidade. [S.l.: s.n.], 2007. v. 7, p. 26-39. Citado na página 30.

AQUINO, C. E. D. et al. Six steps to an effective continuous audit process. Internal Auditor Magazine, The Institute of Internal Auditors, 2008. Citado na página 32.

ARAÚJO, E. A.; CARMONA, C. U. D. M. Desenvolvimento de modelos credit scoring com abordagem de regressão de logística para a gestão da inadimplência de uma instituição de microcrédito. Contabilidade Vista ES Revista, v. 18, n. 3, p. 107-131, 2009. Citado na página 43.

BALANIUK, R. et al. Risk based government audit planning using naïve bayes classifiers. In: Advances in Knowledge-Based and Intelligent Information and Engineering Systems. [S.l.: s.n.], 2012. Citado na página 44.

BARTOLINI, L.; COTTARELLI, C. Treasury bill auctions: issues and uses. IMF Working Paper, 1994. Citado 2 vezes nas páginas 26 e 27.

BENDEL, R. B.; AFIFI, A. A. Comparison of stopping rules in forward "stepwise" regression. Journal of the American Statistical Association, Taylor \& Francis Group, v. 72, n. 357, p. 46-53, 1977. Citado 2 vezes nas páginas 39 e 70.

BRAGA, L. V. et al. O papel do governo eletrônico no fortalecimento da governança do setor público. Revista do Serviço Público (RSP), 2008. Citado na página 19.

BRASIL. Decreto 3931 de 19 de setembro de 2001. 2001. Citado na página 31.

BRASIL. Instrução Normativa 01 de 06 de abril de 2001, do Ministério da Fazenda. 2001. Citado 3 vezes nas páginas 31, 48 e 49.

BRASIL. Lei 10863, de 28/05/2003-Lei Ordinária. 2003. Citado 2 vezes nas páginas 47 e 48.

BRASIL. Decreto 5450 de 31 de maio de 2005. 2005. Citado na página 30.

BRASIL. Decreto 7892 de 23 de janeiro de 2013. 2013. Citado na página 48.

BRASIL. Decreto 8109 de 17 de setembro de 2013. 2013. Citado na página 49.

BULOS, U. L. Constituição federal anotada: acompanhada dos índices alfabético-remissivos da constituição e da jurisprudência. [S.l.]: Saraiva, 2002. Citado na página 47.

CAMPOS, F. As práticas de conluio nas licitações públicas à luz da teoria dos jogos. Análise Econômica, v. 26, n. 50, 2016. Citado na página 44.

CAOUETTE, J. et al. Gestão do risco de crédito: o grande desafio dos mercados financeiros globais. Rio de Janeiro: Qualitymark, SERASA, 2009. Citado na página 43. 
CARLETTA, J. Assessing agreement on classification tasks: the kappa statistic. Computational linguistics, v. 22, n. 2, p. 249-254, 1996. Disponível em: <http: //dl.acm.org/citation.cfm?id=230390>. Citado na página 41.

CARTER, C. R. et al. Reverse auctions - grounded theory from the buyer and supplier perspective. Transportation Research Part E: Logistics and Transportation Review, Elsevier, v. 40, n. 3, p. 229-254, 2004. Citado 2 vezes nas páginas 26 e 30.

CARVAlHO, R. S. Modelos Preditivos para Avaliação de Risco de Corrupção de Servidores Públicos Federais. Dissertação (Mestrado) - Universidade de Brasília, 2015. Citado na página 43.

CARVALHO, R. S.; CARVALHO, R. N. Bayesian models to assess risk of corruption of federal management units. In: 13th Bayesian Modelling Applications Workshop. [S.l.: s.n.], 2016. Citado na página 43.

CGU. Manual da Metodologia para Avaliação da Execução de Programas de Governo. [S.l.]: CGU, 2015. Citado na página 48.

CORDERO, J. D.; SILVEIRA, J. S. T. da; MOREIRA, A. P. Redução de custos nos processos de compras através de pregão eletrônico: Estudo de caso. 2012. Citado 2 vezes nas páginas 26 e 44.

COSTA, G. P. C. da; DUTRA, T. A. d. G. L. Auditoria financeira na era do big data: novas possibilidades para avaliação e resposta a riscos em demonstrações financeiras do governo federal. Revista do TCU, n. 131, p. 54-61, 2014. Citado na página 32.

COSTA, H. G.; MOLL, R. N. Emprego do método de análise hierárquica (ahp) na seleção de variedades para o plantio de cana-de-açúcar. Gestão \&ु Produção, v. 6, n. 3, p. 243-256, 1999. Citado na página 42.

FERNANDES, C. C. C. Transformações na gestão de compras da administração pública brasileira. 2008. Citado na página 52.

FILHO, M. J. Pregão: Comentários à Legislação do pregão comum e eletrônico. [S.1.]: Dialética, 2009. Citado na página 19.

FORTMANN-ROE, S. Understanding the bias-variance tradeoff. http://scott.fortmannroe.com/docs/Bias Variance.html, 2012. Citado 3 vezes nas páginas 13, 35 e 36.

FRIEDMAN, J.; HASTIE, T.; TIBSHIRANI, R. The elements of statistical learning. [S.1.]: Springer series in statistics Springer, Berlin, 2001. v. 1. Citado 4 vezes nas páginas $21,34,35$ e 38 .

GAL, M. S. et al. The Economic Characteristics of Developing Jurisdictions: Their Implications for Competition Law. [S.1.]: Edward Elgar Publishing, 2015. Citado na página 51.

GEVERT, V. G. et al. Modelos de regressão logística, redes neurais e support vector machine (svm's) na análise de crédito a pessoas jurídicas. RECEN-Revista Ciências Exatas e Naturais, v. 12, n. 2, p. 269-293, 2011. Citado na página 43.

GOEPEL, K. D. BPMSG AHP Excel template with multiple inputs. [S.1.]: Version, 2013. Citado na página 81. 
GOLDEN, B. L.; WASIL, E. A.; HARKER, P. T. Analytic hierarchy process. [S.l.]: Springer, 2003. v. 113. Citado na página 42.

GUO, X. et al. On the class imbalance problem. In: IEEE. Natural Computation, 2008. ICNC'08. Fourth International Conference on. [S.l.], 2008. v. 4, p. 192-201. Citado na página 37.

HOERL, A. E.; KENNARD, R. W. Ridge regression: Biased estimation for nonorthogonal problems. Technometrics, Taylor \& Francis Group, v. 12, n. 1, p. 55-67, 1970. Citado na página 38.

HOETKER, G. The use of logit and probit models in strategic management research: Critical issues. Strategic Management Journal, Wiley Online Library, v. 28, n. 4, p. 331-343, 2007. Citado na página 39.

IBGE. Contas nacionais trimestrais. Relatório de Contas Anuais Trimestrais, v. 01/2016, 2016. Citado na página 19.

JAPKOWICZ, N. et al. Learning from imbalanced data sets: a comparison of various strategies. In: MENLO PARK, CA. AAAI workshop on learning from imbalanced data sets. [S.l.], 2000. v. 68, p. 10-15. Citado na página 37.

JENSEN, M. C.; MECKLING, W. H. Theory of the firm: Managerial behavior, agency costs and ownership structure. Journal of financial economics, Elsevier, v. 3, n. 4, p. 305-360, 1976. Citado na página 29.

JR, W. W. H.; DONNER, A. Wald's test as applied to hypotheses in logit analysis. Journal of the american statistical association, Taylor \& Francis, v. 72, n. 360a, p. 851-853, 1977. Citado na página 39.

JUNIOR, R.; MACHADO, R. Acordos contratuais sob a ótica da economia dos custos de transação: o caso de uma agroindústria canavieira no estado de pernambuco. In: Congresso Internacional de Gestão de Redes Agroalimentares, IV. Anais. Ribeirão Preto. [S.l.: s.n.], 2003. Citado 2 vezes nas páginas 28 e 29.

KLEMPERER, P. Auctions: theory and practice. Available at SSRN 491563, 2004. Citado 2 vezes nas páginas 25 e 26.

KOHAVI, R. et al. A study of cross-validation and bootstrap for accuracy estimation and model selection. In: Ijcai. [S.l.: s.n.], 1995. v. 14, n. 2, p. 1137-1145. Citado na página 38.

LANDIS, J. R.; KOCH, G. G. The Measurement of Observer Agreement for Categorical Data. Biometrics, v. 33, n. 1, p. 159, mar. 1977. ISSN 0006341X. Disponível em: <http://www.jstor.org/stable/2529310?origin=crossref $>$. Citado 3 vezes nas páginas 15, 88 e 91.

LESSMANN, S. et al. Benchmarking state-of-the-art classification algorithms for credit scoring: An update of research. European Journal of Operational Research, Elsevier, v. 247, n. 1, p. 124-136, 2015. Citado na página 21.

MAMEDE, G. Comentários ao Estatuto nacional da microempresa e da empresa de pequeno porte: Lei complementar no. 123, de 14 de dezembro de 2006. [S.1.]: Editora Atlas, 2007. Citado 2 vezes nas páginas 30 e 56. 
MATOSO, F. Teoria dos leilões: Uma abordagem para a promoção da defesa e da advocacia da concorrência. 2009. Citado 3 vezes nas páginas 27, 29 e 44.

MCAFEE, R. P.; MCMILLAN, J. Auctions and bidding. Journal of economic literature, JSTOR, v. 25, n. 2, p. 699-738, 1987. Citado 3 vezes nas páginas 25, 26 e 29.

MORAES, R. R. d. Economia proporcionada pela utilização do pregão eletrônico no dnit/to. 2012. Citado 2 vezes nas páginas 26 e 44.

MPOG. Manual do usuário do Sistema de Gestão de Contratos. [S.l.]: MPOG, 2006. Citado 3 vezes nas páginas 52, 53 e 55 .

MUKAI, T. O Novo Estatuto Jurídico Das Licitações E Contratos Públicos: Comentários À Lei 8,666/93: com as Alterações Promovidas Pela Lei 8.883/94. [S.1.]: Editora Revista dos Tribunais, 1994. Citado 4 vezes nas páginas 27, 30, 55 e 89.

PEREIRA, E.; LAGROTERIA, E.; LEAL, J. Concorrência e regulação: estudos e pareceres econômicos. São Paulo: Editora Singular, 2004. Citado na página 27.

PIETRO, M. S. Z. D. Direito administrativo. [S.l.]: Atlas São Paulo, 1999. v. 22. Citado na página 19.

POWERS, D. M. Evaluation: from precision, recall and f-measure to roc, informedness, markedness and correlation. Bioinfo Publications, 2011. Citado na página 41.

RASCHKA, S. Python Machine Learning. [S.1.]: Packt Publishing Ltd, 2015. Citado 3 vezes nas páginas 13, 65 e 66.

SAATY, T. L. Decision making for leaders: the analytic hierarchy process for decisions in a complex world. [S.1.]: RWS publications, 1990. Citado 3 vezes nas páginas 42, 82 e 92.

SALES, L. J. Risk prevention in brazilian government contracts using credit scoring. Interdisciplinary Insights on Fraud, Cambridge Scholars Publishing, v. 17, p. 23, 2014. Citado na página 45.

SALES, L. J.; CARVALHO, R. N. Measuring the risk of public contracts using bayesian classifiers. In: 13th Bayesian Modelling Applications Workshop. [S.l.: s.n.], 2016. Citado na página 43.

SANTOS, L. M. dos; SILVEIRA, S. d. F. R. Fatores determinantes na variação dos preços dos produtos contratados por pregão eletrônico. Revista de Administração Pública, SciELO Brasil, v. 44, n. 6, p. 1405-28, 2010. Citado 4 vezes nas páginas 26, 28, 29 e 44.

SCARPINELLA, V. Licitação na modalidade de pregão: Lei 10,520, de 17 de julho de 2002. [S.1.]: Malheiros Editores, 2003. Citado na página 30.

SEMEDO, D. Credit Scoring. Aplicaçao da Regressao Logıstica vs Redes Neuronais Artificiais na Avaliaçao do Risco de Crédito no Mercado Cabo-Verdiano. Dissertação (Mestrado) - Instituto Superior de Estatıstica e Gestao de Informaçao, Universidade Nova de Lisboa, 2010. Citado na página 43.

SILVA, A. A. d. A economia das compras governamentais em decorrência do pregão eletrônico-uma abordagem econométrica. 2007. Citado 2 vezes nas páginas 26 e 44. 
SLOMSKI, V. Controladoria e governança na gestão pública. [S.l.]: Editora Atlas SA, 2000. Citado na página 30.

STEWART, T. J. Dealing with uncertainties in mcda. In: Multiple criteria decision analysis: state of the art surveys. [S.l.]: Springer, 2005. p. 445-466. Citado na página 42.

THOMAS, L. C.; EDELMAN, D. B.; CROOK, J. N. Credit scoring and its applications. [S.l.]: Siam, 2002. Citado na página 43.

THOMAS, W. On the synthesis of strategies in infinite games. In: SPRINGER. STACS 95. [S.1.], 1995. p. 1-13. Citado na página 29.

TIBSHIRANI, R. Regression shrinkage and selection via the lasso. Journal of the Royal Statistical Society. Series B (Methodological), JSTOR, p. 267-288, 1996. Citado 2 vezes nas páginas 38 e 39.

VALLE, M. G. d.; BONACELLI, M. B. M.; FILHO, S. L. M. S. Aportes da economia evolucionista e da nova economia institucional na constituição de arranjos institucionais de pesquisa. Simpósio de Gestão da Inovação Tecnológica, XXII. Anais. Salvador, 2002. Citado na página 28.

VASARHELYI, M. A.; HALPER, F. B. The continuous audit of online systems. Auditing: A Journal of Practice \& Theory, v. 10, n. 1, p. 110-125, 1991. Citado na página 32.

VASCONCELlOS, M. S. de. Proposta de método para análise de concessões de crédito a pessoas físicas. Tese (Doutorado) — Universidade de São Paulo, 2002. Citado na página 43.

VEALL, M. R.; ZIMMERMANN, K. F. Pseudo-r2 measures for some common limited dependent variable models. Journal of Economic surveys, Wiley Online Library, v. 10, n. 3, p. 241-259, 1996. Citado 2 vezes nas páginas 88 e 91.

WEIGAND, H.; ELSAS, P. Model-based auditing using rea. International Journal of Accounting Information Systems, Elsevier, v. 13, n. 3, p. 287-310, 2012. Citado na página 32.

WEISS, G. M.; PROVOST, F. Learning when training data are costly: the effect of class distribution on tree induction. Journal of Artificial Intelligence Research, p. 315-354, 2003. Citado na página 37.

WILliAMSON, O. E. The economic institutions of capitalism. The Political Economy Reader: Markets as Institutions, 2008. Citado na página 27.

WOOLDRIDGE, J. Introductory econometrics: A modern approach. [S.l.]: Nelson Education, 2015. Citado 5 vezes nas páginas 21, 33, 34, 35 e 36. 

Anexos 



\section{ANEXO A - Descrição dos indicadores utilizados}

\begin{tabular}{|c|c|c|c|}
\hline Variável & Descrição & $\begin{array}{l}\text { Dimensão de } \\
\text { Risco do For- } \\
\text { necedor }\end{array}$ & $\begin{array}{l}\text { Dimensão de } \\
\text { Risco do Con- } \\
\text { trato }\end{array}$ \\
\hline LABEL & $\begin{array}{l}\text { Variável dependente dos } \\
\text { modelos. Identifica se } \\
\text { a empresa ou contrato } \\
\text { foram pré-qualificados } \\
\text { como de "Alto Risco"ou } \\
\text { "Baixo Risco". }\end{array}$ & Não se aplica. & Não se aplica. \\
\hline $\begin{array}{l}\text { TSE-VALOR-DOADO- } \\
\text { TOTAL }\end{array}$ & $\begin{array}{l}\text { Valor total doado pela } \\
\text { empresa nas campanhas } \\
\text { de } 2010,2012 \text { e } 2014 .\end{array}$ & $\begin{array}{l}\text { Vinculação Polí- } \\
\text { tica }\end{array}$ & $\begin{array}{l}\text { Fornecedor Con- } \\
\text { tratado Contra- } \\
\text { tado }\end{array}$ \\
\hline $\begin{array}{l}\text { TRILHAS-VALOR- } \\
\text { ALERTAS-TOTAL }\end{array}$ & $\begin{array}{l}\text { Valor total das licitações } \\
\text { vencidas pela empresa } \\
\text { com alerta emitido pela } \\
\text { CGU. }\end{array}$ & $\begin{array}{l}\text { Histórico de pu- } \\
\text { nições e constata- } \\
\text { ções }\end{array}$ & Não se aplica \\
\hline $\begin{array}{l}\text { TRILHAS-VALOR- } \\
\text { ALERTAS-2014 }\end{array}$ & $\begin{array}{l}\text { Valor das licitações ven- } \\
\text { cidas pela empresa com } \\
\text { alerta emitido pela CGU } \\
\text { em } 2014 \text {. }\end{array}$ & $\begin{array}{l}\text { Histórico de pu- } \\
\text { nições e constata- } \\
\text { ções }\end{array}$ & $\begin{array}{l}\text { Fornecedor Con- } \\
\text { tratado }\end{array}$ \\
\hline $\begin{array}{l}\text { TRILHAS-QTDE- } \\
\text { ALERTAS-TOTAL }\end{array}$ & $\begin{array}{l}\text { Quantidade total das lici- } \\
\text { tações vencidas pela em- } \\
\text { presa com alerta emitido } \\
\text { pela CGU. }\end{array}$ & $\begin{array}{l}\text { Histórico de pu- } \\
\text { nições e constata- } \\
\text { ções }\end{array}$ & Não se aplica \\
\hline $\begin{array}{l}\text { TRILHAS-QTDE- } \\
\text { ALERTAS-2014 }\end{array}$ & $\begin{array}{l}\text { Quantidade das licitações } \\
\text { vencidas pela empresa } \\
\text { com alerta emitido pela } \\
\text { CGU em } 2014 \text {. }\end{array}$ & $\begin{array}{l}\text { Histórico de pu- } \\
\text { nições e constata- } \\
\text { ções }\end{array}$ & $\begin{array}{l}\text { Fornecedor Con- } \\
\text { tratado }\end{array}$ \\
\hline $\begin{array}{l}\text { SICAF-QTDE- } \\
\text { OCORRENCIAS- } \\
\text { TOTAL }\end{array}$ & $\begin{array}{l}\text { Quantidade de punições } \\
\text { da empresa }\end{array}$ & $\begin{array}{l}\text { Histórico de pu- } \\
\text { nições e constata- } \\
\text { ções }\end{array}$ & Não se aplica \\
\hline
\end{tabular}




\begin{tabular}{|c|c|c|c|}
\hline $\begin{array}{l}\text { SICAF-QTDE- } \\
\text { OCORRENCIAS-2014 }\end{array}$ & $\begin{array}{l}\text { Quantidade de punições } \\
\text { da empresa em } 2014 .\end{array}$ & $\begin{array}{l}\text { Histórico de pu- } \\
\text { nições e constata- } \\
\text { ções }\end{array}$ & Não se aplica \\
\hline $\begin{array}{l}\text { SERVIDOR-qtde-socio- } \\
\text { servidor }\end{array}$ & $\begin{array}{l}\text { Quantidade de sócios que } \\
\text { também são servidores } \\
\text { efetivos no governo fede- } \\
\text { ral. }\end{array}$ & $\begin{array}{l}\text { Conflito de inte- } \\
\text { resses }\end{array}$ & Não se aplica \\
\hline $\begin{array}{l}\text { SERVIDOR-qtde-socio- } \\
\text { funcao }\end{array}$ & $\begin{array}{l}\text { Quantidade de sócios que } \\
\text { ocupam função no go- } \\
\text { verno federal. }\end{array}$ & $\begin{array}{l}\text { Conflito de inte- } \\
\text { resses }\end{array}$ & Não se aplica \\
\hline $\begin{array}{l}\text { SERVIDOR-qtde- } \\
\text { funcionario-servidor }\end{array}$ & $\begin{array}{l}\text { Quantidade de funcioná- } \\
\text { rios que também são ser- } \\
\text { vidores efetivos no go- } \\
\text { verno federal. }\end{array}$ & $\begin{array}{l}\text { Conflito de inte- } \\
\text { resses }\end{array}$ & Não se aplica \\
\hline $\begin{array}{l}\text { SERVIDOR-qtde- } \\
\text { funcionario-funcao }\end{array}$ & $\begin{array}{l}\text { Quantidade de funcioná- } \\
\text { rios que ocupam função } \\
\text { no governo federal. }\end{array}$ & $\begin{array}{l}\text { Conflito de inte- } \\
\text { resses }\end{array}$ & Não se aplica \\
\hline $\begin{array}{l}\text { RFB-QTDE-SOCIOS- } \\
\text { MEDIA }\end{array}$ & $\begin{array}{l}\text { Quantidade média de só- } \\
\text { cios da empresa, entre } \\
2011 \text { e } 2014 \text {. }\end{array}$ & $\begin{array}{l}\text { Capacidade Ope- } \\
\text { racional }\end{array}$ & $\begin{array}{l}\text { Fornecedor Con- } \\
\text { tratado }\end{array}$ \\
\hline $\begin{array}{l}\text { RFB-QTDE-SOCIOS- } \\
2014\end{array}$ & $\begin{array}{l}\text { Quantidade de sócios da } \\
\text { empresa em } 2014 .\end{array}$ & $\begin{array}{l}\text { Capacidade Ope- } \\
\text { racional }\end{array}$ & $\begin{array}{l}\text { Fornecedor Con- } \\
\text { tratado }\end{array}$ \\
\hline RFB-qtde-atividades & $\begin{array}{l}\text { Quantidade de atividades } \\
\text { cadastradas pela empresa } \\
\text { na junta comercial. }\end{array}$ & $\begin{array}{l}\text { Capacidade Ope- } \\
\text { racional }\end{array}$ & $\begin{array}{l}\text { Fornecedor Con- } \\
\text { tratado }\end{array}$ \\
\hline $\begin{array}{l}\text { RFB-PAGTO-POR- } \\
\text { SOCIO-MEDIA }\end{array}$ & $\begin{array}{l}\text { Valores recebidos do go- } \\
\text { verno por sócio (média en- } \\
\text { tre } 2011 \text { e } 2014 \text { ). }\end{array}$ & $\begin{array}{l}\text { Capacidade Ope- } \\
\text { racional }\end{array}$ & $\begin{array}{l}\text { Fornecedor Con- } \\
\text { tratado }\end{array}$ \\
\hline $\begin{array}{l}\text { RFB-PAGTO-POR- } \\
\text { SOCIO-2014 }\end{array}$ & $\begin{array}{l}\text { Valores recebidos do go- } \\
\text { verno por sócio em } 2014 .\end{array}$ & $\begin{array}{l}\text { Capacidade Ope- } \\
\text { racional }\end{array}$ & $\begin{array}{l}\text { Fornecedor Con- } \\
\text { tratado }\end{array}$ \\
\hline RFB-PAGTO-TOTAL & $\begin{array}{l}\text { Valor total recebido pela } \\
\text { empresa, entre } 2011 \text { e } \\
2014 \text {. }\end{array}$ & $\begin{array}{l}\text { Capacidade Ope- } \\
\text { racional }\end{array}$ & $\begin{array}{l}\text { Fornecedor Con- } \\
\text { tratado }\end{array}$ \\
\hline RFB-PAGTO-2014 & $\begin{array}{l}\text { Valor recebido pela em- } \\
\text { presa em } 2014 .\end{array}$ & $\begin{array}{l}\text { Capacidade Ope- } \\
\text { racional }\end{array}$ & $\begin{array}{l}\text { Fornecedor Con- } \\
\text { tratado }\end{array}$ \\
\hline $\begin{array}{l}\text { RFB-IDADE- } \\
\text { EMPRESA-2015 }\end{array}$ & $\begin{array}{l}\text { Idade da empresa em } \\
2015\end{array}$ & $\begin{array}{l}\text { Capacidade Ope- } \\
\text { racional }\end{array}$ & $\begin{array}{l}\text { Fornecedor Con- } \\
\text { tratado }\end{array}$ \\
\hline
\end{tabular}




\begin{tabular}{|c|c|c|c|}
\hline $\begin{array}{l}\text { RAIS-QTDE- } \\
\text { LARANJAS-2014 }\end{array}$ & $\begin{array}{l}\text { Quantidade de sócios com } \\
\text { ocupação de nível baixo } \\
\text { em } 2014 \text {. }\end{array}$ & $\begin{array}{l}\text { Capacidade Ope- } \\
\text { racional }\end{array}$ & $\begin{array}{l}\text { Fornecedor Con- } \\
\text { tratado }\end{array}$ \\
\hline $\begin{array}{l}\text { RAIS-QTDE- } \\
\text { FUNCIONARIOS- } \\
\text { MEDIA }\end{array}$ & $\begin{array}{l}\text { Quantidade média de só- } \\
\text { cios com ocupação de ní- } \\
\text { vel baixo entre } 2011 \text { e } \\
2014 \text {. }\end{array}$ & $\begin{array}{l}\text { Capacidade Ope- } \\
\text { racional }\end{array}$ & $\begin{array}{l}\text { Fornecedor Con- } \\
\text { tratado }\end{array}$ \\
\hline $\begin{array}{l}\text { RAIS-QTDE- } \\
\text { FUNCIONARIOS-2014 }\end{array}$ & $\begin{array}{l}\text { Quantidade de funcioná- } \\
\text { rios em } 2014 .\end{array}$ & $\begin{array}{l}\text { Capacidade Ope- } \\
\text { racional }\end{array}$ & $\begin{array}{l}\text { Fornecedor Con- } \\
\text { tratado }\end{array}$ \\
\hline $\begin{array}{l}\text { RAIS-PAGTO-POR- } \\
\text { FUNCIONARIO- } \\
\text { MEDIA }\end{array}$ & $\begin{array}{l}\text { Valores recebidos do go- } \\
\text { verno por funcionário na } \\
\text { empresa (média entre } \\
2011 \text { e } 2014) \text {. }\end{array}$ & $\begin{array}{l}\text { Capacidade Ope- } \\
\text { racional }\end{array}$ & Não se aplica \\
\hline $\begin{array}{l}\text { RAIS-PAGTO-POR- } \\
\text { FUNCIONARIO-2014 }\end{array}$ & $\begin{array}{l}\text { Valores recebidos do go- } \\
\text { verno por funcionário na } \\
\text { empresa em } 2014 \text {. }\end{array}$ & $\begin{array}{l}\text { Capacidade Ope- } \\
\text { racional }\end{array}$ & Não se aplica \\
\hline $\begin{array}{l}\text { RAIS-MEDIA- } \\
\text { SALARIO-SOCIO- } \\
\text { MEDIA }\end{array}$ & $\begin{array}{l}\text { Média do salário dos só- } \\
\text { cios (entre } 2011 \text { e 2014) }\end{array}$ & $\begin{array}{l}\text { Capacidade Ope- } \\
\text { racional }\end{array}$ & $\begin{array}{l}\text { Fornecedor Con- } \\
\text { tratado }\end{array}$ \\
\hline $\begin{array}{l}\text { RAIS-MEDIA- } \\
\text { SALARIO-SOCIO-2014 }\end{array}$ & $\begin{array}{l}\text { Média do salário dos só- } \\
\text { cios em } 2014 .\end{array}$ & $\begin{array}{l}\text { Capacidade Ope- } \\
\text { racional }\end{array}$ & $\begin{array}{l}\text { Fornecedor Con- } \\
\text { tratado }\end{array}$ \\
\hline $\begin{array}{l}\text { RAIS-MEDIA- } \\
\text { SALARIO- } \\
\text { FUNCIONARIOS- } \\
\text { MEDIA }\end{array}$ & $\begin{array}{l}\text { Média do salário dos fun- } \\
\text { cionários (entre } 2011 \text { e } \\
\text { 2014). }\end{array}$ & $\begin{array}{l}\text { Capacidade Ope- } \\
\text { racional }\end{array}$ & Não se aplica \\
\hline $\begin{array}{l}\text { RAIS-MEDIA- } \\
\text { SALARIO- } \\
\text { FUNCIONARIOS-2014 }\end{array}$ & $\begin{array}{l}\text { Média do salário dos fun- } \\
\text { cionários em } 2014 .\end{array}$ & $\begin{array}{l}\text { Capacidade Ope- } \\
\text { racional }\end{array}$ & $\begin{array}{l}\text { Fornecedor Con- } \\
\text { tratado }\end{array}$ \\
\hline dummie-PF & $\begin{array}{l}\text { Variável binária que in- } \\
\text { dica se o fornecedor é pes- } \\
\text { soa física (1) ou jurídica } \\
(0) \text {. }\end{array}$ & $\begin{array}{l}\text { Capacidade Ope- } \\
\text { racional }\end{array}$ & $\begin{array}{l}\text { Fornecedor Con- } \\
\text { tratado }\end{array}$ \\
\hline dummie-ESFL & $\begin{array}{l}\text { Variável binária que in- } \\
\text { dica se o fornecedor é En- } \\
\text { tidade Sem Fins Lucrati- } \\
\text { vos (1) ou com fins lucra- } \\
\text { tivos (0). }\end{array}$ & $\begin{array}{l}\text { Conflito de inte- } \\
\text { resses }\end{array}$ & Não se aplica \\
\hline
\end{tabular}




\begin{tabular}{|c|c|c|c|}
\hline dummie-EPPME & $\begin{array}{l}\text { Variável binária que in- } \\
\text { dica se o fornecedor é Mi- } \\
\text { croempresa ou Empresa } \\
\text { de Pequeno Porte }(1) \text { ou } \\
\text { não }(0) \text {. }\end{array}$ & $\begin{array}{l}\text { Capacidade Ope- } \\
\text { racional }\end{array}$ & Não se aplica \\
\hline $\begin{array}{l}\text { CONVENIOS-valor- } \\
\text { favorecido }\end{array}$ & $\begin{array}{l}\text { Valor recebido pela em- } \\
\text { presa na condição de sub- } \\
\text { contratada em convênios. }\end{array}$ & $\begin{array}{l}\text { Conflito de inte- } \\
\text { resses }\end{array}$ & $\begin{array}{l}\text { Fornecedor Con- } \\
\text { tratado }\end{array}$ \\
\hline $\begin{array}{l}\text { CONVENIOS-valor- } \\
\text { convenente }\end{array}$ & $\begin{array}{l}\text { Valor recebido pela em- } \\
\text { presa na condição de con- } \\
\text { venente em convênios. }\end{array}$ & $\begin{array}{l}\text { Conflito de inte- } \\
\text { resses }\end{array}$ & $\begin{array}{l}\text { Fornecedor Con- } \\
\text { tratado }\end{array}$ \\
\hline $\begin{array}{l}\text { COMPRAS-soma-valor- } \\
\text { homologado-TOTAL }\end{array}$ & $\begin{array}{l}\text { Valor total em licitações } \\
\text { vencidas pela empresa } \\
\text { (entre } 2011 \text { e } 2014) .\end{array}$ & $\begin{array}{l}\text { Perfil de partici- } \\
\text { pação em licita- } \\
\text { ções }\end{array}$ & $\begin{array}{l}\text { Fornecedor Con- } \\
\text { tratado }\end{array}$ \\
\hline $\begin{array}{l}\text { COMPRAS-soma-valor- } \\
\text { homologado- } 2014\end{array}$ & $\begin{array}{l}\text { Valor total em licitações } \\
\text { vencidas pela empresa em } \\
2014 \text {. }\end{array}$ & $\begin{array}{l}\text { Perfil de partici- } \\
\text { pação em licita- } \\
\text { ções }\end{array}$ & $\begin{array}{l}\text { Fornecedor Con- } \\
\text { tratado }\end{array}$ \\
\hline $\begin{array}{l}\text { COMPRAS-soma-qtde- } \\
\text { lances-2014 }\end{array}$ & $\begin{array}{l}\text { Quantidade de lances da- } \\
\text { dos em licitações no ano } \\
\text { de } 2014 \text {. }\end{array}$ & $\begin{array}{l}\text { Perfil de partici- } \\
\text { pação em licita- } \\
\text { ções }\end{array}$ & $\begin{array}{l}\text { Fornecedor Con- } \\
\text { tratado }\end{array}$ \\
\hline $\begin{array}{l}\text { COMPRAS-qtde-UF- } \\
\text { MEDIA }\end{array}$ & $\begin{array}{l}\text { Quantidade de Unidades } \\
\text { da Federação distintas } \\
\text { onde se localizam unida- } \\
\text { des governamentais para } \\
\text { as quais a empresa ven- } \\
\text { deu (média entre } 2011 \text { e } \\
\text { 2014). }\end{array}$ & $\begin{array}{l}\text { Perfil de partici- } \\
\text { pação em licita- } \\
\text { ções }\end{array}$ & Não se aplica \\
\hline $\begin{array}{l}\text { COMPRAS-qtde-UF- } \\
2014\end{array}$ & $\begin{array}{l}\text { Quantidade de Unidades } \\
\text { da Federação distintas } \\
\text { onde se localizam unida- } \\
\text { des governamentais para } \\
\text { as quais a empresa ven- } \\
\text { deu em } 2014 \text {. }\end{array}$ & $\begin{array}{l}\text { Perfil de partici- } \\
\text { pação em licita- } \\
\text { ções }\end{array}$ & Não se aplica \\
\hline $\begin{array}{l}\text { COMPRAS-qtde- } \\
\text { orgaos-MEDIA }\end{array}$ & $\begin{array}{l}\text { Quantidade de órgãos pú- } \\
\text { blicos para os quais a em- } \\
\text { presa vendeu (média en- } \\
\text { tre } 2011 \text { e } 2014 \text { ). }\end{array}$ & $\begin{array}{l}\text { Perfil de partici- } \\
\text { pação em licita- } \\
\text { ções }\end{array}$ & $\begin{array}{l}\text { Fornecedor Con- } \\
\text { tratado }\end{array}$ \\
\hline
\end{tabular}




\begin{tabular}{|c|c|c|c|}
\hline $\begin{array}{l}\text { COMPRAS-qtde- } \\
\text { orgaos-2014 }\end{array}$ & $\begin{array}{l}\text { Quantidade de órgãos pú- } \\
\text { blicos para os quais a em- } \\
\text { presa vendeu no ano de } \\
2014 \text {. }\end{array}$ & $\begin{array}{l}\text { Perfil de partici- } \\
\text { pação em licita- } \\
\text { ções }\end{array}$ & $\begin{array}{l}\text { Fornecedor Con- } \\
\text { tratado }\end{array}$ \\
\hline $\begin{array}{l}\text { COMPRAS-qtde-itens- } \\
\text { compra-WIN-TOTAL }\end{array}$ & $\begin{array}{l}\text { Quantidade de itens de } \\
\text { compra vencidos pela em- } \\
\text { presa entre } 2011 \text { e } 2014 \text {. }\end{array}$ & $\begin{array}{l}\text { Perfil de partici- } \\
\text { pação em licita- } \\
\text { ções }\end{array}$ & $\begin{array}{l}\text { Fornecedor Con- } \\
\text { tratado }\end{array}$ \\
\hline $\begin{array}{l}\text { COMPRAS-qtde-itens- } \\
\text { compra-WIN-2014 }\end{array}$ & $\begin{array}{l}\text { Quantidade de itens de } \\
\text { compra vencidos pela em- } \\
\text { presa em } 2014 \text {. }\end{array}$ & $\begin{array}{l}\text { Perfil de partici- } \\
\text { pação em licita- } \\
\text { ções }\end{array}$ & Não se aplica \\
\hline $\begin{array}{l}\text { COMPRAS-qtde-itens- } \\
\text { compra-TOTAL }\end{array}$ & $\begin{array}{l}\text { Quantidade de itens de } \\
\text { compra disputados pela } \\
\text { empresa entre } 2011 \text { e } \\
2014 \text {. }\end{array}$ & $\begin{array}{l}\text { Perfil de partici- } \\
\text { pação em licita- } \\
\text { ções }\end{array}$ & Não se aplica \\
\hline $\begin{array}{l}\text { COMPRAS-qtde-itens- } \\
\text { compra-2014 }\end{array}$ & $\begin{array}{l}\text { Quantidade de itens de } \\
\text { compra disputados pela } \\
\text { empresa em } 2014 .\end{array}$ & $\begin{array}{l}\text { Perfil de partici- } \\
\text { pação em licita- } \\
\text { ções }\end{array}$ & $\begin{array}{l}\text { Fornecedor Con- } \\
\text { tratado }\end{array}$ \\
\hline $\begin{array}{l}\text { COMPRAS-qtde- } \\
\text { desclassificacao-TOTAL }\end{array}$ & $\begin{array}{l}\text { Quantidade de desclassi- } \\
\text { ficações sofridas pela em- } \\
\text { presa entre } 2011 \text { e } 2014 \text {. }\end{array}$ & $\begin{array}{l}\text { Perfil de partici- } \\
\text { pação em licita- } \\
\text { ções }\end{array}$ & $\begin{array}{l}\text { Fornecedor Con- } \\
\text { tratado }\end{array}$ \\
\hline $\begin{array}{l}\text { COMPRAS-qtde- } \\
\text { desclassificacao-2014 }\end{array}$ & $\begin{array}{l}\text { Quantidade de desclassi- } \\
\text { ficações sofridas pela em- } \\
\text { presa em } 2014 \text {. }\end{array}$ & $\begin{array}{l}\text { Perfil de partici- } \\
\text { pação em licita- } \\
\text { ções }\end{array}$ & aplica \\
\hline $\begin{array}{l}\text { COMPRAS-qtde- } \\
\text { compras-TOTAL }\end{array}$ & $\begin{array}{l}\text { Quantidade de licitações } \\
\text { disputadas pela empresa } \\
\text { entre } 2011 \text { e } 2014 \text {. }\end{array}$ & $\begin{array}{l}\text { Perfil de partici- } \\
\text { pação em licita- } \\
\text { ções }\end{array}$ & $\begin{array}{l}\text { Fornecedor Con- } \\
\text { tratado }\end{array}$ \\
\hline i-dummie-servico & $\begin{array}{l}\text { Variável binária que in- } \\
\text { dica se o contrato é de } \\
\text { serviço (1) ou de entrega } \\
\text { de bens (0) }\end{array}$ & Não se aplica & $\begin{array}{l}\text { Aspectos gerais } \\
\text { da licitação }\end{array}$ \\
\hline $\begin{array}{l}\text { i-dummie- } \\
\text { inexigibilidade }\end{array}$ & $\begin{array}{l}\text { Variável binária que } \\
\text { indica se o contrato } \\
\text { originou-se de uma inexi- } \\
\text { gibilidade de licitação (1) } \\
\text { ou não (0). }\end{array}$ & Não se aplica & $\begin{array}{l}\text { Competitividade } \\
\text { do processo }\end{array}$ \\
\hline
\end{tabular}




\begin{tabular}{|c|c|c|c|}
\hline i-dummie-dispensa & $\begin{array}{l}\text { Variável binária que } \\
\text { indica se o contrato } \\
\text { originou-se de uma } \\
\text { dispensa de licitação (1) } \\
\text { ou não (0). }\end{array}$ & Não se aplica & $\begin{array}{l}\text { Competitividade } \\
\text { do processo }\end{array}$ \\
\hline i-dummie-tomada & $\begin{array}{l}\text { Variável binária que } \\
\text { indica se o contrato } \\
\text { originou-se de uma } \\
\text { tomada de preços (1) ou } \\
\text { não (0). }\end{array}$ & Não se aplica & $\begin{array}{l}\text { Competitividade } \\
\text { do processo }\end{array}$ \\
\hline i-dummie-convite & $\begin{array}{l}\text { Variável binária que } \\
\text { indica se o contrato } \\
\text { originou-se de um convite } \\
\text { (1) ou não (0). }\end{array}$ & Não se aplica & $\begin{array}{l}\text { Competitividade } \\
\text { do processo }\end{array}$ \\
\hline i-dummie-pregao & $\begin{array}{l}\text { Variável binária que } \\
\text { indica se o contrato } \\
\text { originou-se de um pregão } \\
\text { (1) ou não (0). }\end{array}$ & Não se aplica & $\begin{array}{l}\text { Competitividade } \\
\text { do processo }\end{array}$ \\
\hline i-dummie-concurso & $\begin{array}{l}\text { Variável binária que } \\
\text { indica se o contrato } \\
\text { originou-se de um } \\
\text { concurso (1) ou não }(0) .\end{array}$ & Não se aplica & $\begin{array}{l}\text { Competitividade } \\
\text { do processo }\end{array}$ \\
\hline i-dummie-concorrencia & $\begin{array}{l}\text { Variável binária que } \\
\text { indica se o contrato } \\
\text { originou-se de uma } \\
\text { concorrência (1) ou não } \\
(0) \text {. }\end{array}$ & Não se aplica & $\begin{array}{l}\text { Competitividade } \\
\text { do processo }\end{array}$ \\
\hline
\end{tabular}




\begin{tabular}{|c|c|c|c|}
\hline i-qualidade & $\begin{array}{l}\text { Variável que mede a qua- } \\
\text { lidade na especificação do } \\
\text { objeto do contrato, por } \\
\text { meio da utilização de um } \\
\text { algoritmo tf-idf (abrevi- } \\
\text { ação do inglês term fre- } \\
\text { quency-inverse document } \\
\text { frequency), que valora } \\
\text { as palavras da descrição } \\
\text { do objeto considerando } \\
\text { sua frequência nas descri- } \\
\text { ções dos outros contratos. } \\
\text { Quanto mais "raros"os ter- } \\
\text { mos da descrição, maior } \\
\text { o índice de qualidade. }\end{array}$ & Não se aplica & $\begin{array}{l}\text { Aspectos gerais } \\
\text { da licitação }\end{array}$ \\
\hline i-desconto & $\begin{array}{l}\text { Diferença percentual en- } \\
\text { tre o valor estimado do } \\
\text { item contratado e o valor } \\
\text { final da licitação. }\end{array}$ & Não se aplica & $\begin{array}{l}\text { Aspectos gerais } \\
\text { da licitação }\end{array}$ \\
\hline i-especificidade & $\begin{array}{l}\text { Mede a complexidade do } \\
\text { item contratado. É dado } \\
\text { pela divisão entre o va- } \\
\text { lor do contrato e a quanti- } \\
\text { dade de vezes que o item } \\
\text { foi contratado outras ve- } \\
\text { zes. }\end{array}$ & Não se aplica & $\begin{array}{l}\text { Aspectos gerais } \\
\text { da licitação }\end{array}$ \\
\hline i-frequencia-item & $\begin{array}{l}\text { Quantidade de vezes em } \\
\text { que o item foi contratado } \\
\text { outras vezes. }\end{array}$ & Não se aplica & $\begin{array}{l}\text { Aspectos gerais } \\
\text { da licitação }\end{array}$ \\
\hline $\begin{array}{l}\text { i-lances-por- } \\
\text { participante }\end{array}$ & $\begin{array}{l}\text { Quantidade de lances por } \\
\text { participante na licitação } \\
\text { que originou o contrato. }\end{array}$ & Não se aplica & $\begin{array}{l}\text { Competitividade } \\
\text { do processo }\end{array}$ \\
\hline i-qtde-participantes & $\begin{array}{l}\text { Quantidade de partici- } \\
\text { pantes da licitação que } \\
\text { originou o contrato. }\end{array}$ & Não se aplica & $\begin{array}{l}\text { Competitividade } \\
\text { do processo }\end{array}$ \\
\hline i-qtde-lances & $\begin{array}{l}\text { Quantidade de lances da } \\
\text { licitação que originou o } \\
\text { contrato. }\end{array}$ & Não se aplica & $\begin{array}{l}\text { Competitividade } \\
\text { do processo }\end{array}$ \\
\hline
\end{tabular}




\begin{tabular}{|c|c|c|c|}
\hline i-qtde-TA-fornecedor & $\begin{array}{l}\text { Quantidade de termos } \\
\text { aditivos de alteração de } \\
\text { fornecedor do contrato. }\end{array}$ & Não se aplica & $\begin{array}{l}\text { Ocorrências do } \\
\text { contrato }\end{array}$ \\
\hline i-qtde-TA-valor & $\begin{array}{l}\text { Quantidade de termos } \\
\text { aditivos de alteração de } \\
\text { valor do contrato. }\end{array}$ & Não se aplica & $\begin{array}{l}\text { Ocorrências do } \\
\text { contrato }\end{array}$ \\
\hline i-qtde-TA-vigencia & $\begin{array}{l}\text { Quantidade de termos } \\
\text { aditivos de alteração de } \\
\text { vigência do contrato. }\end{array}$ & Não se aplica & $\begin{array}{l}\text { Ocorrências do } \\
\text { contrato }\end{array}$ \\
\hline $\begin{array}{l}\text { i-valor-ocorrencias- } \\
\text { compra }\end{array}$ & $\begin{array}{l}\text { Quantidade de ocorrên- } \\
\text { cias monitoradas pela } \\
\text { CGU identificadas na lici- } \\
\text { tação que originou o con- } \\
\text { trato. }\end{array}$ & Não se aplica & $\begin{array}{l}\text { Irregularidades } \\
\text { na licitação }\end{array}$ \\
\hline $\begin{array}{l}\text { i-qtde-ocorrencias- } \\
\text { compra }\end{array}$ & $\begin{array}{l}\text { Valor das ocorrências mo- } \\
\text { nitoradas pela CGU iden- } \\
\text { tificadas na licitação que } \\
\text { originou o contrato. }\end{array}$ & Não se aplica & $\begin{array}{l}\text { Irregularidades } \\
\text { na licitação }\end{array}$ \\
\hline i-qtde-retificacoes & $\begin{array}{l}\text { Quantidade de retifica- } \\
\text { ções ocorridas no con- } \\
\text { trato. }\end{array}$ & Não se aplica & $\begin{array}{l}\text { Ocorrências do } \\
\text { contrato }\end{array}$ \\
\hline i-aumento-prazo-dias & $\begin{array}{l}\text { Quantidade de dias de ex- } \\
\text { tensão do prazo do con- } \\
\text { trato. }\end{array}$ & Não se aplica & $\begin{array}{l}\text { Ocorrências do } \\
\text { contrato }\end{array}$ \\
\hline i-prazo-dias-final & $\begin{array}{l}\text { Quantidade de dias do } \\
\text { prazo final do contrato } \\
\text { (após eventuais altera- } \\
\text { ções). }\end{array}$ & Não se aplica & $\begin{array}{l}\text { Ocorrências do } \\
\text { contrato }\end{array}$ \\
\hline i-prazo-original & $\begin{array}{l}\text { Quantidade de dias do } \\
\text { prazo original do contrato } \\
\text { (antes de eventuais altera- } \\
\text { ções). }\end{array}$ & Não se aplica & $\begin{array}{l}\text { Ocorrências do } \\
\text { contrato }\end{array}$ \\
\hline i-valor-final & $\begin{array}{l}\text { Valor final do contrato } \\
\text { (considerando eventuais } \\
\text { aditamentos de valor). }\end{array}$ & Não se aplica & $\begin{array}{l}\text { Ocorrências do } \\
\text { contrato }\end{array}$ \\
\hline i-valor-inicial & Valor inicial do contrato. & Não se aplica & $\begin{array}{l}\text { Ocorrências do } \\
\text { contrato }\end{array}$ \\
\hline
\end{tabular}

